\title{
Fine phenomics applied to the Nectopsyche genus (Trichoptera) Species delineation by speciation traits
}

\author{
J. OLÁH ${ }^{1} \&$ J. OLÁH ${ }^{2}$ JR. \\ ${ }^{1}$ János Oláh, Residence postal address: Tarján u. 28, H-4032 Debrecen, Hungary, profolah@gmail.com \\ ${ }^{2} J a ́ n o s$ Oláh Jr., Residence postal address: Tarján u. 6, H-4032 Debrecen, Hungary, sakertour@gmail.com
}

\begin{abstract}
Nectopsyche genus is common in standing or slowly flowing aquatic ecosystems in the New World. Their taxonomy was unduly based too long on forewing pattern that is easily lost in alcohol. In this created taxonomic chaos management projects are unable to determine these beautiful and common animals. We have elaborated a new taxonomy with easy procedure to delineate closely related incipient sibling species without forewing pattern. Our taxonomy enables us to determine specimens collected and stored in alcohol. We have applied the fine phenomics of adaptive speciation traits of the sigmoid profile of the phallicata and of the apicomesal lobe on gonopods. They were combined, if necessary, with nonadaptive neutral traits of the periphallic organs. These adaptive speciation traits are subtle and stable, they are more super than magic. We briefly review: (1) Are speciation traits really subtle? (2) Are speciation traits super or magic? (3) Why neutral traits are variable? (4) Why adaptive traits are stable? We survey the possible adaptive and neutral traits in the Nectopsyche genus. Our adaptive-neutral distinction has potential in character ranking to establish recent pass, contemporary and old historical divergences in coalescence. Applying the adaptive - neutral distinction, as well as the generality, locality and parsimony principles we have elaborated a character ranking sytem for the genus, for the species groups and for the species with a revised lineage structure in the Nectopsyche genus. Six species grous have been characterised and fourty four new species have been described and grouped in the four species groups. (1) N. candida species group: bonta, buzoga, dombora, flinti, garenoa, lenula, obla. (2) N. pavida species group: alma, bobita, capota, hasonla, kifela, kinilta, kurta, laposka, nemritka, nyaka, oliveri, poca, ritka, salka, silva, sima, terda, vagota, valla. (3) N. punctata species group: eka, kurtula, letra, padka, vezna. (4) N. gemma species group: bunka, eltera, flintorum, huzva, iva, kajla, nilta, pohoka, setfela, suta, taga, tarka, tomora. The species of $N$. argentata, $N$. cubana, $N$. gemmoides, $N$. jenseni, $N$. punctata and several unexamined taxa probably represent species complexes. An expected comprehensive revision of the entire genus is needed including forewing pattern with fine phenomics. Inevitable are the re-examination of the speciation traits of the old types and to scrutinise the species status of so called widely distributed species applying the fine phenomics of speciation traits.
\end{abstract}

Keywords. Fine phenomics, speciation traits, adaptive - neutral distinction, new Nectopsyche species.

\section{INTRODUCTION}

$\mathrm{T}$ he beautiful long-horned Nectopsyche genus has been described by Müller (1879) from Brazil, emphasising the unique swimming habit (nektos, swimming, Gr.) of the larvae and the beautifully coloured adult forewing (psyche, personified soul, fairy, Gr.). They are wonderfully patterned and coloured like the Fairy Wrens in Australia! These caddisflies are living in slowly flowing aquatic ecosystems of the New World and producing ecosystem services for us (Oláh 2010). Both the larval and adult stages could be common components of ecology, population, biodiversity, climate, and conservation research as well as management projects. They are common both in North and South America, but we are unable to identify them! How can we estimate their niche occupation, their combined environmental services if we do not know them? The striking metallic or iridescent appearance of the forewing is due largely to hairs and scales with colours of pigment or interference origin as well as the forewing is sometimes further diversified by pigmented membrane pattern. Unfortunately the recent identity of species is based unduly too much on this ephemeral, easily detachable forewing colour pattern. We have to consider that in taxonomic, biodiversity, conservation and population studies everybody collects these insects 
with light traps in alcohol. How can we describe these animals stored in alcohol with denuded forewings, if we give high character value to the intact forewing pattern? Are these forewing patterns really indispensable in the delineation of Nectopsyche species? We are facing a problem of a taxonomic impediment produced by ourselves.

Pinned, unrubbed specimens collected in dry, clean, cyanide killing jars, handled very carefully and mounted on pins, are seldom available for biodiversity and population studies dominated by light trap sampling. Proper sampling, killing, preparing and storing of Nectopsyche adult require extremely careful handling. We agree that a parallel examination and colourful illustration of forewing pattern on pinned material as well as detailed illustrations of the male genitalia are both essential to a proper revision of this genus (Holzenthal 2016). Unfortunately in the present devastated state of taxonomy this optimal condition is lacking and achievable only in some well financed lucky projects or institutions. This tradetion of forewing pattern priority might have already forced Flint (1974a) to excuse when he has described Nectopsyche taleola based on denuded type materials, in spite of the fact that this beautiful species has completely different gross genital morphology compared to the known species. The unreasonable commitment to forewing pattern has significantly slowed down biodiversity research in Nectopsyche taxonomy in the last half century. A remarkable exception is Holzenthal's (1995) seminal study on Nectopsyche gemma species group with beautiful paintings of forewing patterns. The promised colourful forewing atlas of these fairy creatures will be a unique achievement by the author and a great enjoyment for us in combination with gross and fine genitalic traits, but to rely overly on this ephemeral character is not reasonable and least practical. In spite of the apparent diversity of this remarkable genus, probably with hundreds of undescribed taxa, everybody has set aside undetermined the collected materials stored in alcohol.

Taxonomic chaos. The long-lasting taxonomic chaos is resulted in the Nectopsyche genus by inadequate balancing between forewing and genital character states has produced invalid taxonomic entities making any relevant research or management project unrealistic. The taxonomy was primarily based on the adult forewing pattern. The bright pattern of coloured scales and hairs is sensitive to handling and very liable to denude easily, especially in alcohol. Practice oriented environmental projects collect caddisfly communities in alcohol, but this forewing triggered taxonomic chaos prevents even caddisfly specialists to identify specimens collected and stored in alcohol having denuded forewing. The low resolution potential of the ongoing traditional macro-morphological analysis that is the rough gross genital structure greatly limits the sensitivity of species delineation. Reliability of delineation is further decreased by the high and random variability experienced in neutral, non-adaptive traits of the periphallic organs compared to the less variable adaptive, non-neutral traits (Oláh et al. 2015, 2017). Moreover, it was early argued that male genitalia of the Nectopsyche species are rather uniform and this reduced genital diversity does not permit species delimitation without forewing pattern and differences in male genitalia could only be used to supplement colour pattern (Ross 1944, Holzenthal 1995).

This statement maintains and deepens this created taxonomic chaos. (1) Relying on forewings gives no real workable perspective in the Nectopsyche genus for an integrative taxonomy, the basic science of all kind of environmental research or management projects. (2) We are unable to specify old type specimens with damaged forewing pattern. (3) We are unable to determine specimens of running projects stored in alcohol.

Forewing pattern is damaged also on the dry pinned Navás's type specimens therefore most of the taxonomic synonymies established on their fragmental forewing pattern are invalid. The taxonomy of the Nectopsyche genus is further complicated by the fact that an apparently uniform forewing pattern may hide several closely related sibling species, as indicated by divergences in the fine structure of adaptive traits. 
Unfortunately most of the original or redrawn illustrations in Nectopsyche research are not supplied with well-drawn speciation traits of the sigmoid lateral profile of the phallicata, the ventral profile of the phallicata and the ventral view of the apicomesal lobe of gonopod. Probably, many of the published drawings under a single name may represent independent species. Several so called widely distributed Nectopsyche species, collected from Argentina to Venezuela or even to Mexico, are probably species complexes with many incipient sibling species waiting to be described. Similarly to the widely distributed species of $N$. punctata that represents a species complex as demonstrated in the present study. We base our species definition in Nectopsyche primarily on the speciation traits, particularly on the sigmoid profile of the phallicata and on the apicomesal lobe of gonopod, in combination, if adequate, with the alcohol denuded forewing membrane pattern and the macromorphology of neutral periphallic organs.

Invalid synonymies. Many of the poorly described Nectopsyche species have been re-examined, several types redrawn and placed in synonymy. Unfortunately most type has damaged forewings, but still the type examination was dominated by the misconception of forewing pattern taxonomy (Schmid 1949, Flint 1972, 1974a, 1974b, 1981, 1982, 1983, 1991, Holzenthal 1995, Flint et al. 1999). The shape divergences of the speciation traits, the lateral view of sigmoid profile, the ventral view of the phallicata as well as the ventral view of the apicomesal lobe of the gonopod have not been examined and seldom drawn. Firm and stable divergences for species delimitations are rarely possible to establish if we rely upon the published descriptions and drawings as well as restricting our diagnosis to forewing pattern and to the macromorphology of neutral periphallic organs. However, if speciation traits such as the sigmoid profile of the phallicata and the apicomesal lobe of the gonopod have been properly drawn in the published descriptions we have evaluated this character states in our species delineations and re-described that taxon, if new, based only on these old drawings.
A long awaited revision of these beautiful long-horned caddisflies is really needed. The impasse of forewing pattern concept has long retarded progress while creating and maintaining a taxonomic chaos in the taxonomy of this common caddisflies. Initiation of a revision of the Neotropical members of the genus was launched long ago (Holzethal 1995). The present speciation trait survey is planned to contribute to this revision. We demonstrate that it is necessary to complete the promised comprehensive revision of the entire genus with fine phenomics, including the reexamination of the speciation traits of the types and to scrutinise the species status of so called widely distributed species applying the fine phenomics of speciation traits. In spite of the poorly known taxa or the present chaotic taxonomy of this genus here we describe our specimens stored in alcohol applying our speciation trait procedure of fine phenomics.

\section{Fine phenomics: speciation traits}

The potential of fine phenomics in taxonomy is almost infinitive going down into the molecular patterns. The gross genital morphology of low resolution has inherent limits also in Nectopsyche as well as the neutral traits of periphallic organs like cerci and gonopods could be highly variable depending on the effective population size and combined with inherent internal and external environmental disturbances. But in the last few years we have documented that the fine phenomics of the adaptive speciation traits permits to recognise incipient siblings of closely related young phylogenetic species and reveals their high diversity (Oláh et al. 2015). High-tech and highthroughput phenotyping has remarkable potential, seldom utilised yet in taxonomy. Various unexplored procedures are available from the simple fine shape recognition to the more complex analysis of fine surface patterns composed of cellular sensory setal and non-cellular cuticular processes and outgrowths. We have recorded stable specific divergences in the fine surface pattern on the dorsal branch of paraproct in the enigmatic Drusus lepidopterus species complex (Oláh et al. 2017). We believe that taxonomy has to apply 
more fine phenomics instead of relying on DNA barcode distances! Application of fine phenomics of speciation traits is reliable (1) if we have population samples large enough to visualize stability of traits or their ranges of variability; (2) and if we increase the resolution level of our observation with good microscope of high quality and high magnification to recognise subtle, but stable shape divergences.

Fine phenomics of speciation traits. The less diverse gross morphology of genitalia frequently appears very diverse at higher microscopic resolution. Similarly to other caddisfly taxa we experienced that Nectopsyche species stored in alcohol with denuded forewing can also be identified by fine phenomics of speciation traits. Subtle and stable divergences have been detected in genital structures by fine structure analysis (Oláh et al. 2015). These super-traits are produced in nonrandom, adaptive sexual integration processes and function as reproductive barriers between species therefore very sensitive to delineate closely related species. Applying the fine phenomics of speciation traits we can describe sibling species undetected earlier by gross genital structures (Oláh et al. 2017). With very conservative estimates, hundreds of caddisfly species are still waiting to be collected and described in isolated mountain ranges of the well-studied Europe! No doubt that even more hundreds of Nectopsyche species are waiting to be described from the Neotropical Region! In the lack of properly collected, killed, and prepared therefore intact pinned specimens there are two alternatives to determine Nectopsyche species stored in alcohol. We can apply (1) the subtle and stable speciation traits integrated in non-neutral adaptive mechanisms or (2) the combinations of several neutral non-adaptive traits with wider variability ranges. In order to find adaptive non-neutral speciation traits, the traits of reproductive barrier in Nectopsyche, a systematic examination of trait stability and variability is required on population samples of several specimens by fine structure analysis of trait matrices. This can be realised by applying simple visual empirical study of trait matrices or, if divergences visually are not evident, by virtual geo- metric morphometrics. However, before going to survey the character states in Nectopsyche we repeat some routine theoretical aspects of speciation traits, not well represented in the present practice of alpha taxonomy.

Speciation traits: magic or super? The same trait under a divergent ecological adaptation may contribute to non-random mating. These magic traits (Gavrilets 2004) greatly facilitate speciation with gene flow, evading homogenizing effects of recombination. Accumulating evidence suggests that magic traits in speciation is really magic, but not rare (Servedio et al. 2011). However, finding convincing examples is not easy because a putative magic trait must be subject to divergent selection and must generate non-random mating, either by pleiotropy or by epistasis.

Speciation phenotypes are those traits whose divergence contributes to a reduction of gene flow (Shaw \& Mullen 2011). Speciation traits are expressed phenotypes of speciation genes. These traits/genes are underlying the process of speciation. Speciation genes are difficult to distinguish, especially if the multiple genes participate early in an ongoing speciation process and concerted in quantitative trait loci. In alpha taxonomy we are working with the expressed speciation trait, such as with magic traits which are very common. Divergent selection on phenological or host magic traits leads automatically to assortative mating via temporal or spatial isolation.

A trait is super if initiates and realises a speciation process mostly in allopatry by sexual integration processes. It seems that speciation trait of this type is even more distributed, at least among limnephilid taxa evolved in allopatry of the high mountain crenon environment (Oláh et al. 2015). Super trait encoded by speciation genes under divergent sexual integration creates reproductive isolation without any abiotic or additional social integration. Speciation trait manifesting reproductive isolation by powerful sexual integration does not need any other additional natural pressures. This is why speciation traits of sex origin are really super, not simply magic, even with subtle shape divergences. 
Are speciation traits really subtle? In alpha taxonomy of low resolution we are frequently faced with common difficulties how to evaluate minor shape modifications whether these alterations represent ranges of (1) neutral genomic variation; (2) epigenetic variation; (3) phenomic plasticity; or they are sign of (4) developmental instability; (5) early adaptive signatures of diverging populations; or (6) they are already products of non-neutral, non-random adaptive genomic processes, representing diverged reproductive barriers of closely related incipient sibling taxa; indicating some (7) incomplete lineage sorting or (8) hybrid effects in secondary contact clines under reinforcement. Moreover, what seems subtle for the human observer in the inadequate resolution level of traditional taxonomy is robust enough for mate recognition in the universe of caddisflies (Oláh 2017). The speciation traits of recent past are subtle in human perspective both in ontological and epistemological perspectives.

Adaptive versus neutral traits. One of the basic findings of the speciation trait research is the theoretical and practical advantages gained by distinguishing clearly and sharply between the stable adaptive, non-neutral speciation traits and the more variable non-adaptive neutral traits.

Why neutral traits are variable? The apparently neutral traits of historically accumulated greater divergences are integrating contemporary by stochastic processes under diverse impacts of mutation, permutation, transmutation, perturbation, effective population size, gene flow, genetic drift, and recombination. Exposed to these permanent external and internal random impacts and without adaptive protection they are more variable, exhibiting variously wide variability ranges depending on actual population events. But every such recent neutral trait could be a product of various historical adaptive processes and mechanisms integrated similarly to the contemporary adaptive divergences and moreover they could undergo contemporary exaptive processes (Gould \& Vrba 1982).

Why the adaptive speciation traits are stable? Contrary to these variable contemporary neutral traits, the recently diverging or in recent past diverged speciation traits are stable and usually subtle or could be even invisible over time until additional divergences between species accumulate. The stability of these adaptive non-neutral speciation traits is organised and maintained by several integrative and protective mechanisms, listing just a few: (1) reduced effective recombination; (2) linkage disequilibrium; (3) hard, soft and multiple selective sweeps; (4) genetic hitchhiking, or genetic draft; (5) divergence hitchhiking; (6) genome wide hitchhiking; (7) divegently selected traits with genes of large effect; (8) structural reduction in recombination with chromosomal inversion; (9) reinforcement by reproductive character displacement; (10) divergent-specific mate-recognition systems; (11) prezygotic reproductive barrier of assortative mating; (12) partial postzygotic isolation of hybrid incompatibilities.

\section{Neutral genitalic traits}

We clearly distinguish the character states of the non-adaptive contemporary neutral traits from the adaptive non-neutral traits based upon our earlier finding in various caddisfly genera (Oláh et al. 2015). In case if we have no intact forewing pattern or well specified stable speciation traits we can rely on the combinations of these nonadaptive, neutral divergences detected in the periphallic organs: tergum IX, superanal complex (tergum X, cerci, paraproct) and gonopod. The combination of these various divergences with unknown variability could help us to delineate the closely related species in Nectopsyche genus; until a systematic survey is completed in the future on the stability values or on the variability ranges of the particular traits. Below we have collected diagnostic information on character states of the neutral non-adaptive genitalic traits in Nectopsyche. This brief survey of the neutral traits is based mostly on published descriptions and drawings of varying quality and style. Thanks to our colleague, Oliver Flint, the Neotropical representtatives of the genus are better documented with drawings. Wonder why the Nearctic species are so poorly known. 
Tergum IX. Dorsal region of the ventrally vestigial segment IX is characterised with variously produced mesal lobe posterad and with a pair of punctate acrotergite enclosures anterad.

Superanal complex. This is a highly modified complex of the fused segments $\mathrm{X}-\mathrm{XI}$ together with cerci of somite and paraproct of podite origin. Its dominating parts are the elongated cerci, the sensory tactile organ of directional perception in chirality as well as the paraproct, the stimulatory organ shifted deep ventrad covering its basal function to give dorsal guiding for the phallic organ.

(1) Segment $X$. The highly reduced state of the upper part of vernacular leptocerid tergum $X$ with some continuation in the vertically displaced part; this displaced part represent the lower part of segment $\mathrm{X}$, that is the paraproct in leptocerids. The vestigial tergum $X$ is a less sclerotized, less distinct horizontal dorsomesal process, an apparent continuation of tergum IX; it could be short, monolobed, bifid or frequently indiscernible. This upper part of segment $\mathrm{X}$ is usually more developed in Oecetis or Triaenodes genera. Its presence and its shape has diagnostic value: lacking (taleola), tridentate (acutiloba), truncate (aureofasciata), indistinct shallow tripartite (bruchi), slightly produced rounded (exophthalma), more produced rounded triangular (exquisite), more produced broad rounded (monticola), shallow bilobed (gemmoides), long bilobed with deep excision (jenseni), excavated mesally (ortizi).

(2) A lateral pair of sclerotized vertical bracing straps, a synapomorphy of the genus, a composing structure of segment $\mathrm{X}$ suspending the paraproct and connecting it to segment $X$.

(3) Paraproct. The deeply shifted sclerotized horizontal lateral lobes, the paraproct, the intermediate appendages of Schmid (1998) and Harris (1986); segment X of Holzenthal (1995); and tergite X of Flint (1983). The sclerotized lateral arms of the paraproct are variously accompanied by discernible membranous mesal partial connection. The horizontal lateral lobes or arms represent the paraproct, the vestigial somite of segment XI with the genuine paraproct function of phallic guiding. The variously shaped head of the paraproct could be a candidate of speciation traits.

(5) Cerci. This component of the superanal complex is heavily developed in Nectopsyche. Strongly elongated structure has historical divergences in the shape both of the shaft and of the head. The shaft is characterized by various length and width; ventral berm-patterned shape modified in punctata species group. The cercal head is truncate, blunt, produced dorsad or ventrad, variously capitate or clavate and with or without apical setae. Forked head developed in gemma species group. Especially the ventral arm of the forked head could develop specific glabrous, almost shining endings completely lacking any noncellular outgrowths, heavily contrasted from the remaining part of the cerci, that is densely or even tightly covered by minute cuticular formations beside sensory setae and microsetae; these cuticular non-cellular processes or projections are represented by minute points or nodules, spicules, corrugations, and are probably species specific. The glabrous apical region with variously shaped and extended surfaces devoid of any cuticular processes, but may have limited number of sensory setae of cellular origin.

Gonopods. This highly complex, medium long and wide structure is the most diverged periphallic organ substituting the ventrum of segment IX as the most pronounced synapomophy of the genus. Gonopods are connected by their basal plate forming a narrow strong sclerotized bracing bridge under the phallic organ. It seems that besides serving the regular clasping and the phallic guiding function ventrally this highly complex gonopod has taken over the holding function of the lost sternum IX. Vestiges of sternite IX could be partially integrated to the basoventral region of the gonopods, possibly giving material to the basoventral setose processes. Structures are seldom lost without traces! This pair of basoventral processes is usually digitate, quadratic, broad scooplike, sometimes separated by suture or the broad scooplike basoventral lobes could be vari- 
ously fused mesally (pavida species group). The gonopods, possibly the apicomesal lobe, that is the harpago could be modified into a thin or slender elongated process, but having enlarged basal region, possibly the remnant of sternite IX (acutiloba species group). Sometimes, mostly in the Nearctic lineages, the basal region is extremely high and broad enforced probably from remnant material of sternite IX (gracilis species group). Gonopods frequently patterned with variously elongated digitate setae with small outgrowths or alveoli, mostly on ventral and apical margin.

\section{Adaptive genitalic speciation traits}

In the Nectopsyche genus the postmating genitalic speciation trait with high shape stability could function in combination with the premating reproductive barrier of the visual trait of the forewing pattern itself. This is comparable, but in opposite relation to the acoustic trait of display call of male birds having similar plumage patterns. Adaptive speciation traits with subtle and stable shape divergences are the reproductive barriers recently built among sibling species by sexual selection or more precisely by sexual integration. They are intrinsically integrated from structures of the intromittent phallic organs or from periphallic organs having special stimulatory or other intimate functions exerted in postmating processes during copulation. In our present study on Nectopsyche we have found four potential candidates to be involved more intimately in copulatory functions: (1) the very tip of the deeply shifted horizontal arm of the paraproct; (2) the apicomesal lobe of gonopods; (3) the head of the paired dorsal process of the phallotheca; and (4) the ventral sclerite of the aedeagus (phallicata) both its sigmoid lateral profile and its ventral shape. The apicomesal lobe of the gonopods and the head of the phallothecal dorsal process could have a coupling function collaborating to support the pivoting intromittent action of the phallic organ. A similar coupling function was suggested for Triplectides genus between the basomesal lobe of the gonopods and the movable harpago (Oláh 2014). In many other caddisfly taxa we have found frequently only a single dominating genitalic struc- ture as the most responsible actor in the reproductive barrier building. In Nectopsyche a more systematic study on the fine phenomics of the four listed speciation trait candidates is required to quantify their stability or ranges of variability. In this study we have found the lateral sigmoid profile of the phallicata the most stable and reliably trait to delimit closely related incipient sibling species. It needs a more comprehensive comparative study together with the $O$. avara, O. inconspicua (Blahnik \& Holzenthal 2014) and $O$. amazonica species complexes (Oláh 2016) where, similarly, the lateral profile of the phallobase serves the function of speciation traits.

(1) Paraproct apices. Apices of paraproct are supplied with few subapical short sensilla of typical paraproct type and together with their glabrous tip formation may have diagnostic value. The shape formation of the glabrous endings of the paraproct seems diverging in fine structure as visible in lateral or in dorsal view. Being shadowed by complex overlapping structure the lateral or dorsal shapes of the paraproct tips are frequently poorly visible or sometimes almost indiscernible. This is probably the reason behind that this glabrous apical ending is usually not characterized properly in species descriptions and in drawings. A number of species is described by some characterized tip diagnosis and with drawings: heavily sclerotized points (acutiloba); rounded tips (adusta); obliquely truncate (argentata, globigona); long parallel rodlike (aureofasciata); elongate apex with subapical dorsal tooth (aureovittata); dorsal digitate in lateral view (bruchi); truncate both in lateral and dorsal view (cubana); thin, short, narrow and pointed (exophthalma); ventral digitate (exquisite); somewhat truncate (gemmoides); tip angled dorsad (multilineata); thin, tapering and pointed (ortizi); high, dorsal digitate (padrenavasi); widely diverging with blunt apices (splendida); thin, very narrow (tuanis); abruptly narrowed, pointed (utleyorum); variously produced lateral outgrowth subapicad (several species in pavida species group).

(2) Apicomesal lobe of gonopods. The most crucial structure on the gonopod directly exposed 
to adaptive non-neutral divergences is the apicomesal lobe, probably the fused harpago (Holzenthal 1995). This apicomesal organ together with the stimulatory or coupling "swan-necked" process on the phallic organ is localised as an exposed structure most close to the appropriate female genital sensory structures. Its dorsal or ventral surface, again similarly to the apex of the "swan-necked" stimulatory process on the phallic organ, is frequently covered with reticulations, corrugations or roughened otherwise by peg-like or by other non-cellular processes of cuticular origin. Moreover, it has a few innervated setae with sensory and/or stimulatory function, probably with specific number, location and size. In the present study we draw, present and describe only the ventral profile of the apicomesal lobe to delineate species without cuticular and sensory structures. However, it would be reasonable and productive to examine fine surface and setal pattern in the future in order to explore at least a very small fragment of the huge potential of fine phenomics. It would give us more taxonomic information if we specify whether its surface is textured by specific component composed particularly of: minute scobinate points, nodules, small spicules, spines, thorns, irregularly shaped knobs, pegs or microplates of various shapes; or how many setae of cellular origin are present and in which position? This gonopod structure is probably one of the potential candidates of the speciation trait in the genus and participating intimately in the copulation processes.

Phallic organ. Leptocerid phallic organ is frequently located fairly high above the gonopods, but dislocated deep ventrad between or even, in erectile state, below the gonopods at Nectopsyche genus. Structures of phallic organ are not easy to homologise, rather obscurely structured in this genus, due to special circumstances: (1) Phallic organ is localised in a pivoting fulcrum position with overlapping structures, therefore especially the basal region is badly visible. This fulcrum position is created by the synapomorphically deeply shifted ventral arms of the superanal complex, that is the paraproct; by the synapomophically lost sternum IX, that induced thickening the braced ventral ending of the vestigial segment IX; by the very complex gonopods; by the basal plate of gonopods; and by the phallic shield process attaching the phallic organ to the mesal ridge of the gonopods. All these structure together have superimposed masking condition significantly decreasing the visibility of at least some basal parts of the phallic structures. (2) The phallic components are frequently less sclerotized, less pigmented or even membranous. (3) The highly erectile endothecal and endophallic membranes endowed by variously refractory light scattering texture. (4) The usually sclerotized phallic components are rather obscurely structured without discernible boundaries. (5) Pivoting between the sigmoid shaped phallicata and the phallobase (phallotheca) by endothecal erection results in various relative states of the sclerotic components.

The phallic organ of Nectopsyche is composed of almost the complete set of the primitive structures, except parameres. Although according to one of the possible alternative explanations, the swan-necked process is the modified paramere shifted from endotheca to phallotheca. This alternative titillator function was already given to these swan-necked processes by Schmid (1949). At this stage of knowledge we homologize Nectopsyche phallic organ with the following ten structures: (1) Short, badly discernible phallic apode$m e$ with or without easily discernible foramen. (2) Less developed and mostly indiscernible phallic shield reduced to the almost indiscernible articulation not to the vestiges of mesad shifted sternum IX but to the mesal ridges of the gonopods. (3) Phallobase with phallotheca, the less distinct region of the phallic organ, at least its apical ending is indiscernible. (4) Dorsal processes of phallotheca, the swan-necked process of Ross (1944), the modified phallic shield process of Morse (1975), the periphallic process of Holzenthal (1995). (5) The dorsally mostly open, frequently trough-like phallicata, having characteristic sigmoid lateral profile, is the most pronounced structure of the phallic organ. It is considered by Holzenthal (1995) as phallobase, but it has no discernible sclerotic connection to phallobase or phallotheca, moreover it seems moving 
free during erection as visible on several species drawings. It is rather the ventral sclerotized part of the aedeagus or phallicata. (6) Voluminous highly erectile endotheca, (7) Spine like or modified endothecal setae; present or absent. (8) Erectile endophallic membrane. (9) Poorly visible ejaculatory duct. (10) Small U-shaped phallotremal sclerite.

(3) Dorsal process of phallotheca. This swannecked shaped pair of processes frequently present on phallotheca as variously developed filiform process, with more or less expanded apex having concave ventrum with specifically patterned surface texture (Haddock 1977). Here we do not draw and analyse the fine surface structure of its head, just draw its lateral profile. What is really the origin of this process? Swan-necked process is a good metaphor. Probably it is not a modified phallic shield process, because leptocerid phallic shield processes usually articulate to segment IX or to the basal plate of the gonopods and the actual pair of phallic shield processes is present in Nectopsyche as articulating to the mesal ridge of the gonopods. Periphallic process of Holzenthal (1995), again a directional term has no meaning and easily mistaken with the periphallic organs. Without a target study but relying on universal principles of complexity, generality, hierarchy and parsimony we think that this swannecked process is one of the very diverse dorsal processes present on the phallotheca or phallobase at so many other caddisfly taxa in various families.

(4) The Sigmoid Profile. At the examined species available for the present study, we have found the lateral sigmoid profile of the ventral sclerite of the aedeagus (phallicata) as the most diverged and most stable structure deserving the status of speciation trait. The lateral profile of the sigmoid sclerite is fairly stable; however the comparison of specimens has to be realised on phallic organs all in a relaxed state. In erected state especially the basal ventral curve of the sigmoid sclerite is forced under a pivoting tension and its curve state getting variously flexed and altered. Sometimes there is a mesal ridge on the ventrum of the phallicata and the drawn sigmoid profile follows its ventral margin and not the upper lateral margin of the phallicata. The sigmoid lateral profile of the phallicata is a remarkable apomorphic state in the Nectopsyche genus and is organised by integration of this pivoting function. It seems this is a key structure in the functioning of the phallic organ and in building of reproductive barrier during the sexual integration probably by cryptic female choice. Its remarkable diversity and stability are self-evidence as a result of this function. Further study is required to examine in details the ranking of speciation trait candidates in Nectopsyche genus.

\section{Character ranking}

A simple character ranking system for the Nectopsyche genus is presented here. This is our working hypothesis for the present study. We estimate and evaluate the character ranking values for the genus Nectopsyche, for species groups within Nectopsyche and for the species in the species groups to delineate contemporary diverged incipient phylogenetic species.

Phylogenetic systematics of Hennig (1950, 1966), simplified and distorted today as cladistics, establishes character ranking based upon shared derived characteristics. Phylogenetic tree building was both the process and the result of character ranking in taxonomy. However, we face the basic problem that all extant species and genes are a mix of ancestral and derived characteristics and not the extant organism or gene itself that is ancestral/"primitive"/branched early or derived/ young/branched off last (Oláh et al. 2017). Character ranking creates understanding in structural realism of living hierarchies of emergencies with the fundamental idea that characters are not static. Taxonomy faces the routine questions how to distinguish character combinations in order to delineate taxa. Which character state is ancestral or derived? Which character has higher ranking value? We have learnt that early branching lineages without empirical data do not signify ancestral traits (Crisp \& Cook, 2005). Speciation rates differ and are most frequently individual in line- 
ages. Therefore morphological differences do not reflect time differences. The use of computer does not add objectivity to character analysis. Outgroup comparison as an indirect and ontogenetic method is a popular procedure for determining character polarity. However, single outgroup taxa should not be used in assessing the character states of the ingroup (Wägele 1994), but concatenating more outgroup taxa worsens further our blindness, masking reality by stochastic approach, especially without empirical data and knowledge. We have to remember that Hennig has assessed character polarity by analysing character by character not by constructing or compiling character matrices. Present-day mainstream cladistics polarises the characters by huge matrices and by concatenated outgroup addition without empirical reality. Working with DNA sequences rooting between outgroup and ingroup is the only possibility to convert network of molecular characters into a cladogram. But phylogenesis is cladogenesis plus anagenesis and any analysis without non-molecular characters is incomplete, if not irrelevant (Schmitt 2016).

Without applying any masking industry of formal cladistics our character ranking system for taxa in the Nectopsyche genus has unsurpassable advantage. It is based upon our ability to discriminate clearly between adaptive characters of contemporary and neutral character of older historical divergent states. To establish which traits or character states are adaptive versus neutral or plesiomorphic versus apomorphic we rely upon evidences of sexual integration as well as considering the universal principles of commonality, diversity, generality, hierarchy, locality, and parsimony (Winther 2009, Schmitt 2016, Oláh et al. 2017). We use an empirical synthetic method for character definition by combining observed conditions along examined entities gained with analysing character by character or taxa by taxa based on observed ranges of variations. This adaptive-neutral distinction has remarkable potential in coalescent theory that is in this retrospective stochastic procedure to follow genetic drift backward along genealogy of antecedents to the most recent common ancestor, the coancestor of coalescent. We apply both gross and fine phenomics to evaluate character polarity or ranking with empirical evidences, not with mainstream genomics of virtual DNA sequences having only very limited or almost zero knowledge on relevant functional or morphological realities.

Gereric characters. These characters of ancestral architectural divergences are organised by multitudes of integrative mechanisms to assimilate the permanenet flux of internal or external random impacts, adverse, neutral or beneficial. In Nectopsyche the generic characters are stably established synapomorphies, organised by these integrative speciation processes. They are more ancestral, earlier organised:

(1) Atrophication of stems of R and M in the hindwing, similarly to Parasetodes McLachlan, but accompanied with completely different genital architecture, exemplifying an ancestral-derived mixture;

(2) Atrophied sternum IX;

(3) Paraproct dislocation deep ventrad;

(4) Development of variously produced basoventral process on gonopods;

(5) Variously developed dorsal processes on the phallotheca.

Species group characters. Our species grouping in the Nectopsyche genus is based upon more derived historically accumulated greater divergences of the more variable non-adaptive neutral traits on the periphallic organs. They were integrated by stochastic processes under diverse impacts of mutation, permutation, transmutation, perturbation, effective population size, gene flow, genetic drift, and recombination.

(1) Applying the principles of generality, locality and parsimony the probable plesiomorphic state of the genitalia are characterised by simple elongated cerci and simple straight or slightly arched gonopods. Nectopsyche candida species group.

(2) Divergence on the gonopods by scoopformation and fusion of the basoventral processes 
of the gonopods. Nectopsyche pavida species group;

(3) Divergence on the gonopods by enlargement of the basoventral region. Nectopsyche albida species group;

(4) Divergence on the gonopods by elongation of the fused harpago. Nectopsyche acutiloba species group.

(5) Divergence on the shaft of cerci by development of the step-like pattern on the ventrum of the cercal shaft, this means that in lateral view the basoventrum of cerci widens abruptly basad with a step, not gradually as it does at every other species in the entire genus. Nectopsyche punctata species group;

(6) Divergence on the head of the cerci by fork formation. Nectopsyche gemma species group.

Species characters. The delimitation and description of the phylogenetic incipient sibling species is based primarily on the adaptive shapes of the

(1) Sigmoid profile;

(2) Apicomesal lobe of gonopods;

(3) Dorsal processes of the phallotheca;

(4) Paraproct apices.

Shape diversity of these speciation traits has a given range of limits and similar repeated shapes are frequently organised in independent lineages. Member genes in the multigene families evolve as a unit in concert by gene reuse reversal in repeated organisation. Organisation may integrate similar phenotypes at several biological levels. Nature often repeats itself with independent organisation of similar features in lineages. Similar traits in distinct lineages are frequently produced by gene reuse, involving mutations in the same gene (Oláh et al. 2017). Similar shape organisation is frequently combined with different shape organisation present in other speciation traits or in neutral traits of periphallic organs. This trait combination helps alpha taxonomy to differentiate between closely related species in the different lineages. This phenomenon is applied here to delineate sibling species.

\section{MATERIAL AND METHODS}

Supporting a long awaited revision. During Neotropical caddisfly collecting trips in the years of 2005-2017 adult specimens of the Nectopsyche genus were collected with light traps in alcohol, by ourself and by the Swedish Museum of Natural History. Influenced by the declared indispensability of forewing pattern in the taxonomy of these beautiful caddisflies and respected the personal request of our colleague, Ralph Holzenthal, we have set aside undetermined for many years specimens collected in Argentina, Bolivia, Colombia, Ecuador, French Guiana, Mexico and Peru, similarly to many of our colleagues (Oláh 2016). However, the discovery of speciation traits has generated a sensitive and powerful new taxonomic tool to delineate closely related incipient species of caddisflies (Oláh et al. 2015, 2017). The impasse of forewing strategy and the new potential of fine phenomics have challenged us to identify and describe our set aside Nectopsyche specimens stored in alcohol.

Depositories. Type specimens are deposited in the following collections: HNHM (Hungarian Natural History Museum, Budapest), OPC (Oláh Private Collection, under Protection of the Hungarian Natural History Museum), SMNH (Swedish Natural History Musem, Stockholm) or NRM (Naturhistoriska Riksmuseet, Stockholm), USNH (United States National Museum) now National Museum of Natural History, Smithsonian Institution; Washington, DC.

\section{TAXONOMY}

\section{Nectopsyche Müller, 1879}

Type species: Setodes gemma Müller, 1880; first included species.

Nectopsyche Müller, 1879: 38-40: „Die Gehäuse habe ich von folgenden Arten abgebildet: ...12 u 13. Nectopsyche n. g. (?), wovon ich dir einige Röhren schicke. Die Larve $\mathrm{s} \mathrm{c} \mathrm{h} \mathrm{w} \mathrm{i} \mathrm{m} \mathrm{m} \mathrm{t,} \mathrm{was,} \mathrm{soviel} \mathrm{mir} \mathrm{bekannt,} \mathrm{keine} \mathrm{der}$ bischer bekannten Phryganidenlarven kann. Die Hinterbeine sind laugbewimperte Schwimmbeine. Das fertige Insect $\left(\delta^{\pi}\right)$ ist ein prächtiges Thierchen; die Vorderflügel b e s c h u p p t (!), gelb mit silbernen Querbinden un einigen grossen tiefschwarzen Flechen.” 
Leptocella Banks, 1899: 214: „This genus is easily known by the obsolete veins in costal half of the hind wings." Type species: Mystacides uwarowii Kolenati, 1859, original designation. Flint 1974: 127, to synonymy.

Brethesella Navas, 1920: 70, „Similis Leptocellae Banks.” Type species Brethesella decorata Navas, 1920, monobasic. Flint 1982: 57, to synonymy.

Generic diagnosis. As a unique synapomorphy the stems of $\mathrm{R}$ and $\mathrm{M}$ are atrophied in the hindwings. Some species of the genus Parasetodes McLachlan has hindwings with similar atrophication, but less pronounced or even lacking in many species. Moreover, the genital architecture of the two genera is completely different representing independent lineages of large distances. Again a phenome of genome rearrangement initiated by stochastic processes in repeated organisation, integrated by homoplasy and viewed from forward genetics. Synapomorphic genital characters of the Nectopsyche genus: (1) atrophied sternum IX, (2) paraproct dislocation ventrad, (3) development of variously produced basoventral process on gonopods, (4) variously developed dorsal processes on the phallotheca.

\section{Nectopsyche candida species group}

This species group represents probably the plesiomorphic state of the genus having distributed on the entire distributional area both in Neotropical and Nearctic faunal regions (locality principle) and having more general trait combinations (commonality, generality, frequency of occurrence, common equals primitive). Cercal shaft is without ventral step. Cercal head is without fork. The gonopod slender not enlarged basally. Basoventral process of the gonopods as a generic ranking character is present and unmodified digitiform, vestigial only in $N$. diminuta (Banks). The neomorphic character in leptocerids the dorsal process of the phallotheca is present in each known member of the species group.

\section{Nectopsyche bonta Oláh, Johanson \& Malm, sp. nov.}

(Figures 1-5)

Material examined. Holotype, Peru, San Martin Prov., Rio Negro, 37 km (rd.) W Moyobamba, near Olmos-Tarapoto rd., $6^{\circ} 00.278^{\prime} \mathrm{S}, 77^{\circ} 15.437^{\prime}$ W, light, loc. 05, 6.I.2009 leg. T. Malm \& A. Johanson (1 male SMNH). Paratypes, same as holotype ( 2 males, 27 females, SMNH; 1 male, 5 females, OPC).

Diagnosis. This new species is most close to $N$. lenula sp. nov. also has very large eye; tergum

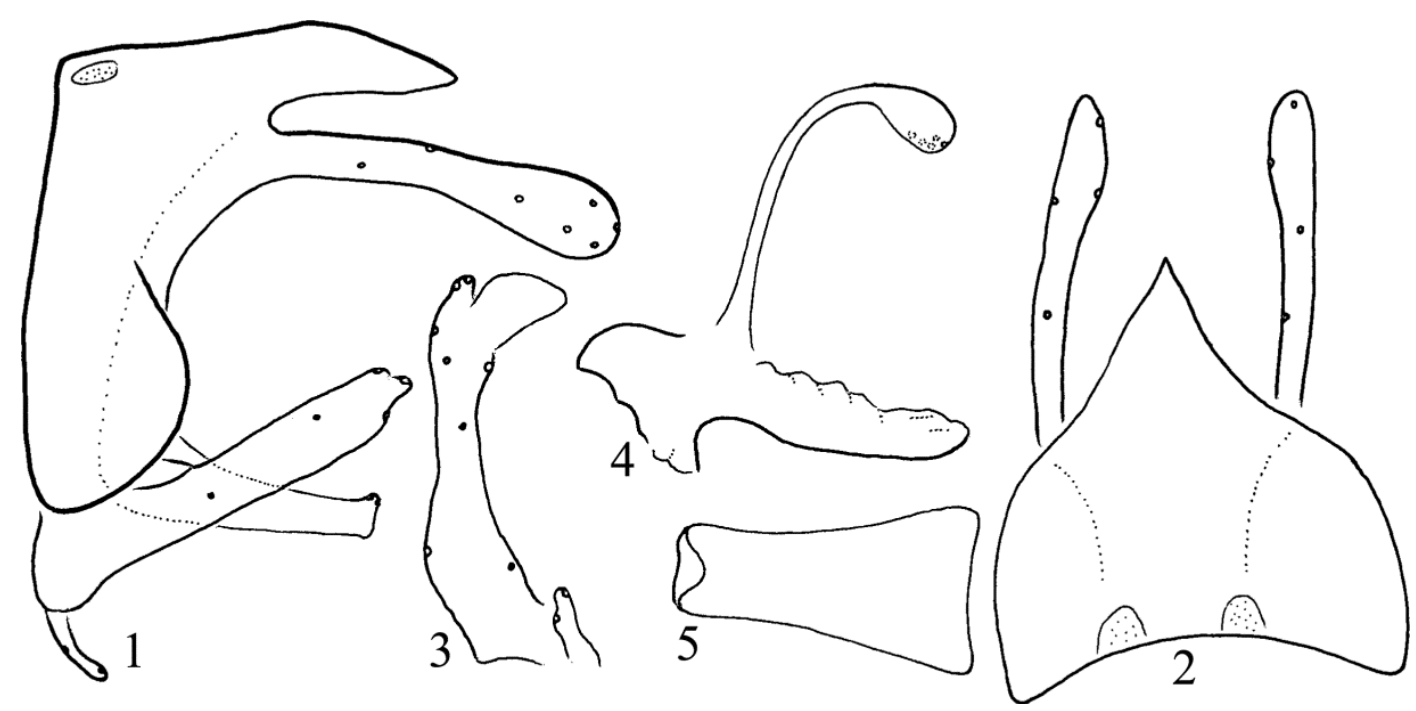

Figures 1-5. Nectopsyche bonta sp. nov. Holotype: 1 = male genitalia in left lateral view, $2=$ male genitalia in dorsal view, $3=$ left gonopod with apicomesal lobe in ventral perpendicular view; $4=$ phallic organ with the sigmoid profile of phallicata in lateral view; $5=$ phallicata in ventral view. 
IX produced posterad with more pointed apex; cerci clavate, not parallel-sided; gonopods straight, more slender; apicomesal lobes of gonopod broader; sigmoid profile longer with smaller basal curve and; as a result the ventral shape of phallicata more fan-shaped.

Description (in alcohol). This species has very large eyes, almost touching ventrum. Body sclerites and wings dark brown. Length of forewing 6 $\mathrm{mm}$; forewing with some scales, but without any membrane pattern as visible on specimens stored in alcohol. Maxillary palp formula IV-(II,III)-I-V. Tibial spur formula 0-2-2.

Male genitalia. Abdominal segment IX without sternum; its ventral ending located at pivoting fulcrum is rounded with braced margin; tergum IX highly produced posterad with pin-pointed apex; punctate acrotergite rounded well separated. The superanal complex without any discernible horizontal dorsomesal process; the deeply shifted sclerotized horizontal lateral processes, the paraproct pair with apex of dorsal angle in lateral view. Cerci without apical fork, clavate. Gonopods slender and straight with produced rounded basoventral angle in lateral view; basoventral process filiform; apicomesal lobe asymmetric; part of apical surface pegged, rugose. Phallic organ seems articulating to the basomesal ridge of the gonopods; the pair of swan-necked dorsal phallothecal processes with well-developed downward curving band-like head; circular in dorsal perpendicular view; apical half of the head is rugose ventrad; the negative copy of the apicomesal lobe of the gonopod; endotheca without discernible setae; sigmoid profile long; apical half produced laterad forming a fan-shaped apex with straight apical margin in ventral view.

Etymology. bonta, from „bonta” special form of straight in Hungarian, refers to straight gonopod and the straight apical margin of the phallicata in ventral view.

\section{Nectopsyche bruchi (Navas, 1920)}

(Figures 6-11)

Material examined. Argentina, Corrientes Province, Carlos Pellegrini Posada, Aguape, 28 ${ }^{\circ} 32^{\prime}$
26"S, 57 10'20"W, 24.XI.2011, at UV light/ watertrap, leg. A. G. Duff (1 male, OPC).

Remarks. Forewing is without any pattern on the single specimen stored in alcohol. The apicomesal lobe of the gonopod is almost complete circular in ventral view. The phallicata is withdrawn into phallotheca (phallobase?). The membranous apical margin of the phallotheca visible (pointed line profile on the drawings) rather intact in lateral view, that is very seldom discernible structure in the Nectopsyche species. The sigmoid profile of the phallicata is elongated and stretched without produced apical curve, basal curve small.

\section{Nectopsyche buzoga Oláh, Johanson \& Malm, sp. nov.}

(Figures 12-17)

Material examined. Holotype, Argentina, Chaco, PN Chaco, campground, $77 \mathrm{~m}, 26^{\circ} 48.608^{\prime} \mathrm{S}$, 59³6.893'W, 12.I.2008 leg. K. Hill, D. Marshall $\&$ M. Moulds (1 male, SMNH).

Diagnosis. This new species belongs to the $N$. candida species group and is most close to $N$. nigricapilla but differs by having not any forewing membrane pattern at least in alcohol. Tergum IX less produced posterad; cerci with clubbed clavate apex, not downward curving; dorsal process of the phallotheca differently shaped; sigmoid profile more patterned, with almost hook-shaped basal curve, not stretched; ventral profile of the phallicata is not drawn at $N$. nigricapilla.

Description (in alcohol). This species has large eyes, almost touching ventrad. Length of forewing $9 \mathrm{~mm}$, forewing with few short setae and without any scales and without any membrane pattern as visible on the single specimen stored in alcohol. Maxillary palp formula IV-II-(I,III)-V. Tibial spur formula 0-2-2.

Male genitalia. Abdominal segment IX without sternum; its ventral ending located at pivoting fulcrum is rounded with braced margin; tergum IX less produced posterad slightly trilobed; punctate acrotergite rounded well sepa 


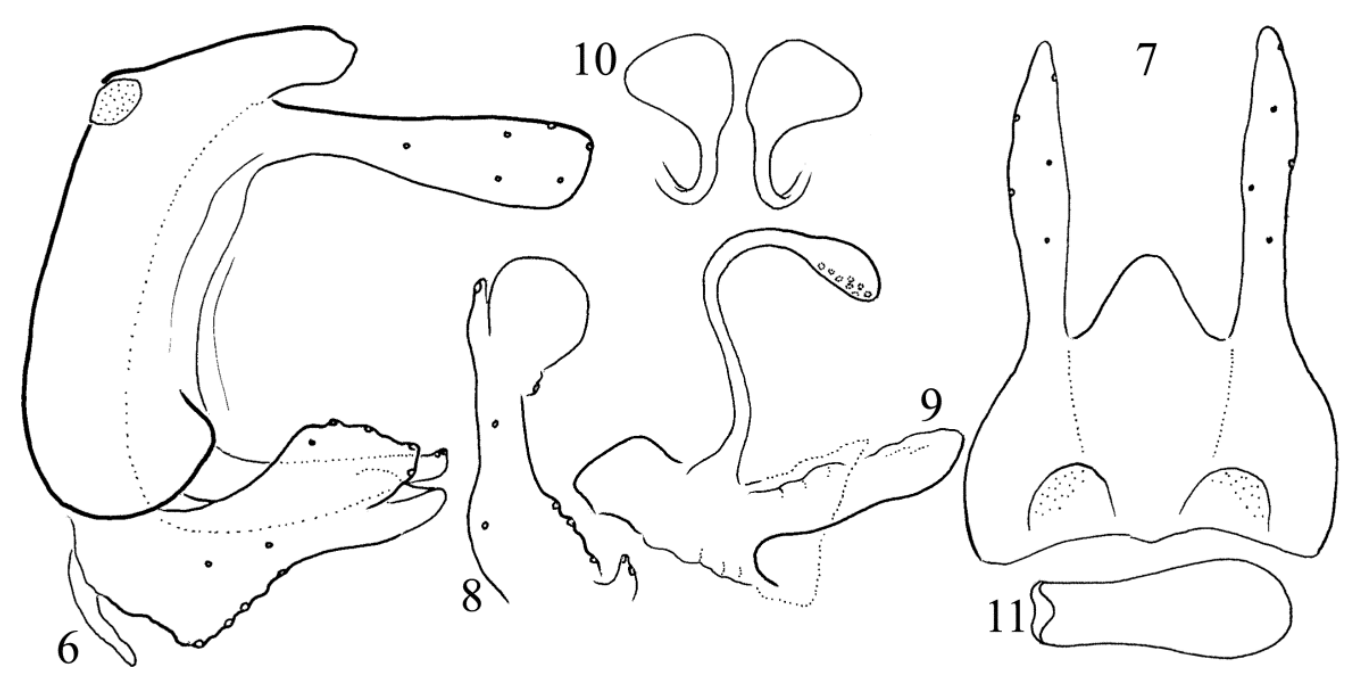

Figures 6-11. Nectopsyche bruchi (Navas, 1920). $6=$ male genitalia in left lateral view, $7=$ male genitalia in dorsal view, $8=$ left gonopod with apicomesal lobe in ventral perpendicular view; $9=$ phallic organ with the sigmoid profile of phallicata in lateral view; $10=$ enlarged apex of the dorsal process of the phallotheca; $11=$ phallicata in ventral view.

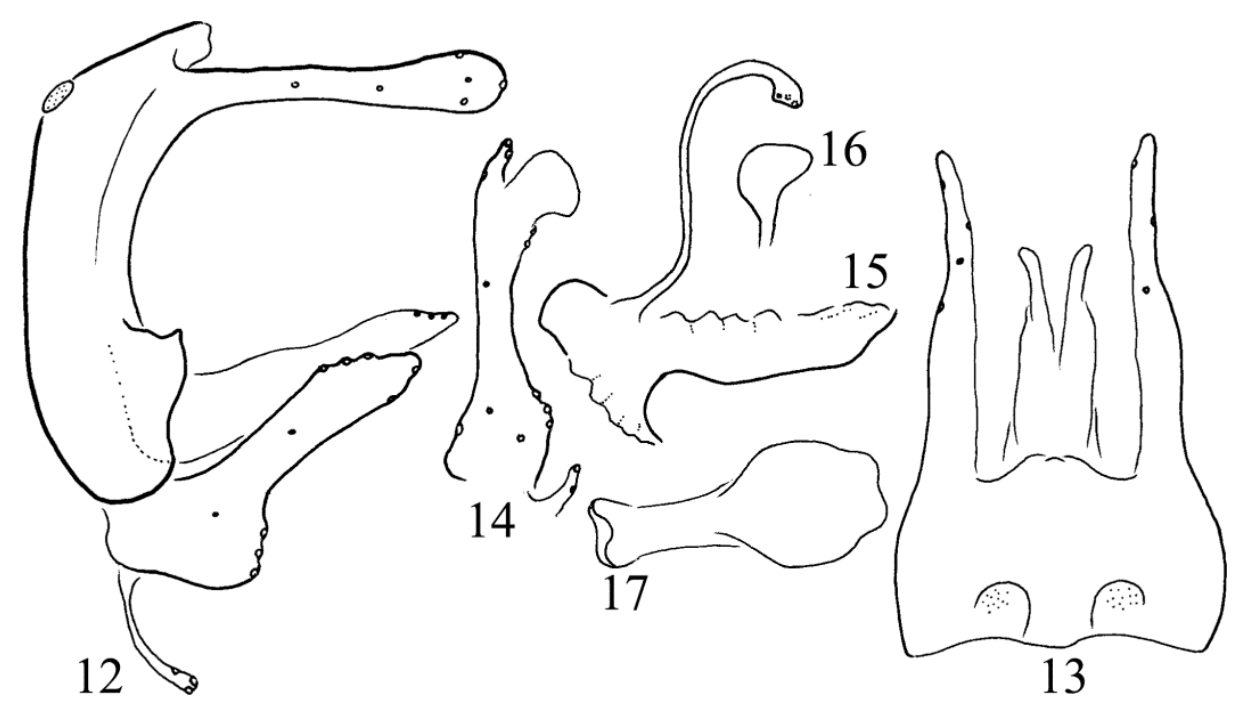

Figures 12-17. Nectopsyche buzoga sp. nov. Holotype: $12=$ male genitalia in left lateral view, 13 = male genitalia in dorsal view, $14=$ left gonopod with apicomesal lobe in ventral perpendicular view; 15 = phallic organ with the sigmoid profile of phallicata in lateral view; $16=$ enlarged apex of the dorsal process of the phallotheca; $17=$ phallicata in ventral view.

rated. The superanal complex with just discernible short horizontal dorsomesal process, the small mesal hump of the trilobed dorsum; the deeply shifted sclerotized horizontal lateral processes, the paraproct pair with obliquely truncate apex in lateral view. Cerci without apical fork, slender; apex clavate. Gonopods straight with produced rounded basoventral angle in lateral view; baso- ventral process filiform; apicomesal lobe slightly arching band; part of apical surface pegged, rugose. Phallic organ seems articulating to the basomesal ridge of the gonopods; the pair of swannecked dorsal phallothecal processes with very slim shaft, but well developed downward curving band-like asymmetric head; it seems a negative copy of the apicomesal lobe of the gonopod; 
endotheca without discernible setae; sigmoid profile with well-produced basal curve and irregular middle and apicad; apical half strongly produced laterad in ventral view.

Etymology. buzoga, from „buzogány” maze or clubbed in Hungarian, refers to the clavate shape of the cercal head as well as the apical region of the phallicata in ventral view.

\section{Nectopsyche candida (Hagen, 1861)}

(Figures 18-24)

Material examined. USA, SC, Aiken Co. Savannah River Site, Upper Three Runs Cr., bridge at road SRP 8 -I, $33.37026^{\circ} \mathrm{N}, 81.62960^{\circ} \mathrm{W}, 50.3$ $\mathrm{m}$ elevation, 4-5.IX.2009, black light, leg. Z. Burington (6 males, OPC).

Remarks. Based on the examined six specimens the speciation traits of apicomesal lobe of gonopods and the sigmoid profile of the phallic organ are rather stable. The drawn shape variations in the figures are integrated results of preparation, viewing angle distortion (random plane alterations), subjective drawing capacity and the actual individual shape variations. The apicomesal lobe on the gonopods sub-circular with a small hump basomesad. The sigmoid profile of the phallicata with well-produced apical curve and very small and almost half-closed basal curve; the small basal curve with varying shape alteration seems sensitive to the erection state of the aedeagus.

\section{Nectopsyche cubana (Banks, 1938)}

Nectopsyche cubana (Banks, 1938): Flint 1968: 54-55: "Material. Jamaica, Trelawny: Martha Brae near Fal-

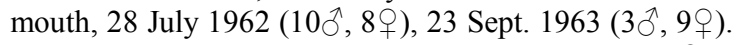
St. Andrew: Hermitage Dam, 22-23 July 1962 (2ㅇ)." Flint has identified these specimens with some hesitancy as $N$. cubana.

Nectopsyche cubana (Banks, 1938): Botosaneanu 1979: 58. In this synthesis on the caddisflies of Cuba and the Isla de Pinos detailed drawings were published of the genitalia of Nectopsyche cubana without giving any exact information about the collecting data of the drawn specimen. Only the distribution of Nectopsyche cubana in Cuba and Isla de Pinos was given: Oriental, Central and Occidental Cuba and Isla de Pinos. Botosaneanu remarked that his specimens from Cuba are not quite identical with the specimens from Jamaica.

Nectopsyche cubana (Banks, 1938): Botosaneanu 1980: 93-95. Collected specimens: Provincia Camagüey: $10^{\lambda}$, Provincia Pinar del Rio: $1 \delta^{\lambda}, 4$, Isla de Pinos: $21 \hat{\jmath}, 3$ ㅇ․ The drawn specimen in Botosaneanu 1979: 58 was selected from these collections.

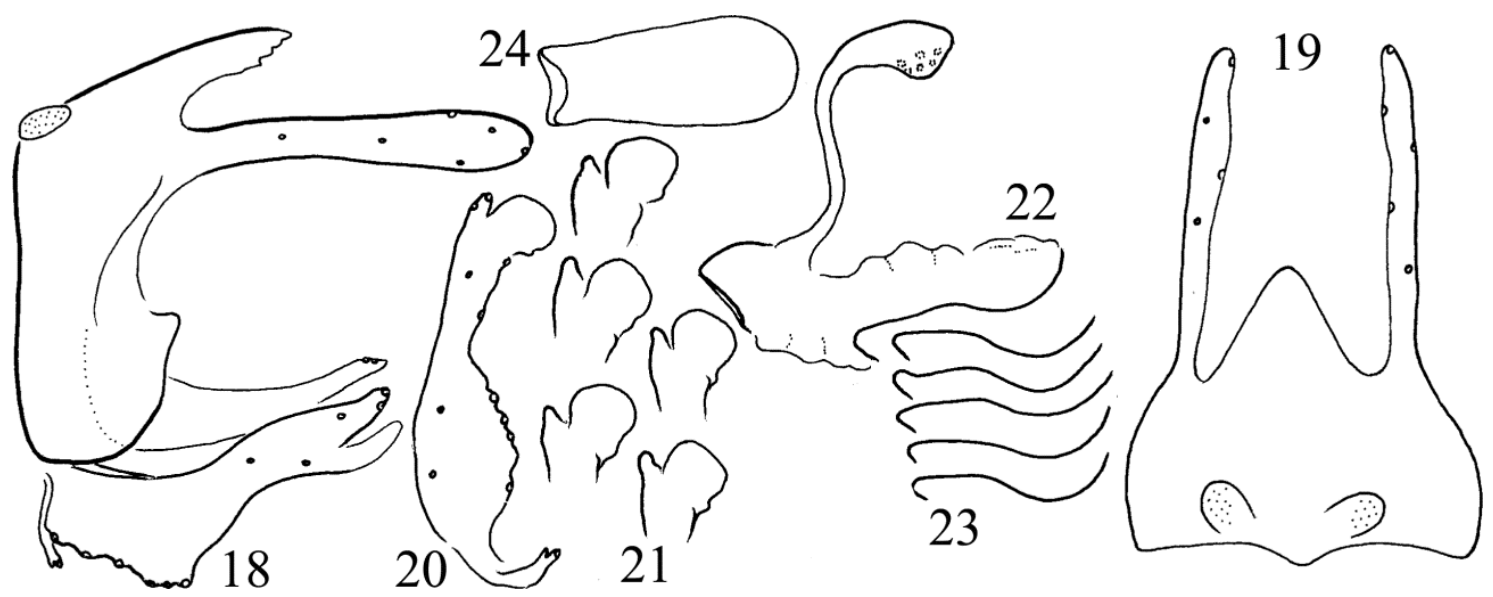

Figures 18-24. Nectopsyche candida (Hagen, 1861). 18 = male genitalia in left lateral view, $19=$ male genitalia in dorsal view, $20=$ left gonopod with apicomesal lobe in ventral perpendicular view; $21=$ apicomesal lobes on gonopod of five specimes from the same population; 22 = phallic organ with the sigmoid profile of phallicata in lateral view; $23=$ sigmoid profile of the phallicata of five specimens from the same population; $24=$ phallicata in ventral view. 
Remarks. This is a species that probably represents a species complex of closely related incipient sibling species. The specimen drawn from Jamaica (Flint 1968) and the specimen drawn collected probably from Isla de Pinos (Botosaneanu 1979) are not $N$. cubana, based on the speciation traits. They represent two new species in the Nectopsyche candida species group.

\section{Nectopsyche diminuta (Banks, 1920)}

(Figures 25-30)

Material examined. French Guiana, St-Laurent du-Maroni, Maroni River: A-CHIMATOCAMPOP, village $5^{\circ} 13.716^{\prime} \mathrm{N}, 54^{\circ} 17.498^{\prime} \mathrm{W} 0 \mathrm{~m}$, 6.ii.2007, FRG 12 N. leg. N. Jönsson (14 males, 1 female; SMNH; 5 males, OPC).

Remarks. This is a unique species in the genus with lost basoventral process. This synapomorphy is lacking or highly vestigial. The neutral trait of cerci is rather variable in the examined population. Based on the examined five specimens the speciation traits of apicomesal lobe of gonopods and the sigmoid profile of the phallic organ are stable. The drawn shape variations in the figures are integrated results of preparation, viewing angle distortion (random plane alterations), subjective drawing capacity and the actual individual shape variations. The apicomesal lobe on the gonopods slightly downward curving sub-circular. The sigmoid profile of the phallicata almost without apical curve and less produced open basal curve.

\section{Nectopsyche dombora Oláh, Johanson \& Malm, sp. nov.}

(Figures 31-35)

Material examined. Holotype, Bolivia, El Beni Dept. Liberalta, Chiquitania, Esmeralda Hotel area by river, $10.98270^{\circ} \mathrm{S}, 65.92366^{\circ} \mathrm{W}, 132 \mathrm{mas}$, 4.XI.2013, light trap, ID \#NHRS-BOL13-07, leg. N. Apelqvist, J. Jonsson \& V. Sossa, Export permit: SENASAG No 019471 (1 male, SMNH). Paratype: same as holotype (1 male, OPC).
Diagnosis. This new species with large eyes is most close to $N$. bonta sp. nov. but paraproct differently shaped; apicomesal lobes of gonopod ovoid, not with mesad directed apical angle; sigmoid profile highly diverged, with hookshaped basal curve, not L-shaped as well as the apical curve is more developed; ventral shape of phallicata with convex apical margin, not concave.

Description (in alcohol). This species has very large eyes, ventral interocular distance half eye. Body sclerites and wings dark brown. Length of forewing $7 \mathrm{~mm}$; forewing with some scales, but without any membrane pattern as visible on specimens stored in alcohol. Maxillary palps lacking both on holotype and paratype. Tibial spur formula 0-2-2.

Male genitalia. Abdominal segment IX without sternum; its ventral ending located at pivoting fulcrum is rounded with braced margin; tergum IX highly produced posterad with pin-pointed apex; punctate acrotergite rounded well separated. The superanal complex without any discernible horizontal dorsomesal process; the deeply shifted sclerotized horizontal lateral processes, the paraproct pair with apex of supapical dorsal depression. Cerci without apical fork, clavate. Gonopods slender and straight with produced rounded basoventral angle in lateral view; basoventral process filiform; apicomesal lobe ovoid; part of apical surface pegged, rugose. Phallic organ seems articulating to the basomesal ridge of the gonopods; the pair of swan-necked dorsal phallothecal processes with well-developed downward curving head; circular in dorsal perpendicular view; apical half of the head is rugose ventrad; the negative copy of the apicomesal lobe of the gonopod; endotheca without discernible setae; sigmoid profile with hook-shaped basal curve and well produced apical curve; apical half produced laterad forming a fan-shaped apex with convex apical margin in ventral view.

Etymology. dombora, from „domború” convex in Hungarian, refers to convex apical margin of the phallicata in ventral view. 


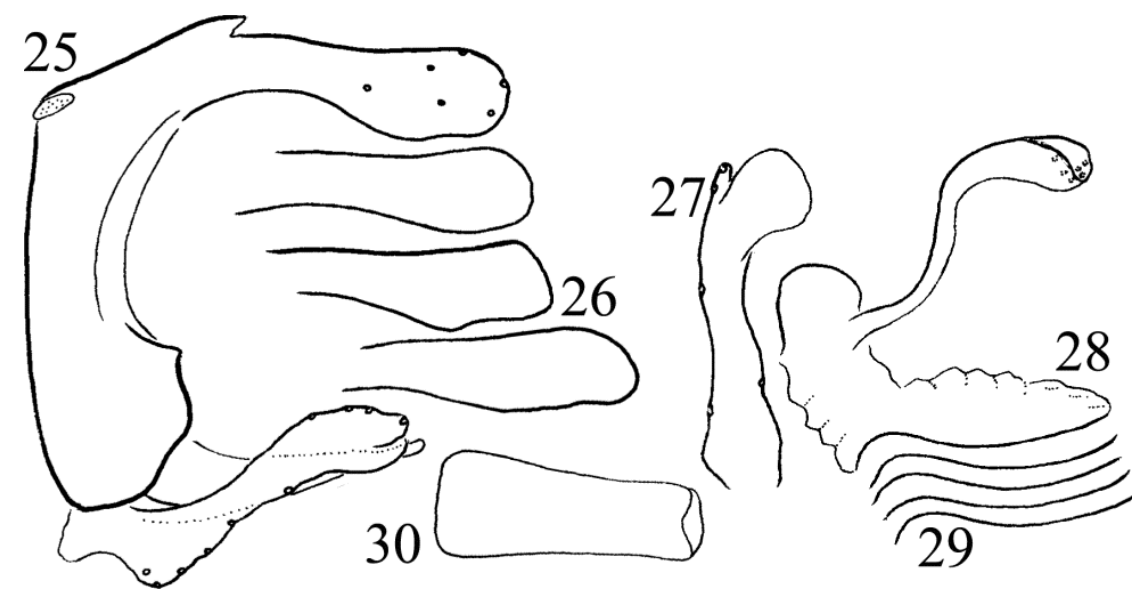

Figures 25-30. Nectopsyche diminuta (Banks, 1920). $25=$ male genitalia in left lateral view, $26=$ cercal head of three specimens from the same population, 27 = left gonopod with apicomesal lobe in ventral perpendicular view; $28=$ phallic organ with the sigmoid profile of phallicata in lateral view; $29=$ sigmoid profile of the phallicata of four specimens from the same population; $30=$ phallicata in ventral view.

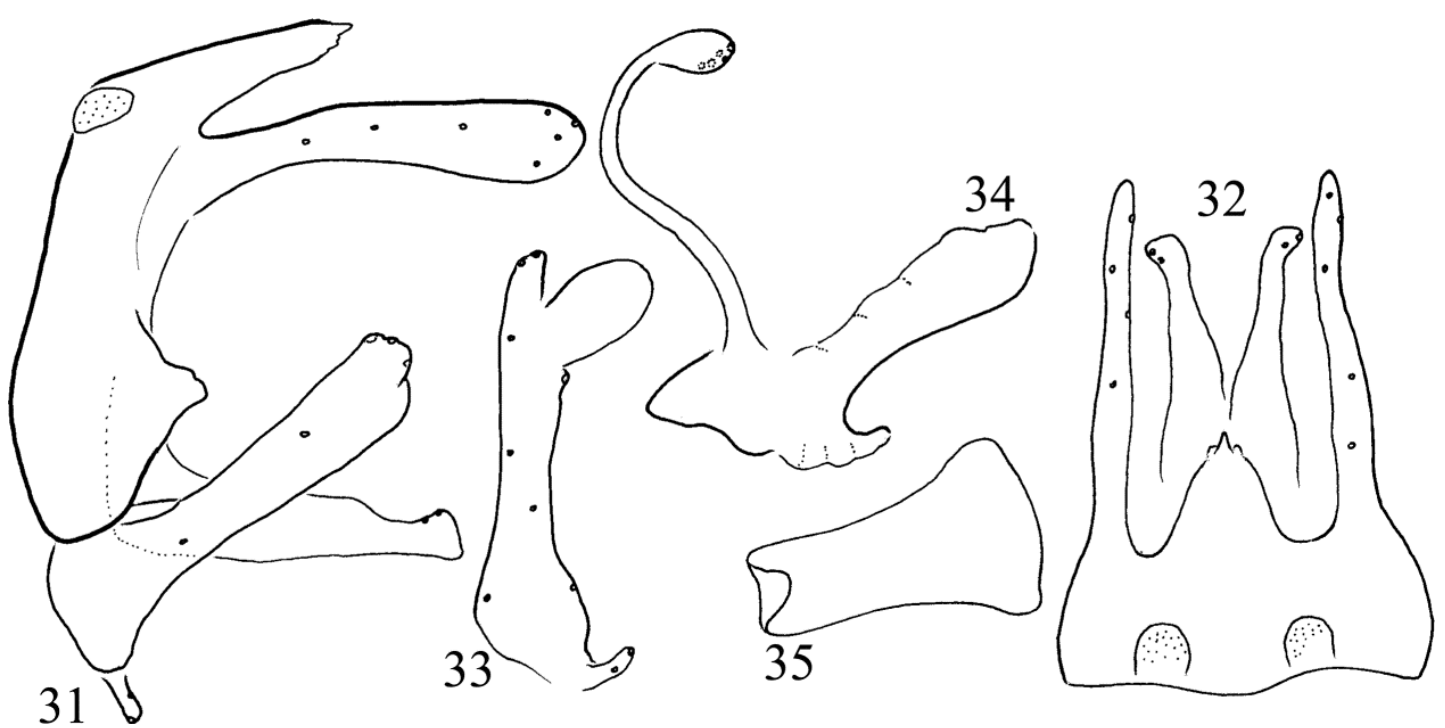

Figures 31-35. Nectopsyche dombora sp. nov. Holotype: $31=$ male genitalia in left lateral view, $32=$ male genitalia in dorsal view, 33 = left gonopod with apicomesal lobe in ventral perpendicular view; 34 = phallic organ with the sigmoid profile of phallicata in lateral view; $35=$ phallicata in ventral view.

\section{Nectopsyche exquisita (Walker, 1852)}

(Figures 36-42)

Material examined. USA, GA/SC, Rabun/Oconee Cos. Chattooga R. \& Rt. $28,34^{\circ} 55^{\prime} \mathrm{N}, 83^{\circ} 10^{\prime}$ W, 29.VI.1991, leg. M. Floyd \& B. Nichols (6 males, 1 female; OPC).
Remarks. Based on the examined six specimens we have found some variability range in the speciation traits of apicomesal lobe of gonopods and the sigmoid profile of the phallic organ are stable. The drawn shape variations in the figures are integrated results of preparation, viewing angle distortion (random plane alterations), subjective drawing capacity and the actual individual 
shape variations. The apicomesal lobe on the gonopods more or less ovoid. The sigmoid profile of the phallicata short, abbreviated and characterized by small basal curve liable to shape alteration under the impact of erection state.

\section{Nectopsyche flinti Oláh \& Oláh, sp. nov.}

(Figure 43)

Nectopsyche gemma (Müller, 1880) Flint 1974: 129. "Material. - Surinam, Coeroeni-eiland, 30 Aug. 1959, at light $1 \delta$." "This form matches specimens at the Museum of Comparative Zoology, Harvard University, identified as gemma by Müller many years ago." Misidentification!

Diagnosis and description. This species was determined as $N$. gemma by the forewing pattern (Flint 1974). Later it was recognised that a number of species have been mixed under this name and the species figured and described from Surinam is a new undescribed species (Flint 1991). Here we re-diagnose and describe formally this species based upon the figure in lateral view of the single male specimen deposited in the U. S. National Museum.

$N$. flinti sp. nov. has the head of the cerci unforked, gonopods without enlarged base and endotheca apparently without spines. This new species does not belong to the gemma species group in spite of the gemma type forewing pattern. It is a member of the $N$. candida species group. Based upon the sigmoid profile of the phallicata $N$. flinti is most close to $N$. garenoa $\mathrm{sp}$. nov., but differs by the more produced, less open basal curve and the less developed apical curve. Head of the paraproct truncate obliquely ventrad, not digitate ventrad. There are marked divergences in neutral traits as well: tergite IX has less produced apical region and gonopods are slimmer.

Etymology. We named this species in honour of Oliver Flint who has first described it as $N$. gemma, but later recognised its independent taxonomic identity.

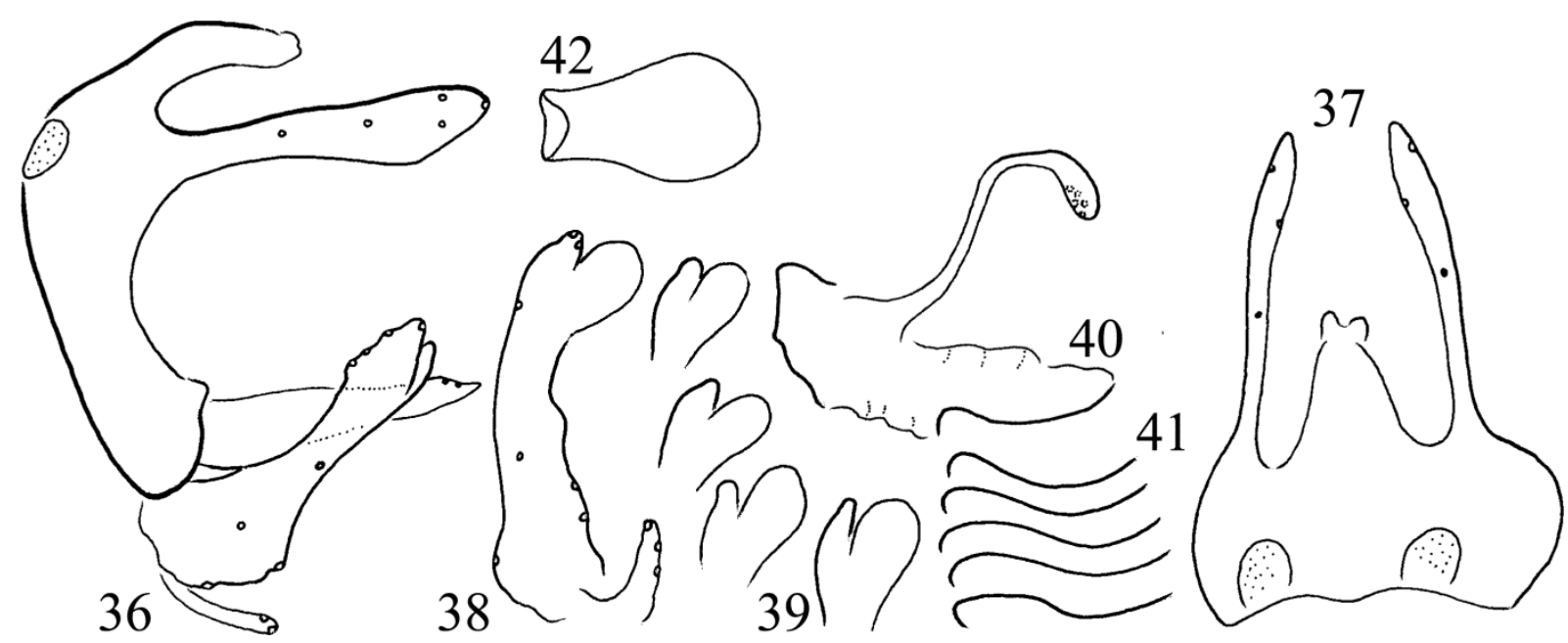

Figures 36-42. Nectopsyche exquisita (Walker, 1852). 36 = male genitalia in left lateral view, 37 = male genitalia in dorsal view, $38=$ left gonopod with apicomesal lobe in ventral perpendicular view; $39=$ apicomesal lobes on gonopod of four specimes from the same population; $40=$ phallic organ with the sigmoid profile of phallicata in lateral view; $41=$ sigmoid profile of the phallicata of five specimens from the same population; $42=$ phallicata in ventral view. 


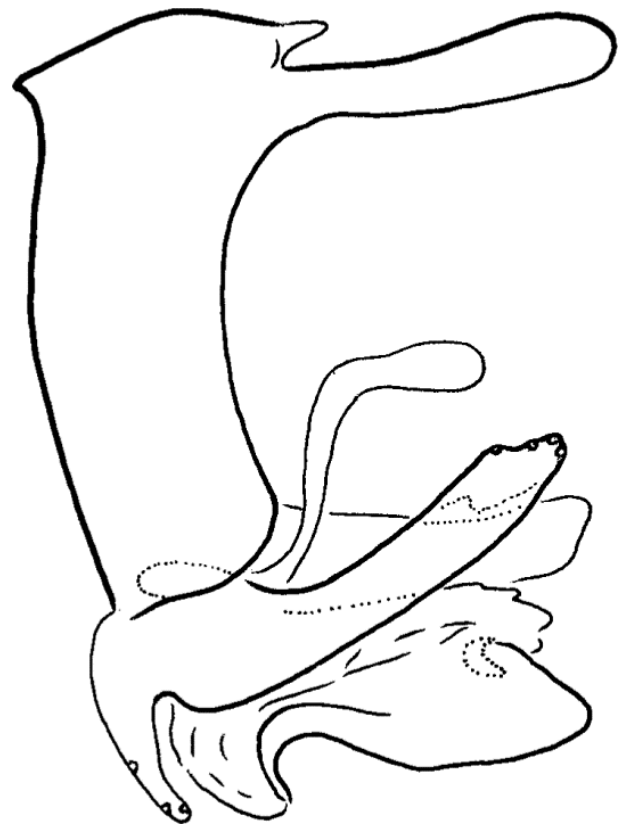

Figure 43. Nectopsyche flinti sp. nov. $43=$ male genitalia in left lateral view, reproduced from the original drawing.

\section{Nectopsyche garenoa Oláh \& Oláh, sp. nov.}

(Figures 44-48)

Material examined. Holotype, Ecuador, Amazonian Lowland, Terra Firme, Gareno Lodge, near Puerto Napo, 400 m, 13.VIII.2011, light trap, leg. J. Oláh Jr. (1 male, OPC).

Diagnosis. This new species is most close to $N$. obla sp. nov. but tergum IX monolobed, not bilobed apicad; cerci parallel-sided, not with ventrally produced head; paraproct head with ventral digitate process, not simply truncate; apicomesal lobe on gonopods smaller; dorsal process of the phallotheca differently shaped; ventral profile of the phallicata with truncate apical margin, not bilobed; sigmoid profile differently shaped.

Description (in alcohol). This species has small eyes. Length of forewing $8 \mathrm{~mm}$, forewing with few short setae and without any scales and without any membrane pattern as visible on the single specimen stored in alcohol. Maxillary palp formula I-IV-II-III-V. Tibial spur formula 0-2-2.
Male genitalia. Abdominal segment IX without sternum; its ventral ending located at pivoting fulcrum is rounded with braced margin; tergum IX highly produced posterad monolobed; punctate acrotergite rounded well separated. The superanal complex without any discernible horizontal dorsomesal process; the deeply shifted sclerotized horizontal lateral processes, the paraproct pair with rounded apices in dorsal view and digitate ventrad in lateral view. Cerci without apical fork, almost parallel-sided shaft and with rounded apex. Gonopods straight with produced rounded basoventral angle in lateral view; basoventral process filiform; apicomesal lobe slightly arching band; part of apical surface pegged, rugose. Phallic organ seems articulating to the basomesal ridge of the gonopods; the pair of swan-necked dorsal phallothecal processes with very slim shaft, but well developed downward curving band-like head; the negative copy of the apicomesal lobe of the gonopod; endotheca without discernible setae; phallicata with a ventromesal ridge; sigmoid profile short with almost equal length of the basal and apical curves; apical half strongly produced laterad forming a fan-shaped apex in ventral view.

Etymology. garenoa, from the name of the type locality: Garenoa Lodge on the Amazonian Lowland.

\section{Nectopsyche lenula Oláh \& Oláh, sp. nov.}

$$
\text { (Figures 49-53) }
$$

Material examined. Holotype, Bolivia, Guayamerin, 29-30.XI.1966, leg. S. Mahunka, Hungarian Zoological Expedition II, S. America No.BB:No.442 (1 male, HNHM)

Diagnosis. This new species having large eyes is most close to $N$. bonta sp. nov. but tergum IX less produced posterad; cerci parallel-sided, not clavate; paraproct head less upward angled; gonopods straight, narrow but with not so smooth ventral margin in lateral view; apicomesal lobes of gonopod more narrow with downward directed apex; sigmoid profile highly diverged, short, not long; basal curve more produced. 


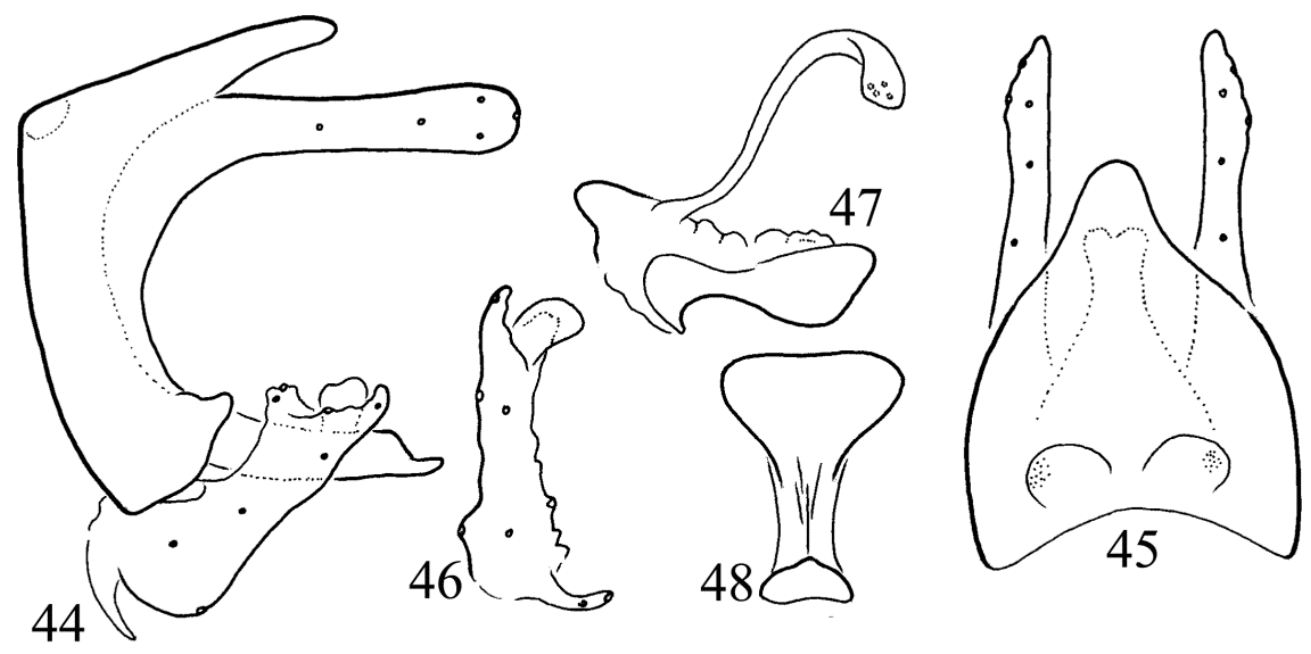

Figures 44-48. Nectopsyche garenoa sp. nov. Holotype: $44=$ male genitalia in left lateral view, $45=$ male genitalia in dorsal view, $46=$ left gonopod with apicomesal lobe in ventral perpendicular view; 47 = phallic organ with the sigmoid profile of phallicata in lateral view; $48=$ phallicata in ventral view.

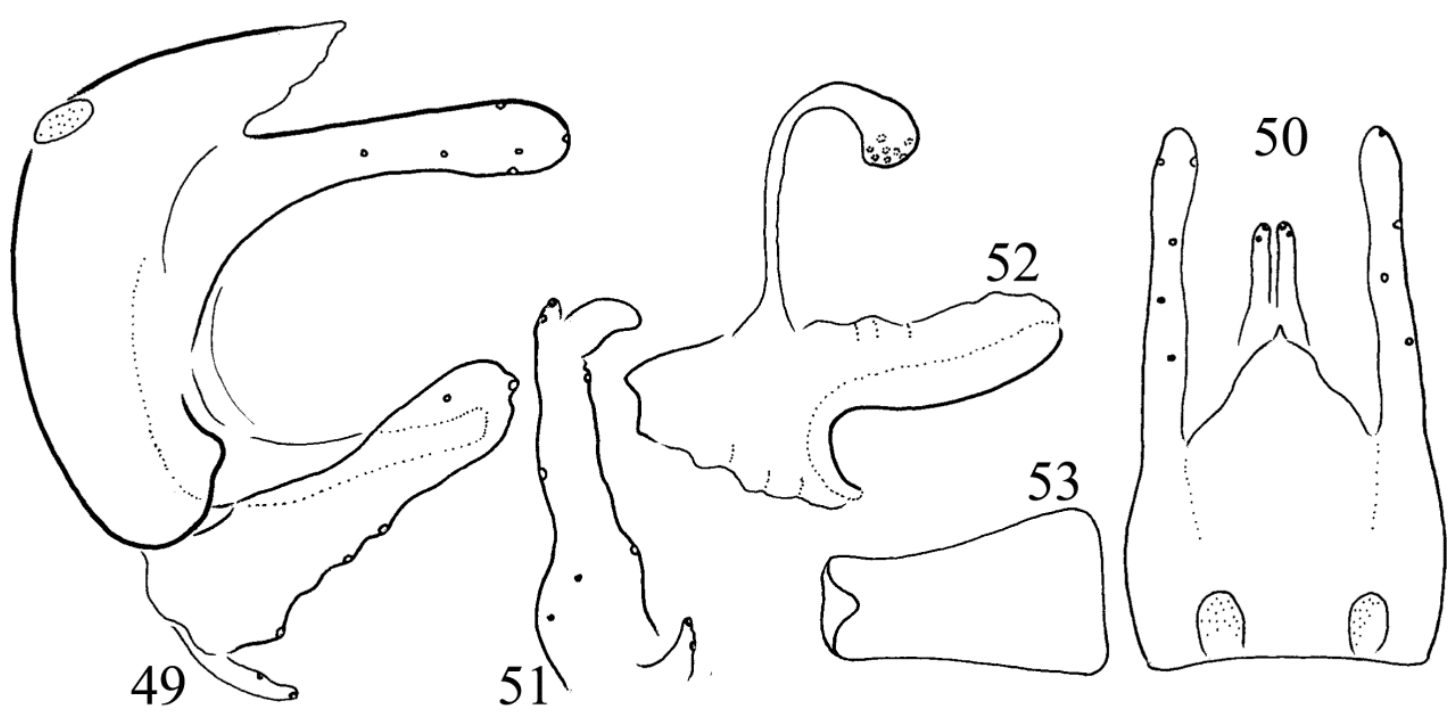

Figures 49-53. Nectopsyche lenula sp. nov. Holotype: 49 = male genitalia in left lateral view, 50 = male genitalia in dorsal view, $51=$ left gonopod with apicomesal lobe in ventral perpendicular view; $52=$ phallic organ with the sigmoid profile of phallicata in lateral view; $53=$ phallicata in ventral view.

Description (in alcohol). This species has very large eyes, almost touching ventrum. Length of forewing $7 \mathrm{~mm}$; forewing with some scales, but without any membrane pattern as visible on specimens stored in alcohol. Maxillary palp formula IV-(II,III)-(I,V). Tibial spur formula 0-2-2.

Male genitalia. Abdominal segment IX without sternum; its ventral ending located at pivoting fulcrum is rounded with braced margin; tergum IX produced posterad with pin-pointed apex; punctate acrotergite rounded well separated. The superanal complex without any discernible horizontal dorsomesal process; the deeply shifted sclerotized horizontal lateral processes, the paraproct pair with truncate apex in lateral view. Cerci without apical fork, parallel-sided. Gonopods 
slender and straight with slightly produced rounded basoventral angle in lateral view; basoventral process filiform; apicomesal lobe elongated, downward directed; part of apical surface pegged, rugose. Phallic organ seems articulating to the basomesal ridge of the gonopods; the pair of swannecked dorsal phallothecal processes with welldeveloped downward curving head; circular in dorsal perpendicular view; apical half of the head is rugose ventrad; the negative copy of the apicomesal lobe of the gonopod; endotheca without discernible setae; sigmoid profile short with produced basal curve; apical half produced laterad forming a fan-shaped apex with straight apical margin in ventral view.

Etymology. lenula, from „lenyúló” extending downward in Hungarian, refers to the apicomesal lobe of the gonopods more elongated with downward extending apex.

\section{Nectopsyche obla Oláh, Johanson \& Malm, sp. nov.}

(Figures 54-58)

Material examined. Holotype, Peru, San Martin Prov., Rio Huallaga tributary, small river passing Chazuta, 6 ${ }^{\circ} 34.665^{\prime} \mathrm{S}, 76^{\circ} 08.209^{\prime} \mathrm{W}$, light, loc. 11, 10.I.2009 leg. T. Malm \& A. Johanson (1 male SMNH).

Diagnosis. This new species is most close to $N$. garenoa sp. nov. but tergum IX produced posterad with bilobed apex, not monolobed; cerci short and clavate, not long and parallel-sided; paraproct head obliquely truncate, not with ventral digitate process; apicomesal lobes of gonopod more broad fan-shaped; sigmoid profile highly diverged; ventral shape of phallicata with apical sinus of concavity.

Description (in alcohol). This species has small eyes. Length of forewing $9 \mathrm{~mm}$, forewing without any scales and without any membrane pattern as visible on the single specimen stored in alcohol. Maxillary palp formula IV-(I,II,III)-V. Tibial spur formula 0-2-2.

Male genitalia. Abdominal segment IX without sternum; its ventral ending located at pivoting fulcrum is rounded with braced margin; tergum IX highly produced posterad bilobed; punctate acrotergite rounded well separated. The superanal complex without any discernible horizontal dorsomesal process; the deeply shifted sclerotized horizontal lateral processes, the paraproct pair with obliquely truncate apices in lateral view. Cerci without apical fork, clavate. Gonopods straight with produced rounded basoventral angle in lateral view; basoventral process long filiform; apicomesal lobe broad fan-shaped; part of apical surface pegged, rugose. Phallic organ seems articulating to the basomesal ridge of the gonopods; the pair of swan-necked dorsal phallothecal processes with well-developed downward curving band-like head; apical half of the head is rugose ventrad; the negative copy of the apicomesal lobe of the gonopod; endotheca without discernible setae; phallicata with a ventromesal ridge; sigmoid profile uniquely patterned; apical half strongly produced laterad forming a fan-shaped apex with apicomesal sinus in ventral view.

Etymology. obla, from „öböl” sinus in Hungarian, refers to bilobed apex of the posterad produced tergite IX and to the apical concavity of the phallicata in ventral view.

\section{Nectopsyche padrenavasi Holzenthal, 1999}

$$
\text { (Figures 59-64) }
$$

Material examined. Argentina, Corrientes Province, Ituzaingo, Howard Johnson Express Inn, $27^{\circ} 35^{\prime} 38^{\prime \prime}$ S, 56 $48^{\prime} 12^{\prime \prime} \mathrm{W}, 25 . X I .2011$, at lighted windows, leg. A. G. Duff (2 males, 15 females; OPC). Corrintes, PN Mburucuyá campground, $120 \mathrm{~m}, 28^{\circ} 00.893^{\prime} \mathrm{S}, 58^{\circ} 02.262^{\prime} \mathrm{W}$, 8.I.2008, leg. K. Hill, D. Marshall, \&M. Moulds (1 male, SMNH).

Remarks. Based on the examined three specimens we have found some variability in the speciation traits of the sigmoid profile of the phallicata. The drawn shape variations in the figures are integrated results of preparation, viewing angle distortion (random plane alterations), subjective drawing capacity and the actual individual 


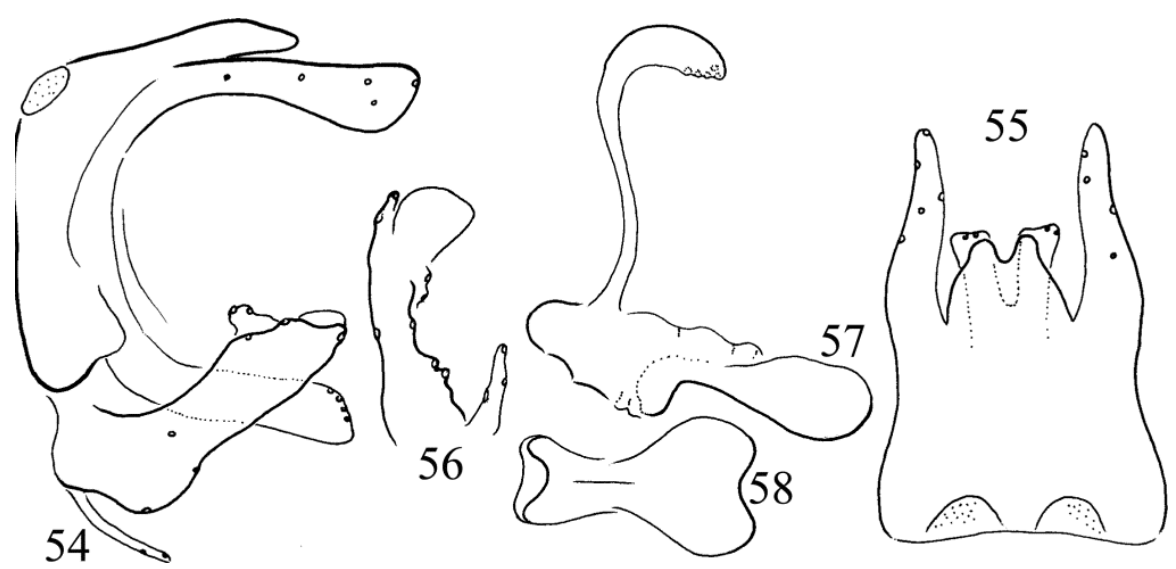

Figures 54-58. Nectopsyche obla sp. nov. Holotype: 54 = male genitalia in left lateral view, 55 = male genitalia in dorsal view, $56=$ left gonopod with apicomesal lobe in ventral perpendicular view; $57=$ phallic organ with the sigmoid profile of phallicata in lateral view; $58=$ phallicata in ventral view.

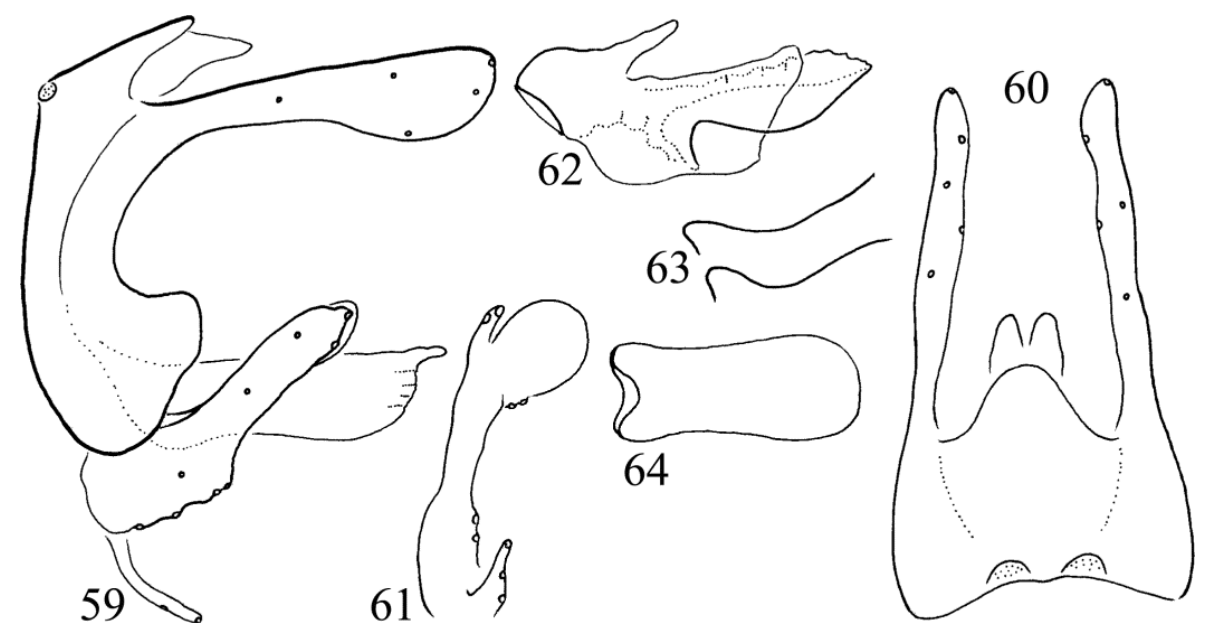

Figures 59-64. Nectopsyche padrenavasi Holzenthal, 1999. 59 = male genitalia in left lateral view, $60=$ male genitalia in dorsal view, $61=$ left gonopod with apicomesal lobe in ventral perpendicular view; $62=$ phallic organ with the sigmoid profile of phallicata in lateral view; 63 = sigmoid profile of the phallicata of two specimens from the same population; $64=$ phallicata in ventral view.

shape variations. The sigmoid profile of the phallicata short abbreviated and characterized by small basal curve liable to shape alteration under the impact of erection state.

\section{Nectopsyche paludicola Harris, 1986}

(Figures 65-68)

Material examined. USA, Alabama, Baldwin County, Nelson Branch, Perdido River, 23.VI. 1982, blacklight, leg. S. Harris \& P. O’Neil (7 males, OPC).

Remarks. Based on the examined seven specimens we have found a stable population with very small variability range both in the neutral and the adaptive speciation traits. The drawn shape variations in the figures are integrated results of preparation, viewing angle distortion (random plane alterations), subjective drawing capacity and the actual individual shape variations. The sigmoid profile of the phallicata short particularly abbreviated with deep basal hook. 


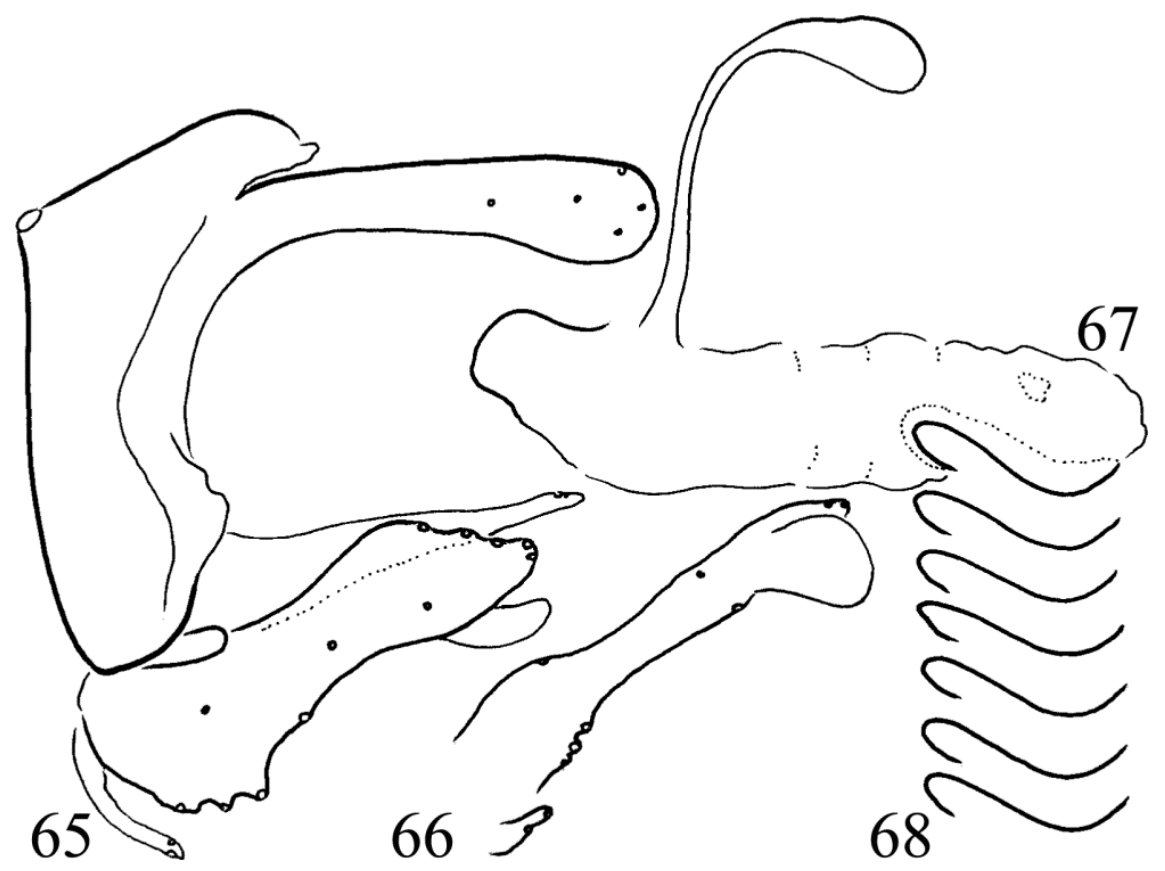

Figures 65-68. Nectopsyche paludicola Harris, 1986. 65 = male genitalia in left lateral view, 66 = left gonopod with apicomesal lobe in ventral perpendicular view; $67=$ phallic organ with the sigmoid profile of phallicata in lateral view; $68=$ sigmoid profile of the phallicata of six specimens from the same population.

\section{Nectopsyche pavida species group}

This species group has retained or regained some material of the lost IX ventrum by rearrangement in the form of a broad scoop-like pair of ventral plate, frequently variously fused mesad and forming a large ventral concave less sclerotized cumbuliform plate, indistinctly connected to gonopods or segment IX. Most of its ventral surface is densely covered with spicules or microtrichiae, the non-cellular, non-innervated, nonsocketed, and non-articulated minute processes of cuticular origin. The apical regions are supplied with a few sensory setae, probably with high diagnostic value for future fine phenomic studies.

\section{Nectopsyche alma Oláh, Johanson \& Malm, sp. nov.}

(Figures 69-73)

Material examined. Holotype, French Guiana, Maripasoula, Maroni River, Damason campo, Village, $4^{\circ} 35.112^{\prime} \mathrm{N}, 54^{\circ} 24.799^{\prime} \mathrm{W} 38 \mathrm{~m}$, 7.II.2007, FRG 13, leg. N. Jönsson (1 male, SMNH).
Diagnosis. This new species has the scoop shaped basoventral processes of gonopods fused. Most close to $N$. adusta but without any forewing pattern, at least in alcohol; also differs by having cerci long, not short; paraproct as long as cerci, not short. The speciation trait of sigmoid profile almost L-shaped, not sigmoid, basal curve much more produced; apicomesal lobes large and circular.

Description (in alcohol). This species has small eyes. Length of forewing $7 \mathrm{~mm}$, forewing membrane uniform and unicolor without any pattern, with pterostigmal enlargement on specimen stored in alcohol. Maxillary palp formula IV(I,II)-III-V. Tibial spur formula 0-2-2.

Male genitalia. Abdominal segment IX short, without sternum; its ventral ending located at pivoting fulcrum is tapering with braced margin; tergum IX produced posterad with broad, monolobed apex in dorsal view. The superanal complex has deeply shifted sclerotized horizontal lateral processes, the paraproct with narrowing, slightly knobby apices visible both from lateral 


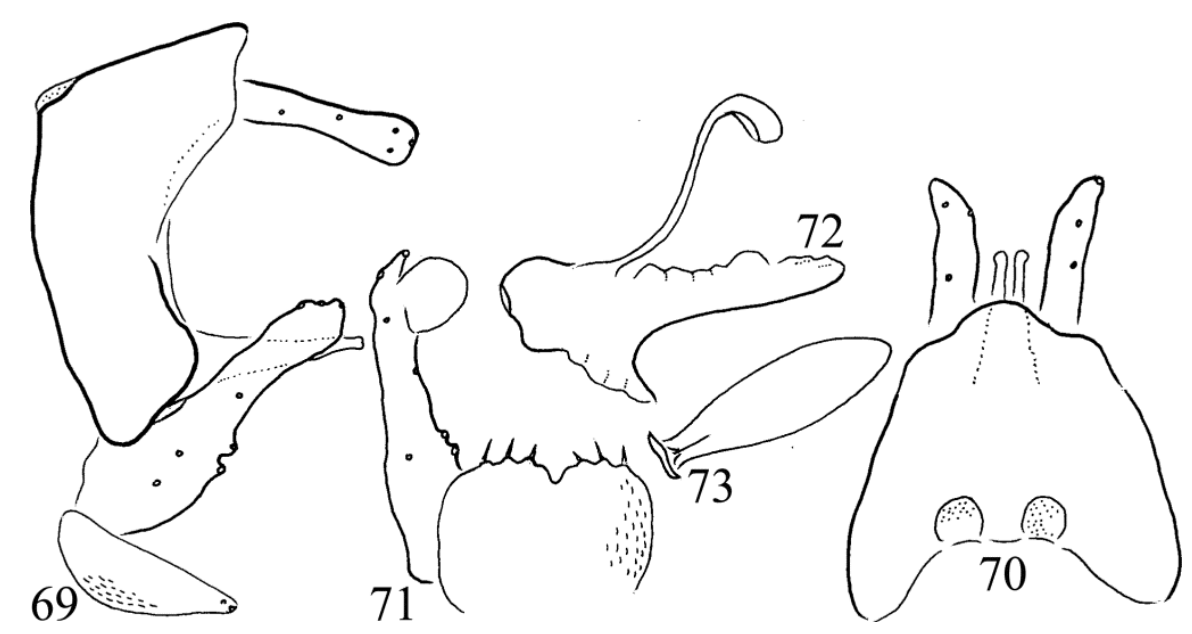

Figures 69-73. Nectopsyche alma sp. nov. Holotype: $69=$ male genitalia in left lateral view, 70 = male genitalia in dorsal view, $71=$ left gonopod with apicomesal lobe and ventral plate in ventral perpendicular view; $72=$ phallic organ with the sigmoid profile of phallicata in lateral view; $73=$ phallicata in ventral view.

and dorsal view. Cerci without fork, short almost parallel-sided. Gonopods almost straight in lateral view; apex monolobed; gonopod basoventrum broad ventrad; scoop shaped pair of basoventral processes fused, with narrow and deep apicomesal cleft and with three sensory setae apicad on both sides; apicomesal lobes regular circular, large. Phallic organ seems articulating to the basomesal ridge of the gonopods; the pair of swan-necked dorsal phallothecal processes slender with large downward turning apex, rounded triangular fanshaped in perpendicular dorsal view; the endotheca without any setae; lateral profile of the phallicata with large basal curve, apical curve less produced, the entire profile is stretched, less sigmoid.

Etymology. alma, from "alma" apple in Hungarian, refers to the circular apicomesal lobe on the gonopods.

\section{Nectopsyche bobita Oláh, Johanson \& Malm, sp. nov.}

(Figures 74-78)

Material examined. Holotype, French Guiana, Approuague-Kaw, Kaw Mtn. $4^{\circ} 32.805^{\prime} \mathrm{N}, 52^{\circ}$ $11.458^{\prime} \mathrm{W} 60$ mao 25.I.2007, FRG 6 leg. N. Jönsson (1 male, SMNH)
Diagnosis. This new species has the scoop shaped basoventral processes of gonopods fused. Most close to N. sima, but differs by the particular combination of both the adaptive and neutral traits. Tergite IX more produced posterad; cerci with larger semicircular head; gonopod head differently lobed, basoventral lobes fused, without apicomesal excision, apicomesal lobe rounded, not narrow. Sigmoid profile diverged.

Description (in alcohol). This species has small eyes. Length of forewing $9 \mathrm{~mm}$, forewing membrane uniform and unicolor some setal pattern indiscernible on specimen stored in alcohol. Maxillary palp formula IV-II-III-I-V. Tibial spur formula 0-2-2.

Male genitalia. Abdominal segment IX without sternum; its ventral ending located at pivoting fulcrum is subquadrangular with braced margin; tergum IX produced posterad with slightly bifid apex in dorsal view. The superanal complex has deeply shifted sclerotized horizontal lateral processes, the paraproct is narrow tapering apicad in lateral view and slightly dilated and laterad directed in dorsal view. Cerci without fork, straight shaft and ventrad produced large semicircular head. Gonopods almost straight, broader basad in lateral view; its basoventrum less pigmented; scoop shaped pair of basoventral processes fused; 


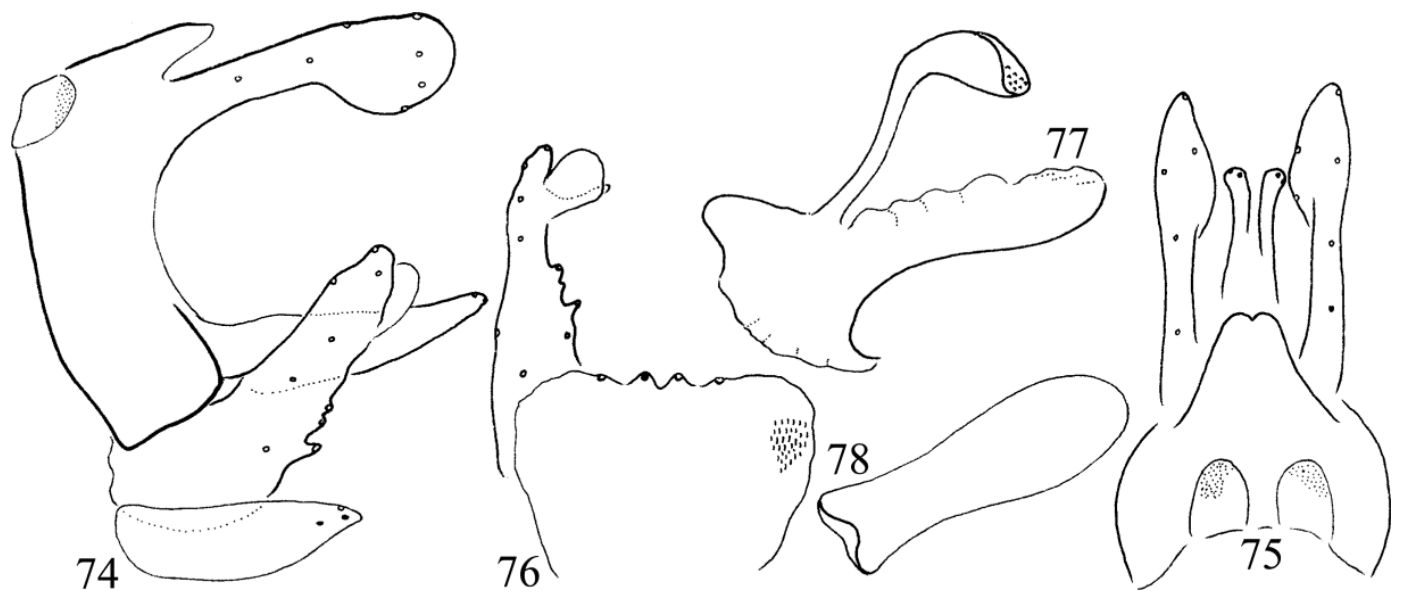

Figures 74-78. Nectopsyche bobita sp. nov. Holotype: $74=$ male genitalia in left lateral view, $75=$ male genitalia in dorsal view, $76=$ left gonopod with apicomesal lobe and ventral plate in ventral perpendicular view; $77=$ phallic organ with the sigmoid profile of phallicata in lateral view; $78=$ phallicata in ventral view.

apicomesal lobe rounded; part of apical surface rugose. Phallic organ seems articulating to the basomesal ridge of the gonopods; the pair of swan-necked dorsal phallothecal processes rather robust with large apex, triangular fan-shaped in perpendicular dorsal view; the endotheca without any setae; lateral profile of the phallicata distinct sigmoid with less developed basal curve.

Etymology. bobita, from "bóbita" topknot in Hungarian, refers to shape of the enlarged swanneck process of the phallotheca dominating on the genitalia.

\section{Nectopsyche capota Oláh, Johanson \& Malm, sp. nov.}

(Figures 79-83)

Material examined. Holotype, Bolivia, El Beni Dept. Liberalta, Chiquitania, Esmeralda Hotel area by river, $10.98270^{\circ} \mathrm{S}, 65.92366^{\circ} \mathrm{W}, 132 \mathrm{mas}$, 4.XI.2013, light trap, ID \#NHRS-BOL13-07, leg. N. Apelqvist, J. Jonsson \& V. Sossa, Export permit: SENASAG No 019471 (1 male, SMNH). Paratypes: same as holotype (2 males, SMNH; 2 males, OPC).

Diagnosis. This new species has the scoopshaped basoventral processes of gonopods fused. Having ventrad capitate medium-long cerci, elon- gated apicomesal lobes on gonopods and open basal curve on the sigmoid profile most close to $N$. nilta sp. nov., but differs by the differently shaped neutral traits: tergite IX is produced posterad, not short; cerci has a head with cut or truncated dorsoapical corner, not with produced corner; paraproct head is tapering both in lateral and dorsal view, not patterned. There are subtle, but stable speciation trait divergences in the shape of swan-necked process, sigmoid profile, the ventral profile of the phallicata and of the apicomesal lobe of gonopod.

Description (in alcohol). This species has small eyes. Length of forewing $8 \mathrm{~mm}$, forewing membrane darker brown, uniform and unicolor without any pattern on specimen stored in alcohol. Maxillary palp formula IV-(I,II,III)-V. Tibial spur formula 0-2-2.

Male genitalia. Abdominal segment IX without sternum; its ventral ending located at pivoting fulcrum is rounded with braced margin; tergum IX much produced posterad with pointed monolobed apex in dorsal view. The superanal complex has deeply shifted sclerotized horizontal lateral processes, the paraproct tapering apicad. Cerci without fork, medium-long and ventrad capitate, dorsoapical corner straight truncated. Gonopods slightly concave dorsad in lateral view; its basoventrum more developed; scoop-shaped pair of 


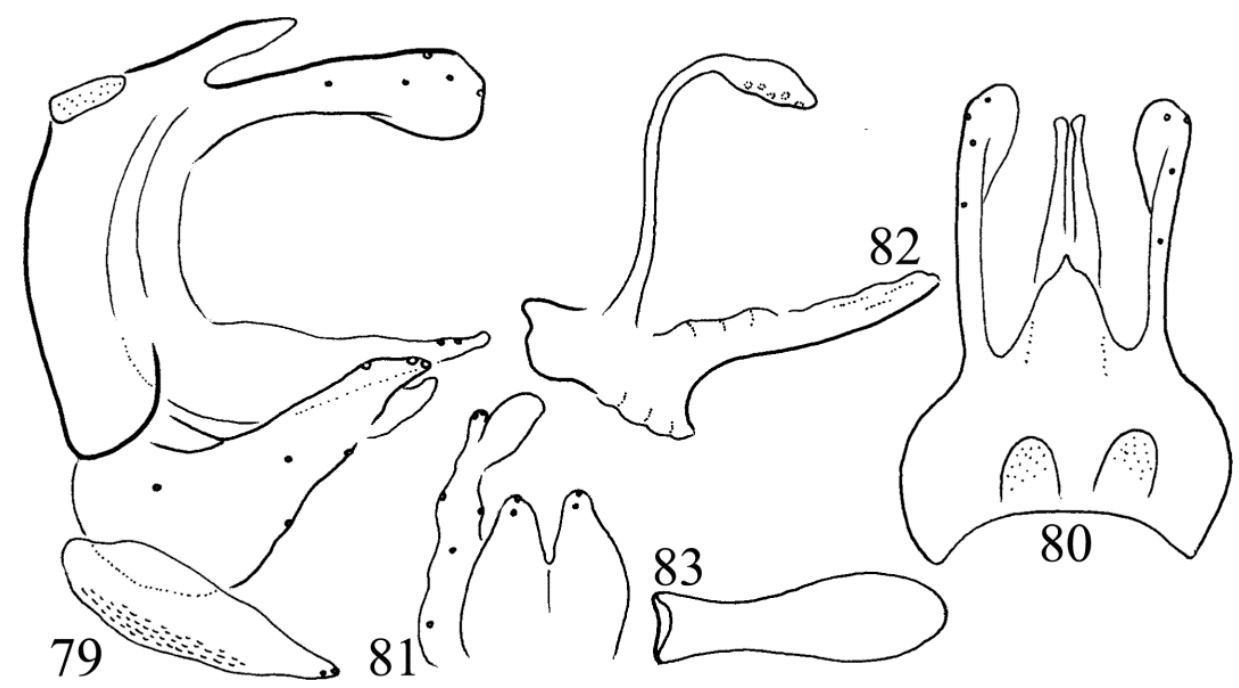

Figures 79-83. Nectopsyche capota sp. nov. Holotype: $79=$ male genitalia in left lateral view, $80=$ male genitalia in dorsal view, $81=$ left gonopod with apicomesal lobe and ventral plate in ventral perpendicular view; $82=$ phallic organ with the sigmoid profile of phallicata in lateral view; 83 = phallicata in ventral view.

basoventral processes fused, with wide apicomesal cleft with two subapical sensory setae on both lobes; apicomesal lobe elongated in ventral view; part of apical surface rugose. Phallic organ seems articulating to the basomesal ridge of the gonopods; the pair of swan-necked dorsal phallothecal processes slender filiform with elongated fanshaped apex; the endotheca without any setae; sigmoid profile of the phallicata with open basal curve, apical curve less produced.

Etymology. capota, from "lecsapott", "levágott" cut-off, truncate in Hungarian, refers to the truncate dorsoapical corner on the head of the cerci.

\section{Nectopsyche hasonla Oláh, Johanson \& Malm, sp. nov.}

(Figures 84-88)

Material examined. Holotype, Bolivia, Santa Cruz Dept. Robore, Chiquitania, Santiago de Chiquitos, Las Pozas, $18.36459^{\circ} \mathrm{S}, 59.63920^{\circ} \mathrm{W}, 412$ mas, 8.XI.2013, light trap, ID \#NHRS-BOL13-12, leg. N. Apelqvist, J. Jonsson \& V. Sossa, Export permit: SENASAG No 019471 (1 male, SMNH). Paratypes: same as holotype (14 males, SMNH; 7 males, OPC).
Diagnosis. This new species has the scoop shaped basoventral processes of gonopods fused. Most close to $N$. pavida, the nominate species of the species group but differs by having distinguishing alterations in the shape of the periphallic organ, tergite IX with double apical lobes, not with single; the shape of paraproct apex upturned dorsoapical process, not without; basoventral process of gonopod with truncated apices. The speciation trait of sigmoid profile less sigmoid apicad; apicomesal lobe of gonopods longer.

Description (in alcohol). This species has small eyes. Length of forewing $8 \mathrm{~mm}$, forewing membrane uniform and unicolor without any pattern. Maxillary palp formula IV-(I,II,III)-V. Tibial spur formula 0-2-2.

Male genitalia. Abdominal segment IX short, without sternum; its ventral ending located at pivoting fulcrum is tapering with braced margin; tergum IX produced posterad with bilobed apex in dorsal view. The superanal complex has deeply shifted sclerotized horizontal lateral processes, the paraproct abruptly narrowing apicad and with upward turning dorsoapical angle. Cerci without fork, ventral capitate. Gonopods almost straight in lateral view; apex subtriangular; scoop shaped pair of basoventral processes fused, truncated 


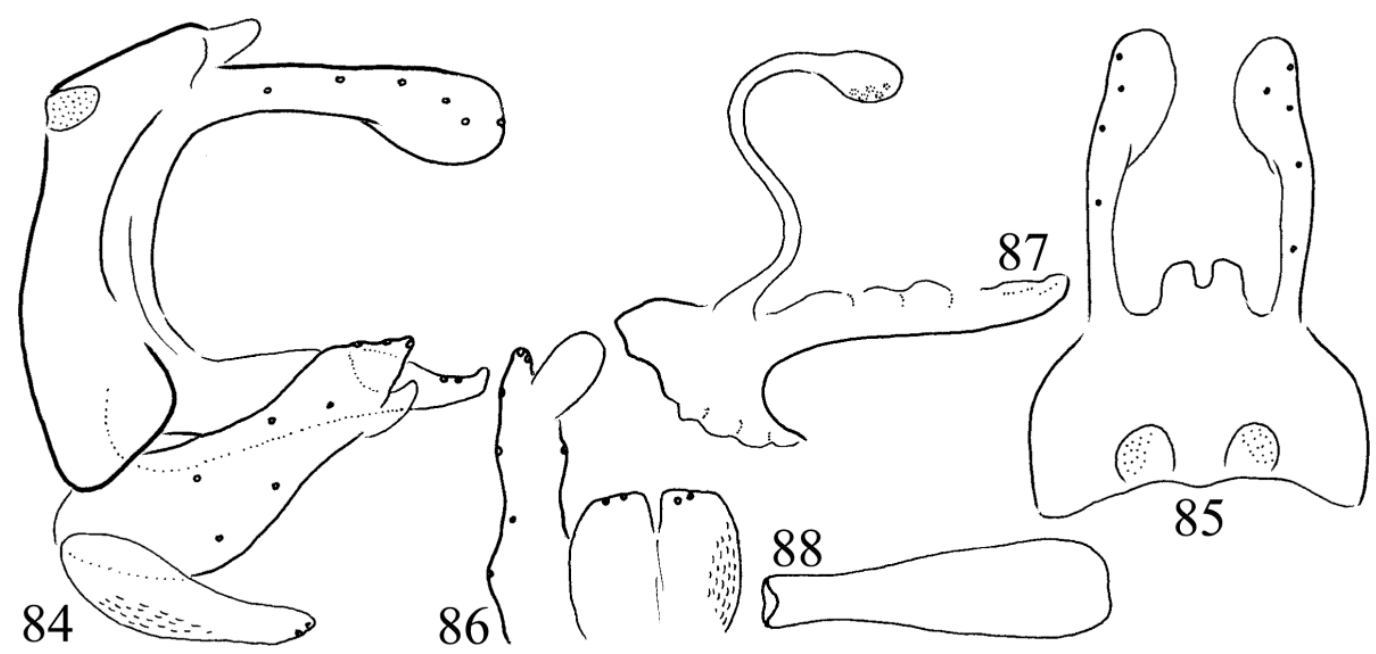

Figures 84-88. Nectopsyche hasonla sp. nov. Holotype: 84 = male genitalia in left lateral view, 85 = male genitalia in dorsal view, $86=$ left gonopod with apicomesal lobe and ventral plate in ventral perpendicular view; $87=$ phallic organ with the sigmoid profile of phallicata in lateral view; $88=$ phallicata in ventral view.

with narrow and deep apicomesal cleft and with two sensory setae apicad on both sides; apicomesal lobes elongated. Phallic organ seems articulating to the basomesal ridge of the gonopods; the pair of swan-necked dorsal phallothecal processes slender with large downward turning apex, rounded fan-shaped in perpendicular dorsal view; the endotheca without any setae; lateral profile of the phallicata with large basal curve, apical curve less produced, the entire profile is stretched, less sigmoid apicad.

Etymology. hasonla, from "hasonló" similar in Hungarian, refers to the overall similarity of this new species to the nominate species of the species group, N. pavida.

\section{Nectopsyche kifela Oláh, Johanson \& Malm, sp. nov.}

(Figures 89-93)

Material examined. Holotype, French Guiana, Maripasoula, Maroni River, Damason campo, Village, $4^{\circ} 35.112^{\prime} \mathrm{N}, \quad 5^{\circ} 24.799^{\prime} \mathrm{W} 38 \mathrm{~m}$, 7.II. 2007, FRG 13, leg. N. Jönsson (1 male, SMNH). Paratypes, Maripasoula, Lawa River, Gzaan Dayé, $4^{\circ} 01.130^{\prime} \mathrm{N}, 54^{\circ} 19.015^{\prime} \mathrm{W}, 74 \mathrm{~m}$, 8.ii.2007, FRG 14, leg. N. Jönsson (5 males, SMNH; 2 males, OPC).
Diagnosis. This new species has the scoop shaped basoventral processes of gonopods fused. Most close to $N$. oliveri sp. nov. but without any forewing pattern; also differs by the particular combination of both the adaptive and neutral traits. Segment IX short, not long; cerci with convex dorsum, not straight; cercal apex capitate, not straight dorsad; gonopod head bilobed due to the well visible apicomesal lobe, not simple lobed; head of the swan-necked phallothecal dorsal process downward produced, not horizontal. Sigmoid profile of the phallicata long, not abbreviated.

Description (in alcohol). This species has small eyes. Length of forewing $7 \mathrm{~mm}$, forewing membrane uniform and unicolor without any pattern, with pterostigmal enlargement on specimen stored in alcohol. Maxillary palp formula (IV,II)-(I,III)-V. Tibial spur formula 0-2-2.

Male genitalia. Abdominal segment IX short, without sternum; its ventral ending located at pivoting fulcrum is subquadrangular with braced margin; tergum IX produced posterad with monolobed apex in dorsal view. The superanal complex has deeply shifted sclerotized horizontal lateral processes, the paraproct with narrowing, slightly knobby apices visible both from lateral and dorsal view. Cerci without fork; long capitate, occupying 


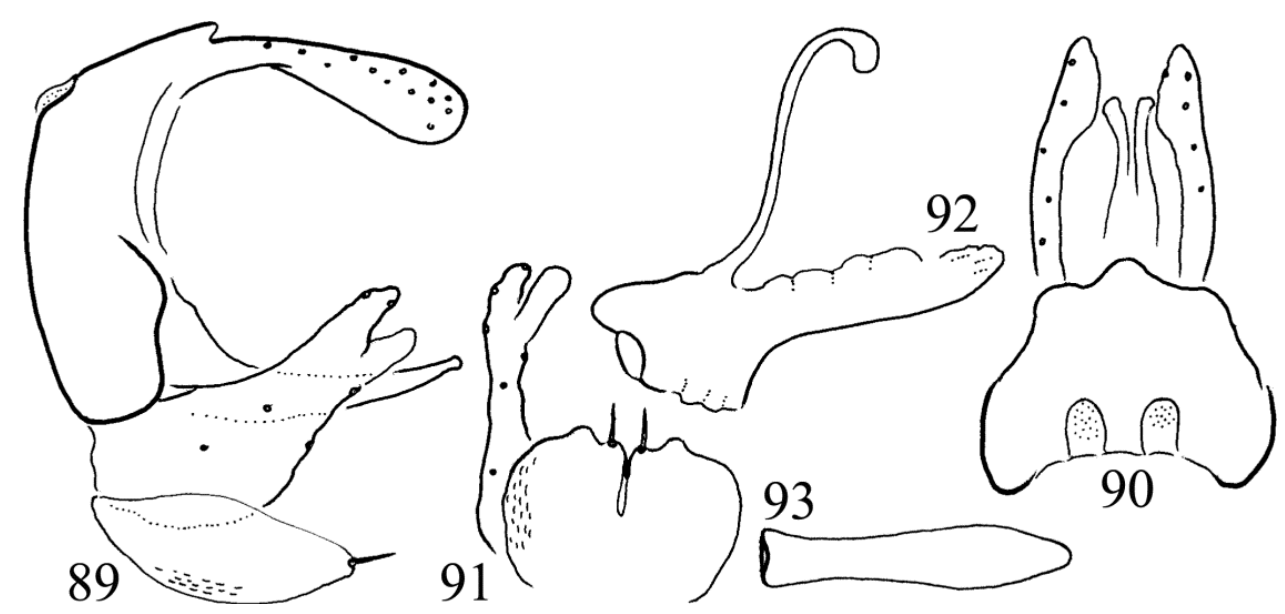

Figures 89-93. Nectopsyche kifela sp. nov. Holotype: $89=$ male genitalia in left lateral view, $90=$ male genitalia in dorsal view, $91=$ left gonopod with apicomesal lobe and ventral plate in ventral perpendicular view; $92=$ phallic organ with the sigmoid profile of phallicata in lateral view; $93=$ phallicata in ventral view.

larger length of the cerci; ventral half of the long capitate head shining glabrous without any cuticular non-cellular outgrowths. Gonopods almost straight in lateral view; apex bilobed; gonopod basoventrum broad ventrad; scoop shaped pair of basoventral processes fused, with narrow and deep apicomesal cleft and with smaller mesad and larger submesad humps; smaller mesad humps with a single sensory seta; apicomesal lobe elongated in ventral view; part of apical surface rugose. Phallic organ seems articulating to the basomesal ridge of the gonopods; the pair of swan-necked dorsal phallothecal processes slender with large downward turning apex, rounded triangular fan-shaped in perpendicular dorsal view; the endotheca without any setae; lateral profile of the phallicata with open basal curve, apical curve less produced, the entire profile is stretched, less sigmoid.

Etymology. kifela, from "kifelé" towards outside in Hungarian, refers to the basal curve of the sigmoid profile directed outside in the anterad direction, not inside into the posterior direction.

\section{Nectopsyche kinilta Oláh, Johanson \& Malm, sp. nov.}

(Figures 94-98)

Material examined. Holotype, Bolivia, El Beni Dept. Liberalta, Chiquitania, Esmeralda Hotel area by river, $10.98270^{\circ} \mathrm{S}, 65.92366^{\circ} \mathrm{W}, 132$ mas, 4.XI.2013, light trap, ID \#NHRS-BOL13-07, leg. N. Apelqvist, J. Jonsson \& V. Sossa, Export permit: SENASAG No 019471 (1 male, SMNH).

Diagnosis. This new species has the scoopshaped basoventral processes of gonopods fused. Having ventrad capitate medium-long cerci and elongated apicomesal lobes on gonopods most close to $N$. hasonla sp. nov., but differs by the differently shaped neutral traits of cerci, paraproct and the fused scoop-shaped basoventral process. There are subtle, but stable speciation trait divergences in the shape of swan-necked process, sigmoid profile, the ventral profile of the phallicata and of the apicomesal lobe of gonopod.

Description (in alcohol). This species has small eyes. Length of forewing $7 \mathrm{~mm}$, forewing membrane uniform and unicolor without any pattern on specimen stored in alcohol. Maxillary palp formula (I,IV)-II-III,V. Tibial spur formula 0-2-2.

Male genitalia. Abdominal segment IX without sternum; its ventral ending located at pivoting fulcrum is rounded with braced margin; tergum IX less produced posterad with short broad monolobed apex in dorsal view. The superanal complex has deeply shifted sclerotized horizontal lateral processes, the paraproct abruptly narrowing api- 


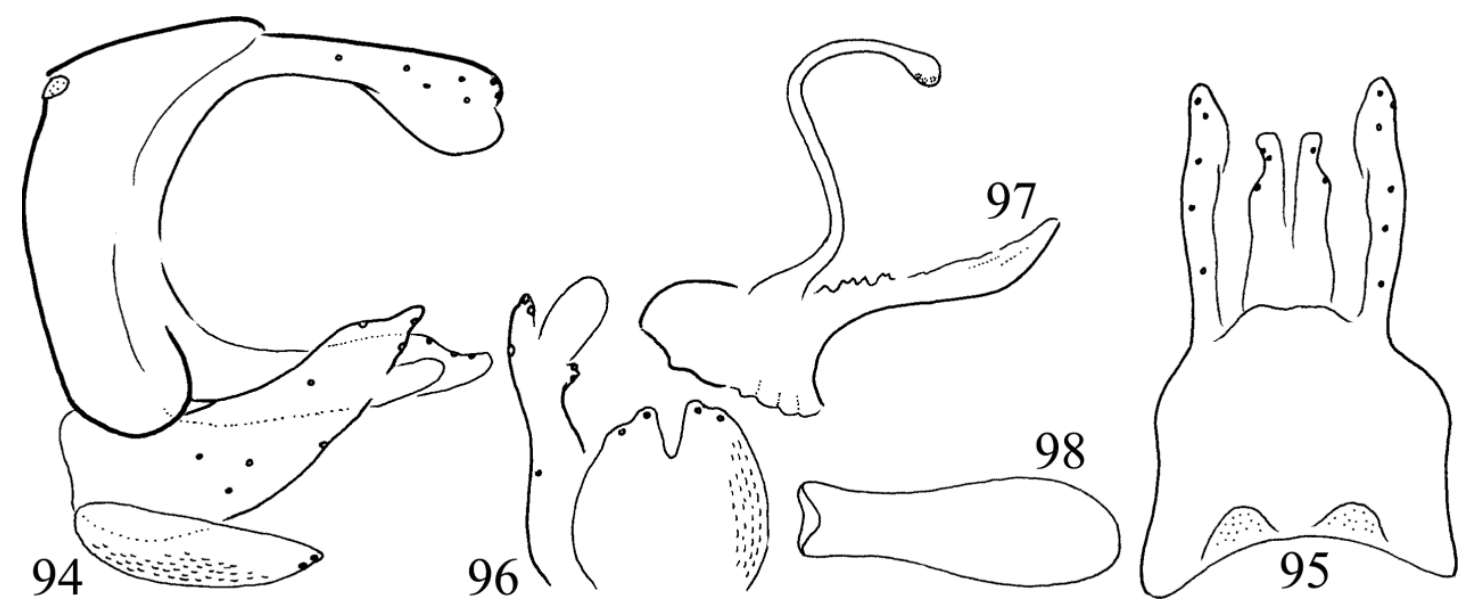

Figures 94-98. Nectopsyche kinilta sp. nov. Holotype: 94 = male genitalia in left lateral view, 95 = male genitalia in dorsal view, 96 = left gonopod with apicomesal lobe and ventral plate in ventral perpendicular view; 97 = phallic organ with the sigmoid profile of phallicata in lateral view; 98 = phallicata in ventral view.

cad with slightly laterad produced knobby apex in dorsal view. Cerci without fork, medium-long and ventrad capitate, dorsal half of apical margin less produced than the glabrous ventral half. Gonopods concave dorsad in lateral view; its basoventrum more developed; scoop-shaped pair of basoventral processes fused, with wide apicomesal cleft with two subapical sensory seta on both lobes; apicomesal lobe elongated ovoid in ventral view; part of apical surface rugose. Phallic organ seems articulating to the basomesal ridge of the gonopods; the pair of swan-necked dorsal phallothecal processes slender filiform with small fan-shaped apex; the endotheca without any setae; sigmoid profile of the phallicata with open basal curve, apical curve produced.

Etymology. kinilta, from "kinyílt" opened in Hungarian, refers to the less curving, more open basal curve of the phallicata.

\section{Nectopsyche kurta Oláh, Johanson \& Malm, sp.} nov.

(Figures 99-103)

Material examined. Holotype, French Guiana, Maripasoula, Lawa River: Maripasoula, 83 mao $3^{\circ} 37.959^{\prime} \mathrm{N}, 54^{\circ} 1.426^{\prime} \mathrm{W}, 9 . \mathrm{II} .2007$, light trap, FRG 15, leg. N. Jönsson (1 male, SMNH).
Diagnosis. This new species has the scoopshaped basoventral processes of gonopods fused. Most close to $N$. sima sp. nov., but differs by much shorter cerci and by the more produced apex of the phallothecal dorsal process and the less curved sigmoid profile.

Description (in alcohol). This species has small eyes. Length of forewing $7 \mathrm{~mm}$, forewing membrane uniform and unicolor without any pattern on specimen stored in alcohol. Maxillary palp formula IV-(I,II,III)-V. Tibial spur formula $0-2-2$.

Male genitalia. Abdominal segment IX without sternum; its ventral ending located at pivoting fulcrum is rounded with braced margin; tergum IX less produced posterad with monolobed apex in dorsal view. The superanal complex has deeply shifted sclerotized horizontal lateral processes, the paraproct narrowing apicad with laterad and upward produced knobby apex. Cerci without fork, very short and capitate. Gonopods concave dorsad in lateral view; its basoventrum more developed; scoop-shaped pair of basoventral processes fused, with wide apicomesal cleft with a single subapical sensory seta on both lobes; apicomesal lobe elongated quadrangular; part of apical surface rugose. Phallic organ seems articulating to the basomesal ridge of the gonopods; the pair of 


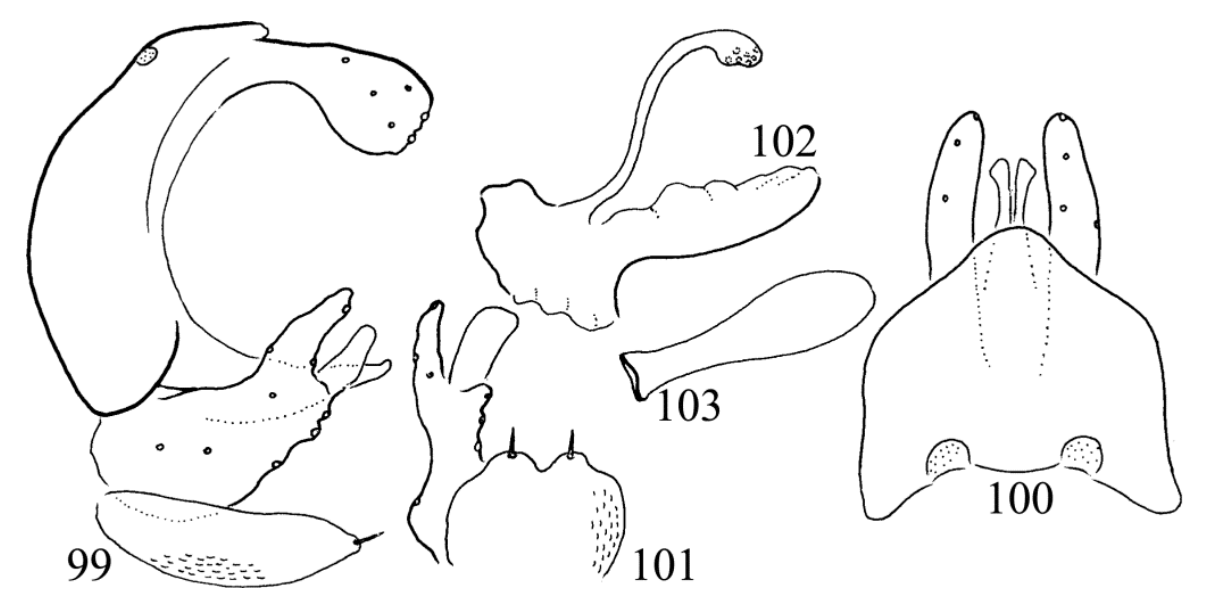

Figures 99-103. Nectopsyche kurta sp. nov. Holotype: $99=$ male genitalia in left lateral view, $100=$ male genitalia in dorsal view, $101=$ left gonopod with apicomesal lobe and ventral plate in ventral perpendicular view; $102=$ phallic organ with the sigmoid profile of phallicata in lateral view; 103 = phallicata in ventral view.

swan-necked dorsal phallothecal processes slender with large apex; the endotheca without any setae; lateral sigmoid profile of the phallicata with well-developed basal curve, apical curve less produced.

Etymology. kurta, from "kurta" short, abbreviated in Hungarian, refers to the unusually short cerci.

\section{Nectopsyche laposka Oláh, Johanson \& Malm, sp. nov.}

(Figures 104-109)

Material examined. Holotype, Peru, San Martin Prov., Rio Negro, 37 km (rd.) W Moyobamba, near Olmos-Tarapoto rd., $6^{\circ} 00.278^{\prime} \mathrm{S}, 77^{\circ} 15.437^{\prime}$ W, light, loc. 05, 6.I.2009 T. Malm \& K.A. Johanson (1 male, SMNH). Paratype: same as holotype (1 male, 10 associated females, SMNH; 1 male, 5 associated females, OPC).

Diagnosis. This new species has the scoop shaped basoventral processes of gonopods fused. Most close to $N$. oliveri sp. nov. but differs by having membrane pattern on forewing different. The speciation trait of sigmoid profile distinguishing $N$. laposka sp. nov. from $N$. oliveri sp. nov. is highly diverged; it is stretched, very low (shallow) almost flat, not deep and high like the sigmoid profile of $N$. oliveri sp. nov.
Description (in alcohol). This species has slightly enlarged eyes; interocular distance is twice of the eye. Body is dark brown. Length of forewing $7 \mathrm{~mm}$, forewing membrane has darker background with four large and one small pale spots on the costal margin on specimen stored in alcohol. Maxillary palp formula (I,II, IV)-III-V. Tibial spur formula 0-2-2.

Male genitalia. Abdominal segment IX short, without sternum; its ventral ending located at pivoting fulcrum broad rounded with braced margin; tergum IX produced posterad with broad, monolobed apex in dorsal view. The superanal complex with a pair of discernible small lobes of dorsomesal process, the upper remnant of segment X; the deeply shifted sclerotized horizontal lateral processes, the paraproct with narrowing, slightly upward and laterad knobby apices visible both from lateral and dorsal view. Cerci without fork, short, somehow clavate ventrad. Gonopods almost straight in lateral view; apex slightly bilobed; gonopod basoventrum broad ventrad; scoop shaped pair of basoventral processes fused, with narrow and deep apicomesal cleft and the lateral lobes with three sensory setae apicad on both sides; apicomesal lobes large, fan-shaped. Phallic organ seems articulating to the basomesal ridge of the gonopods; the pair of swan-necked dorsal phallothecal processes slender with large downward turning apex, rounded triangular fanshaped in perpendicular dorsal view; the endotheca without any setae; sigmoid profile of the phallicata stretched, almost flat. 


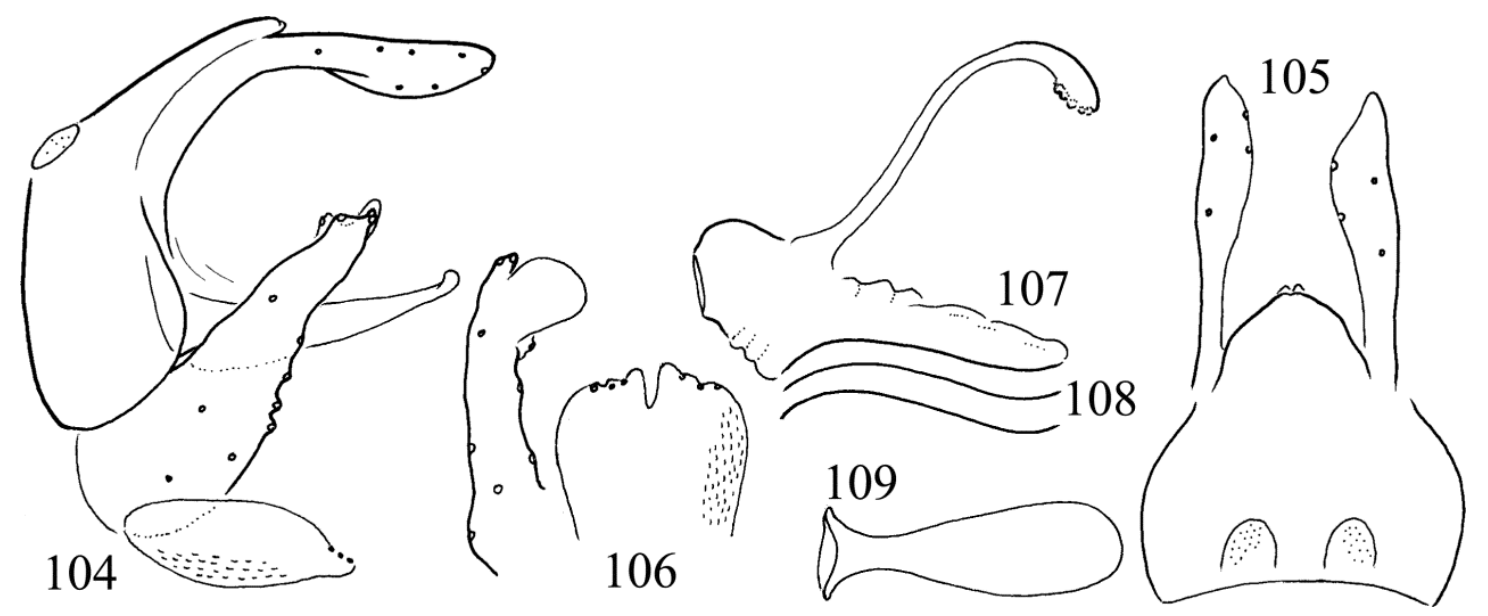

Figures 104-109. Nectopsyche laposka sp. nov. Holotype: 104 = male genitalia in left lateral view, $105=$ male genitalia in dorsal view, 106 = left gonopod with apicomesal lobe and ventral plate in ventral perpendicular view; 107 = phallic organ with the sigmoid profile of phallicata in lateral view; $108=$ sigmoid profile of phallicata of two specimens from the same population; $109=$ phallicata in ventral view.

Etymology. laposka, from "laposka", diminutive of flat in Hungarian, refers to stretched, almost flat sigmoid profile.

\section{Nectopsyche muhni (Navas, 1916)}

(Figures 110-116)

Material examined. Argentina, Entre Ríos Federación, camping Siriri, $38 \mathrm{~m}, 30^{\circ} 58.098^{\prime} \mathrm{S}$, $57^{\circ} 56.633^{\prime}$ W, 4.I.2008, leg. K. Hill, D. Marshall, M. Moulds (3 males, SMNH; 2 males, OPC).

Remarks. The five specimens collected in Argentina near the type locality at Santa Fe is similar to the drawings of the type specimen examined and prepared by Schmid (1949), but dissimilar to the drawings prepared by Flint (1974) from specimen collected in Suriname. Probably the specimens of Suriname represent an independent new species. The neutral trait of cerci is highly variable in the examined population, but the adaptive trait of sigmoid profile is very stable at the five examined specimens. The sampled population must be exposed to sever external or internal stochastic impact indicated by the unusually large variability of the cerci and even one specimen has apicomesal lobe of the gonopod somehow diverged from the others.

\section{Nectopsyche nemritka Oláh, Johanson \& Malm, sp. nov.}

(Figures 117-121)

Material examined. Holotype, French Guiana, Maripasoula, Lawa River, Gzaan Dayé, $4^{\circ} 01.130^{\prime}$ $\mathrm{N}, 54^{\circ} 19.015^{\prime} \mathrm{W}, 74 \mathrm{~m}, 8 . \mathrm{II} .2007, \mathrm{FRG} 14$, leg. N. Jönsson (1 male, SMNH).

Diagnosis. This new species has the scoopshaped basoventral processes of gonopods fused. Bearing shoulder structure on the paraproct this unique species is most close to $N$. ritka sp. nov. but differs by the particular combination of both the adaptive and neutral traits. Cerci ventrally produced, not regular capitate; paraproct shoulder less pointed laterad; gonopod less robust; apicomesal lobe rounded, not quadrangular; head of the dorsal phallothecal process less patterned ventrad, elongated simple; sigmoid profile with less produced basal curve.

Description (in alcohol). This species has small eyes. Length of forewing $6.5 \mathrm{~mm}$, forewing membrane dark brown, but uniform and unicolor without any pattern on specimen stored in alcohol. Maxillary palp formula IV-(II,III)-I-V. Tibial spur formula 0-2-2.

Male genitalia. Abdominal segment IX without sternum; its ventral ending located at pivoting 

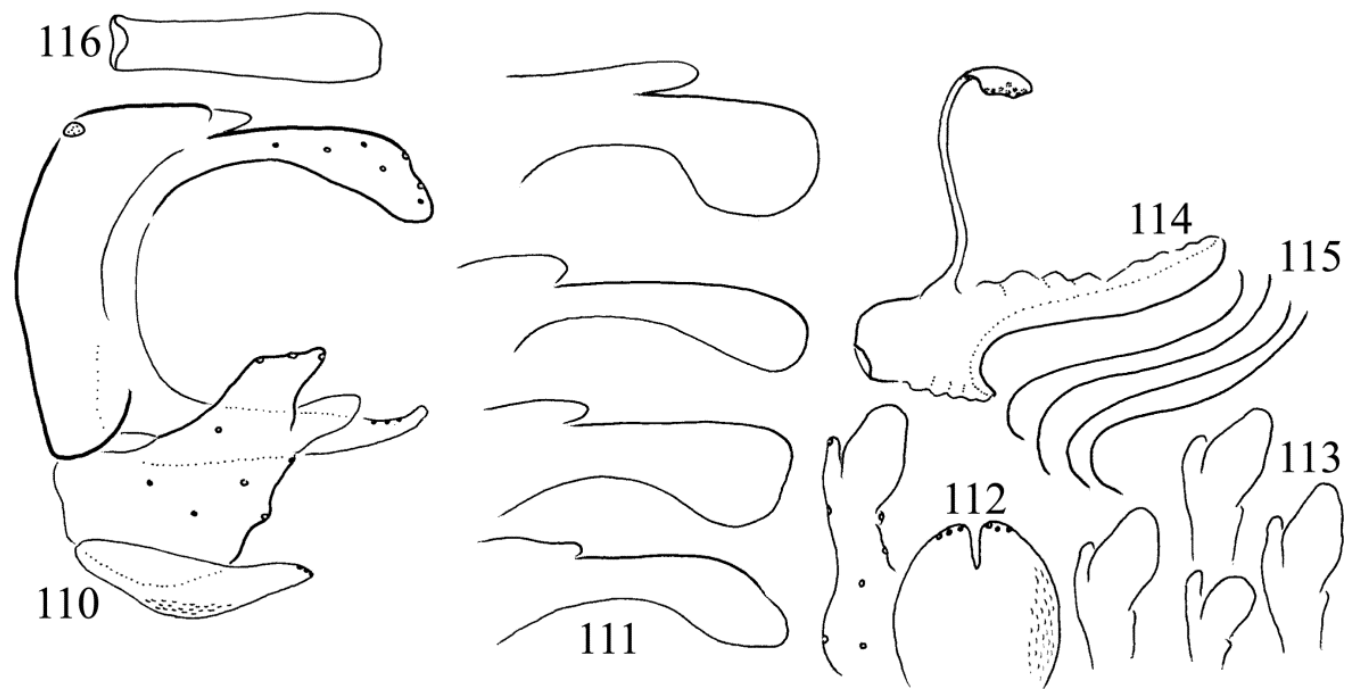

Figures 110-116. Nectopsyche muhni (Navas, 1916). $110=$ male genitalia in left lateral view; $111=$ cerci of four specimens from the same population; 112 = left gonopod with apicomesal lobe and ventral plate in ventral perpendicular view;

$113=$ apicomesal lobe on gonopod of four specimens from the same population; $114=$ phallic organ with the sigmoid profile of phallicata in lateral view; $115=$ sigmoid profile of phallicata of four specimens from the same population; $116=$ phallicata in ventral view.

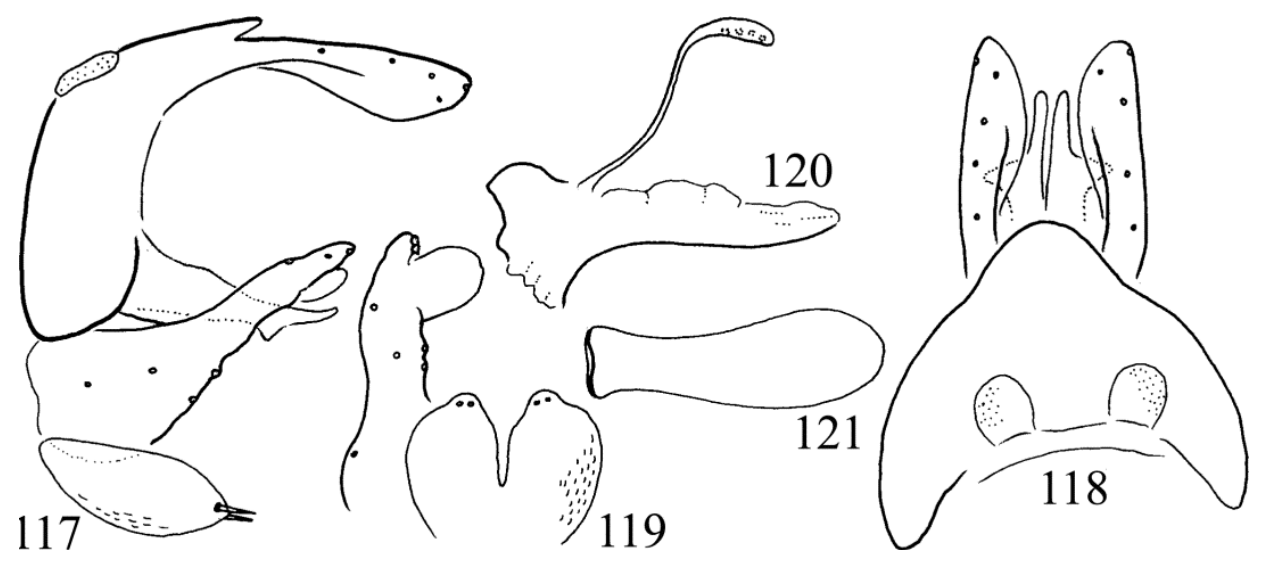

Figures 117-121. Nectopsyche nemritka sp. nov. Holotype: $117=$ male genitalia in left lateral view, $118=$ male genitalia in dorsal view, $119=$ left gonopod with apicomesal lobe and ventral plate in ventral perpendicular view; $120=$ phallic organ with the sigmoid profile of phallicata in lateral view; 121 = phallicata in ventral view.

fulcrum is rounded with braced margin; tergum IX produced posterad with broad monolobed apex in dorsal view. The superanal complex has deeply shifted sclerotized horizontal lateral processes, the paraproct with pronounced lateral pointed shoulder visible both from lateral and dorsal view. Cerci without fork, head produced ventrad. Gonopods concave dorsad in lateral view; its basoventrum more developed; scoop-shaped pair of basoventral processes fused, with very deep apicomesal cleft and 2 subapical sensory setae; apicomesal lobe rounded; part of apical surface rugose. Phallic organ seems articulating to the basomesal ridge of the gonopods; the pair of swan-necked dorsal phallothecal processes slender with elongated apex; the endotheca without any setae; lateral sigmoid profile of the phallicata with less-developed basal curve, apical curve almost lacking. 
Etymology. nemritka, from "nemritka" not unusual, not rare in Hungarian. However with this name we refer to that it is related, but not identical with $N$. ritka sp. n. There are integrated definite divergences between the two species.

\section{Nectopsyche nyaka Oláh, Johanson \& Malm, sp. nov.}

(Figures 122-127)

Material examined. Holotype, Peru, Moyobamba, Puerto Mirador, outside bungalow, $6^{\circ}$ $01.965^{\prime}$ S, $76^{\circ} 57.450^{\prime} \mathrm{W}$, 4.I.2009, T. Malm \& K. A. Johanson (1 male, SMNH). Paratype: same as holotype (1 male, OPC). San Martin Prov., Rio Huallaga tributary, small river passing Chazuta, $6^{\circ} 34.665^{\prime} \mathrm{S}, 76^{\circ} 08.209^{\prime} \mathrm{W}$, light, loc. 11, 10.I. 2009 leg. T. Malm \& K.A. Johanson (1 male SMNH). San Martin Prov., Rio Mayo, 11 km (rd.) E Mayobamba, 6 $6^{\circ} 04.989^{\prime} \mathrm{S}, 7^{\circ} 53.065^{\prime} \mathrm{W}$, light, loc. 06, 6.I.2009 leg. T. Malm \& K.A. Johanson (2 males, 25 associated females, SMNH).

Diagnosis. This new species has the scoop shaped basoventral processes of gonopods fused. Most close to $N$. alma sp. nov. but differs by having cerci short and stout, not long and slender; the scoop-shaped fused basoventral processes of gonopods have apically truncate lateral lobes, not rounded. The speciation trait of sigmoid profile almost L-shaped, not sigmoid, basal curve right angled; apicomesal lobe of gonopods with basal neck, not without any basal constriction.

Description. (in alcohol). This species has small eyes, somewhat darker brown. Length of forewing $5.5 \mathrm{~mm}$, forewing membrane has darker background with lighter subcostal and radial cells, elongated scales partially denuded on specimen stored in alcohol. Maxillary palp formula IV(I,II)-III-V. Tibial spur formula 0-2-2.

Male genitalia. Abdominal segment IX short, without sternum; its ventral ending located at pivoting fulcrum is tapering with braced margin; tergum IX produced posterad with broad, monolobed apex in dorsal view. The superanal complex has deeply shifted sclerotized horizontal lateral processes, the paraproct with narrowing, slightly upward and laterad knobby apices visible both from lateral and dorsal view. Cerci without fork short, somehow clavate. Gonopods almost straight in lateral view; apex monolobed; gonopod basoventrum broad ventrad; scoop shaped pair of basoventral processes fused, with narrow and deep apicomesal cleft and truncate lateral lobes having few sensory setae apicad on both sides, two on left and four on right lobe on the holotype. Phallic organ seems articulating to the basomesal ridge of the gonopods; the pair of swan-necked dorsal phallothecal processes slender with large downward turning apex, rounded triangular fanshaped in perpendicular dorsal view; the endotheca without any setae; lateral profile of the phallicata with large right angled basal curve, apical curve less produced.

Etymology. nyaka, from "nyaka" neck of something in Hungarian, refers to the basal constriction of the circular apicomesal lobe of gonopod.

\section{Nectopsyche oliveri Oláh \& Oláh, sp. nov.}

\section{(Figures 128-129)}

Nectopsyche quatuorguttata (Navas, 1922): 61, described from a female with four hyaline pale spots present on forewing costa; female type was collected in Bolivia; now it is lost.

Nectopsyche quatuorguttata (Navas, 1922): 61, Flint 1974: 127: "The male genitalia of a specimen from Guyana (Surinam=Dutch Guiana!) are illustrated here. The genitalia are very similar to those of $N$. muhni (Nav.), from which it is easily distinguished by the coloration." Holotype: Deposited in Rijksmuseum van Natuurlijke Historie in Leiden: Surinam, Tafelberg Expedition, Boven Saramacca, base camp near DeKockberg, 25 Mar. 1953, at light, leg. Dr. D. C. Geijskes, 1ð̂," Misidentification!

Diagnosis and description. N. quatuorguttata (Navas) was described from Bolivia from a single female specimen with four hyaline pale spots present on forewing costa. The female type form Bolivia is lost. We have a female specimen from Bolivia, collected by the Hungarian Soil Zoological Expedition and determined by Flint as $N$. quatuorguttata. However, the specimen stored in alcohol has lost any membrane coloration and as 


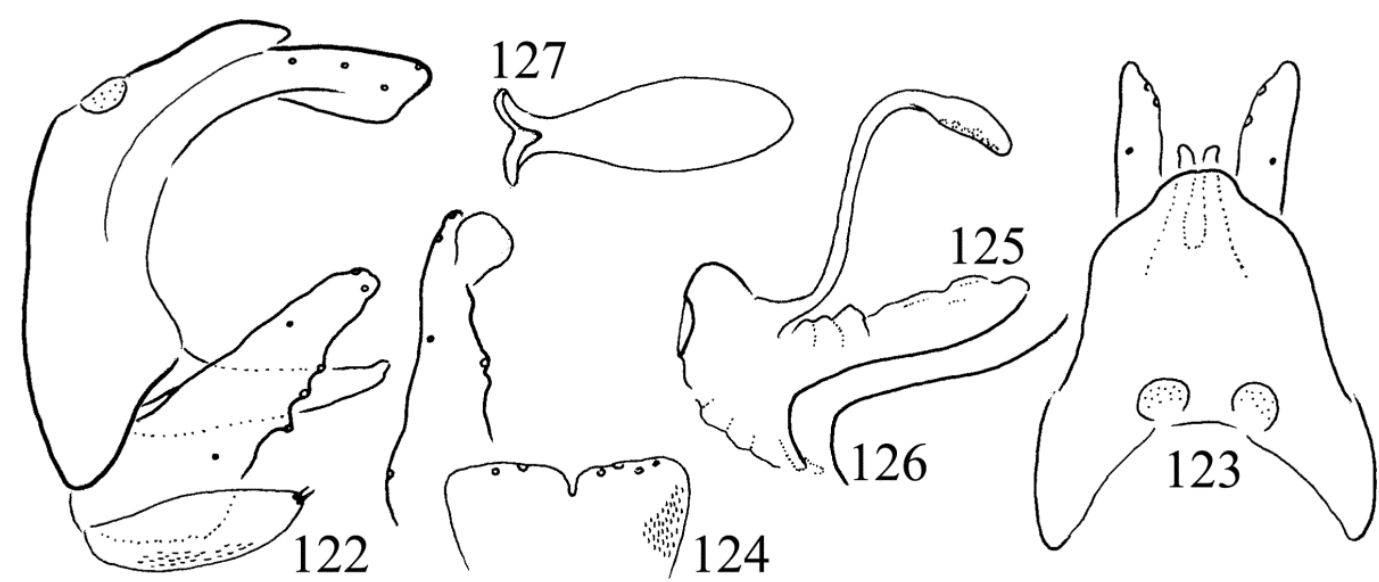

Figures 122-127. Nectopsyche nyaka sp. nov. Holotype: 122 = male genitalia in left lateral view, 123 = male genitalia in dorsal view, 124 = left gonopod with apicomesal lobe and ventral plate in ventral perpendicular view; 125 = phallic organ with the sigmoid profile of phallicata in lateral view; $126=$ sigmoid profile of phallicata of one specimen from the same population; 127 = phallicata in ventral view.

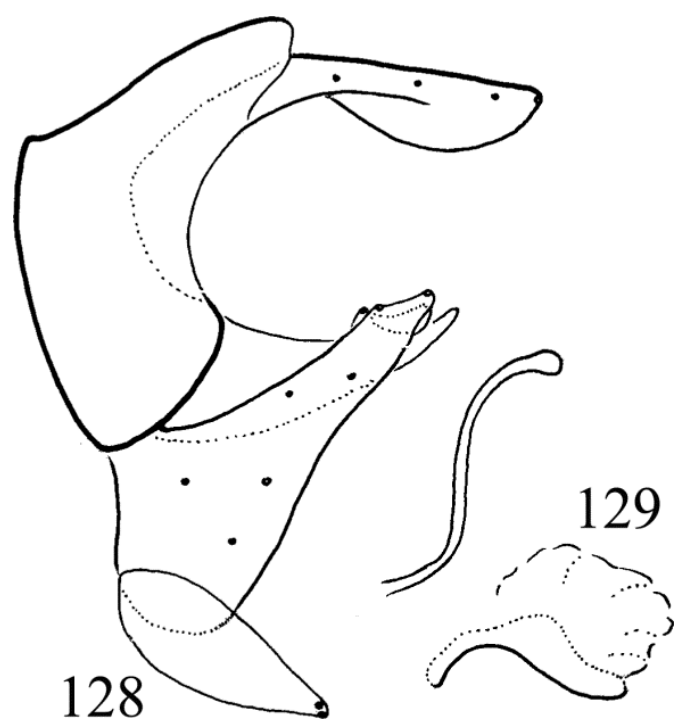

Figures 128-129. Nectopsyche oliveri Oláh sp. nov. Holotype: $128=$ male genitalia in left lateral view; $129=$ phallic organ with the sigmoid profile of phallicata in lateral view. Reproduced from the original drawing.

usual it remained without any forewing pattern. The delimitation of $N$. laposka sp. nov., as an independent species having the basic forewing membrane pattern similar to $N$. quatuorguttata, is based on the highly diverged sigmoid profile. Its sigmoid profile was compared to the properly drawn sigmoid profile of the only known male species with quatourguttata forewing pattern collected in Surinam. As a consequence the spe- cimen from Surinam represents a new species and $N$. quatuorguttata is known only by the forewing pattern of the single female collected in Bolivia. Single male and six females collected in Suriname have slightly different forewing pattern of the costal pale spots compared to Navas forewing drawing of the genuine $N$. quatourguttata from Bolivia. Moreover N. laposka sp. nov. collected in Peru and described here exhibits also slightly different membrane pattern on the forewing. The specimen collected in Surinam was determined by the forewing pattern of the four large, pale spots on the costal margin of the primarily black forewing. Disregarding the alcohol sensitive, ephemeral forewing pattern and based on the potential of the speciation traits with high sensitivity to delineate species boundaries in closely related Nectopsyche species as well as the discovery of several sibling species with similar genital architecture recorded in limited geographical region here we describe this single male from Surinam as a new species most close to $N$. laposka sp. nov.

This new species has the scoop shaped basoventral processes of gonopods fused. $N$. oliveri $\mathrm{sp}$. nov. has periphallic organs rather similar to $N$. laposka sp. nov., but the sigmoid profile of the phallicata is different, it is deep and not shallow flat, the basal curve is much more produced. Unfortunately the apicomesal lobe of gonopod was not drawn, not published, not available to compare to $N$. laposka sp. nov. 
Etymology. We dedicate this new species to Oliver Flint who has drawn the single male specimen as $N$. quatuorguttata and deposited in the collection of the Smithsonian Institution.

\section{Nectopsyche pavida (Hagen, 1861)}

(Figures 130-136)

Material examined. USA, SC, Aiken Co. Savannah River Site, Tinker Cr., SRP SRP 8-I, $33.35515^{\circ} \mathrm{N}, 81.58370^{\circ} \mathrm{W}, 55.2 \mathrm{~m}$ elevation, 4 5.IX.2009, black light, leg. Z. Burington (6 males, OPC).

Remarks. In the examined population the nominate species of the Nectopsyche pavida species group exhibited high stabilities both in the neutral, non-adaptive traits of cerci and gonopods as well as in the adaptive speciation traits of the apicomesal lobe on the gonopods and the sigmoid profile of the phallicata.

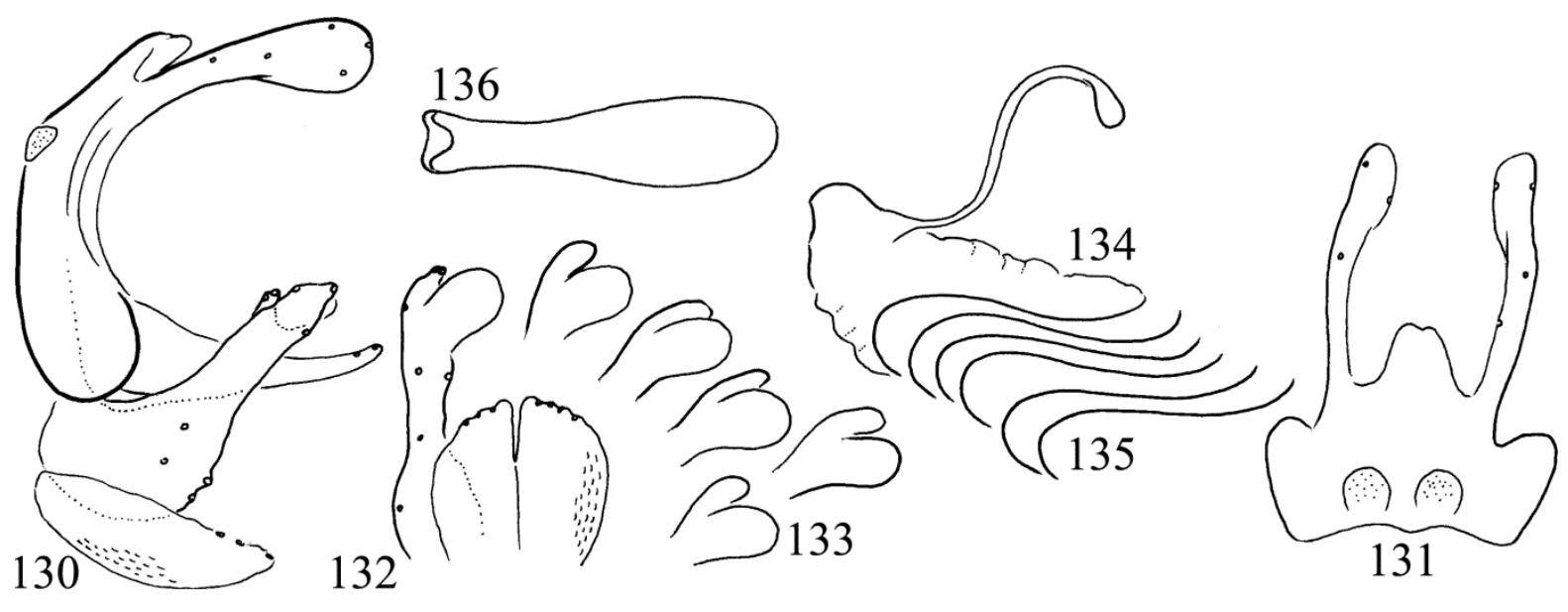

Figures 130-136. Nectopsyche pavida (Hagen, 1861). 130 = male genitalia in left lateral view; 131 = genitalia in dorsal view; 132 = left gonopod with apicomesal lobe and ventral plate in ventral perpendicular view; 133 = apicomesal lobe on gonopod of five specimens from the same population; 134 = phallic organ with the sigmoid profile of phallicata in lateral view; $135=$ sigmoid profile of phallicata of five specimens from the same population; 136 = phallicata in ventral view.

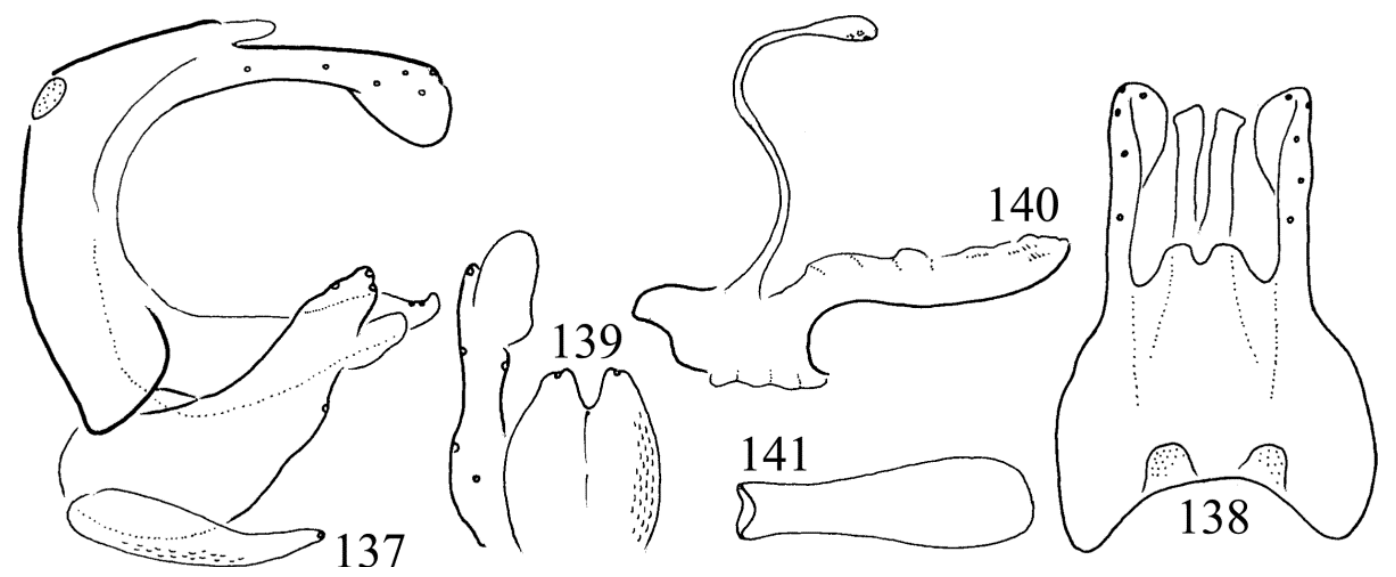

Figures 137-141. Nectopsyche poca sp. nov. Holotype: 137 = male genitalia in left lateral view, $138=$ male genitalia in dorsal view, 139 = left gonopod with apicomesal lobe and ventral plate in ventral perpendicular view; $140=$ phallic organ with the sigmoid profile of phallicata in lateral view; 141 = phallicata in ventral view. 


\section{Nectopsyche poca Oláh, Johanson \& Malm, sp. nov.}

(Figures 137-141)

Material examined. Holotype, Bolivia, El Beni Dept. Liberalta, Chiquitania, Esmeralda Hotel area by river, $10.98270^{\circ} \mathrm{S}, 65.92366^{\circ} \mathrm{W}, 132$ mas, 4.XI.2013, light trap, ID \#NHRS-BOL13-07, leg. N. Apelqvist, J. Jonsson \& V. Sossa, Export permit: SENASAG No 019471 (1 male, SMNH).

Diagnosis. This new species has the scoop shaped basoventral processes of gonopods fused. Most close to $N$. hasonla sp. nov. but differs by having distinguishing alterations in the shape of the periphallic organ, cerci with small depression on the dorsoapical corner in lateral view; the shape of paraproct apex with much shorter subapical dorsal concavity; basoventral process of gonopod with tapering apices, not truncated. The speciation trait of sigmoid profile more curved apicad; apicomesal lobe of gonopods larger produced with small belly mesobasad, not ovoid.

Description (in alcohol). This species has small eyes. Length of forewing $7 \mathrm{~mm}$, forewing membrane uniform and unicolor without any pattern. Maxillary palp formula (I,IV)-(II,III)-V. Tibial spur formula 0-2-2.

Male genitalia. Abdominal segment IX short, without sternum; its ventral ending located at pivoting fulcrum is tapering with braced margin; tergum IX produced posterad with bilobed apex in dorsal view. The superanal complex has deeply shifted sclerotized horizontal lateral processes, the paraproct abruptly narrowing apicad and with upward turning dorsoapical angle, producing a short dorsoapical depression. Cerci without fork, ventral capitate, with small excision on dorsoapical corner. Gonopods almost straight in lateral view; apex subtriangular; scoop shaped pair of basoventral processes fused, tapering with narrow and deep apicomesal cleft and with single sensory seta apicad on both sides; apicomesal lobes large with small mesobasal hump. Phallic organ seems articulating to the basomesal ridge of the gonopods; the pair of swan-necked dorsal phallothecal processes slender with elongated apex, rounded fan-shaped in perpendicular dorsal view; the endotheca without any setae; lateral profile of the phallicata with large basal curve, apical curve is also produced.

Etymology. poca, from "pocak" a special form of belly in Hungarian, refers to the small hump on the mesobasal region of the apicomesal lobe of the gonopod.

\section{Nectopsyche ritka Oláh, Johanson \& Malm, sp. nov.}

(Figures 142-146)

Material examined. Holotype, French Guiana, Maripasoula, Lawa River: Maripasoula, 83 mao $3^{\circ} 37.959^{\prime} \mathrm{N}, 54^{\circ} 1.426^{\prime} \mathrm{W}, 9 . \mathrm{II} .2007$, light trap, FRG 15, leg. N. Jönsson (1 male, SMNH). Paratype, Maripasoula, Lawa River, Gzaan Dayé, $4^{\circ} 01.130^{\prime} \mathrm{N}, 54^{\circ} 19.015^{\prime} \mathrm{W}, 74 \mathrm{~m}, 8 . \mathrm{II} .2007, \mathrm{FRG}$ 14 , leg. N. Jönsson (1 male, OPC).

Diagnosis. This new species has the scoop shaped basoventral processes of gonopods fused. Bearing shoulder structure on the paraproct this unique species is most close to $N$. valla sp. nov. but differs by the particular combination of both the adaptive and neutral traits. Tergite IX less produced posterad; cerci rounded capitate, not pointed capitate; paraproct shoulder pointed laterad; gonopod more robust; apicomesal lobe quadrangular, not rounded; head of the dorsal phallothecal process patterned ventrad, not simple; sigmoid profile with more produced basal curve.

Description (in alcohol). This species has small eyes. Length of forewing $7.5 \mathrm{~mm}$, forewing membrane uniform and unicolor without any pattern on specimen stored in alcohol. Maxillary palp formula IV-(I,II,III)-V. Tibial spur formula 0-2-2.

Male genitalia. Abdominal segment IX without sternum; its ventral ending located at pivoting fulcrum is subquadrangular with braced margin; tergum IX less produced posterad with monolobed apex in dorsal view. The superanal complex has deeply shifted sclerotized horizontal lateral processes, the paraproct with pronounced lateral pointed shoulder visible both from lateral and 


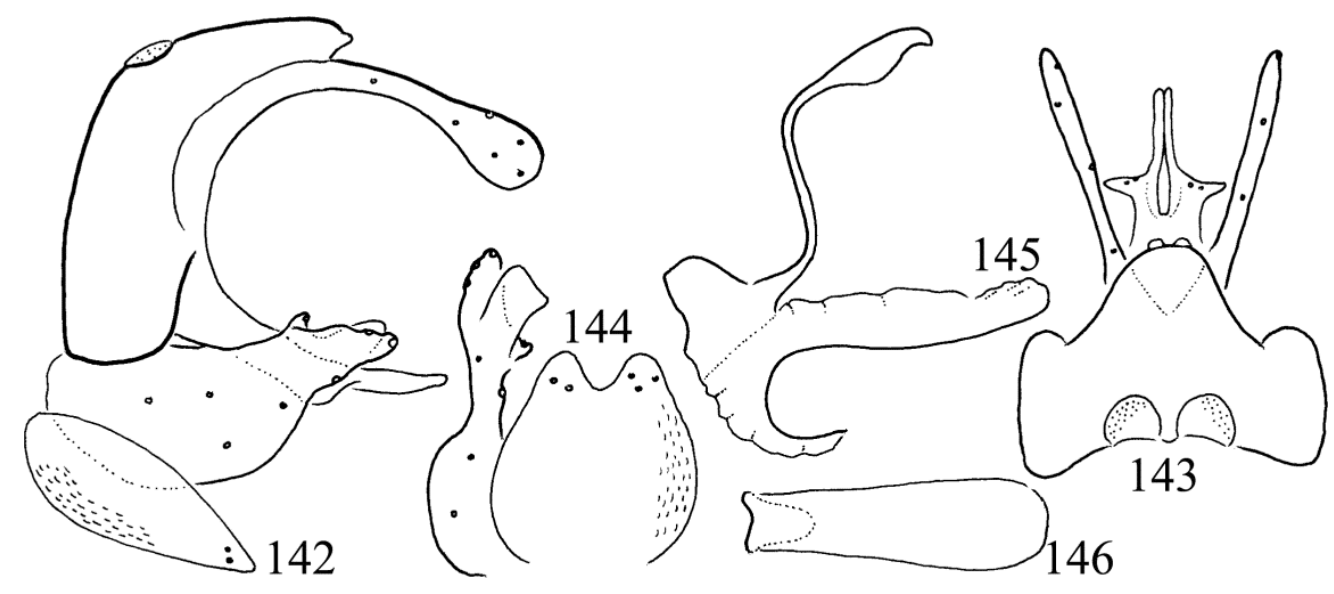

Figures 142-146. Nectopsyche ritka sp. nov. Holotype: 142 = male genitalia in left lateral view, $143=$ male genitalia in dorsal view, 144 = left gonopod with apicomesal lobe and ventral plate in ventral perpendicular view; 145 = phallic organ with the sigmoid profile of phallicata in lateral view; $146=$ phallicata in ventral view.

dorsal view. Cerci without fork, capitate. Gonopods almost straight dorsad in lateral view; its basoventrum more developed; scoop-shaped pair of basoventral processes fused, with wide and deep apicomesal cleft and 2-3 subapical sensory setae; apicomesal lobe quadrangular; part of apical surface rugose. Phallic organ seems articulating to the basomesal ridge of the gonopods; the pair of swan-necked dorsal phallothecal processes slender with large apex of patterned ventrum; the endotheca without any setae; lateral profile of the phallicata with well-developed basal curve, apical curve less produced.

Etymology. ritka, from "ritka" unusual, rare in Hungarian, refers to the unique structure on the lateral shoulder on the paraproct and on the head of the swan-necked dorsal phallothecal process.

\section{Nectopsyche salka Oláh, Johanson \& Malm, sp. nov.}

(Figures 147-151)

Material examined. Holotype, Bolivia, El Beni Dept. Liberalta, Chiquitania, Esmeralda Hotel area by river, $10.98270^{\circ} \mathrm{S}, 65.92366^{\circ} \mathrm{W}, 132$ mas, 4.XI.2013, light trap, ID \#NHRS-BOL13-07, leg. N. Apelqvist, J. Jonsson \& V. Sossa, Export permit: SENASAG No 019471 (1 male, SMNH). Paratypes: same as holotype (1 male, SMNH; 1 male, OPC).
Diagnosis. This new species has the scoopshaped basoventral processes of gonopods fused. Having short cerci and elongated apicomesal lobes on gonopods most close to N. kurta sp. nov., but differs by the differently shaped neutral traits of cerci and the fused scoop-shaped basoventral process. There are subtle, but stable speciation trait divergences in the shape of swan-necked process, sigmoid profile, the ventral profile of the phallicata and of the apicomesal lobe of gonopod.

Description (in alcohol). This species has small eyes. Length of forewing $6 \mathrm{~mm}$, forewing membrane uniform and unicolor without any pattern on specimen stored in alcohol. Maxillary palp formula IV-(I,II)-(III,V). Tibial spur formula 0-2-2.

Male genitalia. Abdominal segment IX without sternum; its ventral ending located at pivoting fulcrum rounded with braced margin; tergum IX well-produced posterad with monolobed apex in dorsal view. The superanal complex has deeply shifted sclerotized horizontal lateral processes, the paraproct narrowing apicad with slightly laterad produced knobby apex. Cerci without fork, very short and capitate, dorsal half of apical margin more produced than the glabrous ventral half. Gonopods concave dorsad in lateral view; its basoventrum more developed; scoop-shaped pair of basoventral processes fused, with wide apicomesal cleft with a single subapical sensory seta on 


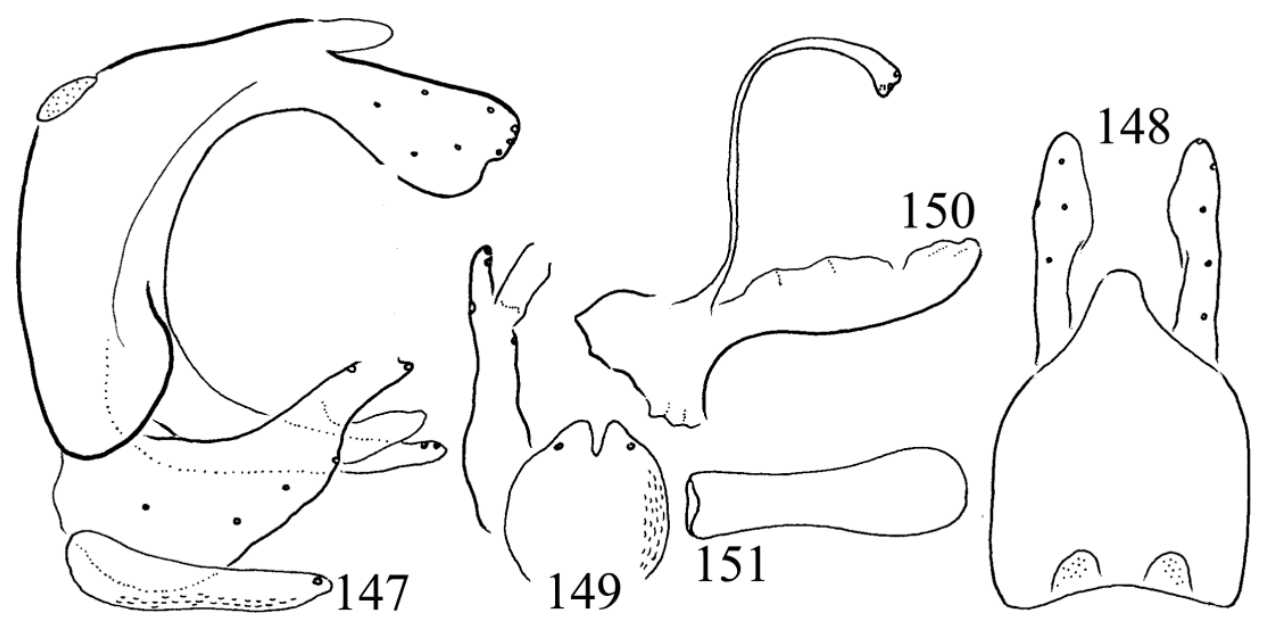

Figures 147-151. Nectopsyche salka sp. nov. Holotype: 147 = male genitalia in left lateral view, $148=$ male genitalia in dorsal view, 149 = left gonopod with apicomesal lobe and ventral plate in ventral perpendicular view; $150=$ phallic organ with the sigmoid profile of phallicata in lateral view; $151=$ phallicata in ventral view.

both lobes located laterad; apicomesal lobe elongated quadrangular with straight lateral margin and with two slight mesal humps in ventral view; part of apical surface rugose. Phallic organ seems articulating to the basomesal ridge of the gonopods; the pair of swan-necked dorsal phallothecal processes very slender filiform with small fanshaped apex; the endotheca without any setae; lateral sigmoid profile of the phallicata with welldeveloped basal curve, apical curve less produced.

Etymology. salka, from "szálka" diminutive form of thread, filament in Hungarian, refers to the very thin filiform swan-necked process on the dorsum of the phallotheca

\section{Nectopsyche silva Oláh, Johanson \& Malm, sp. nov.}

\section{(Figures 152-157)}

Material examined. Holotype, French Guiana, Maripasoula, Lawa River: Maripasoula, 83 mao $3^{\circ} 37.959^{\prime} \mathrm{N}, 54^{\circ} 1.426^{\prime} \mathrm{W}, 9$. II. 2007 , light trap, FRG 15, leg. N. Jönsson (1 male, SMNH). Paratypes: same as holotype (1 male, SMNH; 1 male, OPC).

Diagnosis. This new species has the scoopshaped basoventral processes of gonopods fused. Most close to $N$. alma sp. nov. but differs by having cerci shorter and capitate ventrad, not parallel-sided; gonopods more robust; apicomesal lobe on the gonopods smaller. The speciation trait of sigmoid profile more stretched basad.

Description. (in alcohol). This species has small eyes. Length of forewing $5 \mathrm{~mm}$, forewing membrane uniform and unicolor without any pattern on specimen stored in alcohol. Maxillary palp formula IV-(I,II,III)-V. Tibial spur formula 0-2-2.

Male genitalia. Abdominal segment IX short, without sternum; its ventral ending located at pivoting fulcrum rounded with braced margin; tergum IX produced posterad with broad, monolobed apex in dorsal view. The superanal complex has deeply shifted sclerotized horizontal lateral processes, the paraproct with narrowing, slightly knobby apices visible both from lateral and dorsal view. Cerci without fork, very short, shorter than tergite IX; ventrad capitate. Gonopods almost straight in lateral view; apex monolobed, tapering; gonopod basoventrum broad ventrad; scoopshaped pair of basoventral processes fused, with wide and deep apicomesal cleft and with three sensory setae subapicad on both sides. Phallic organ seems articulating to the basomesal ridge of the gonopods; the pair of swan-necked dorsal phallothecal processes slender with large apex, rounded triangular fan-shaped in perpendicular 


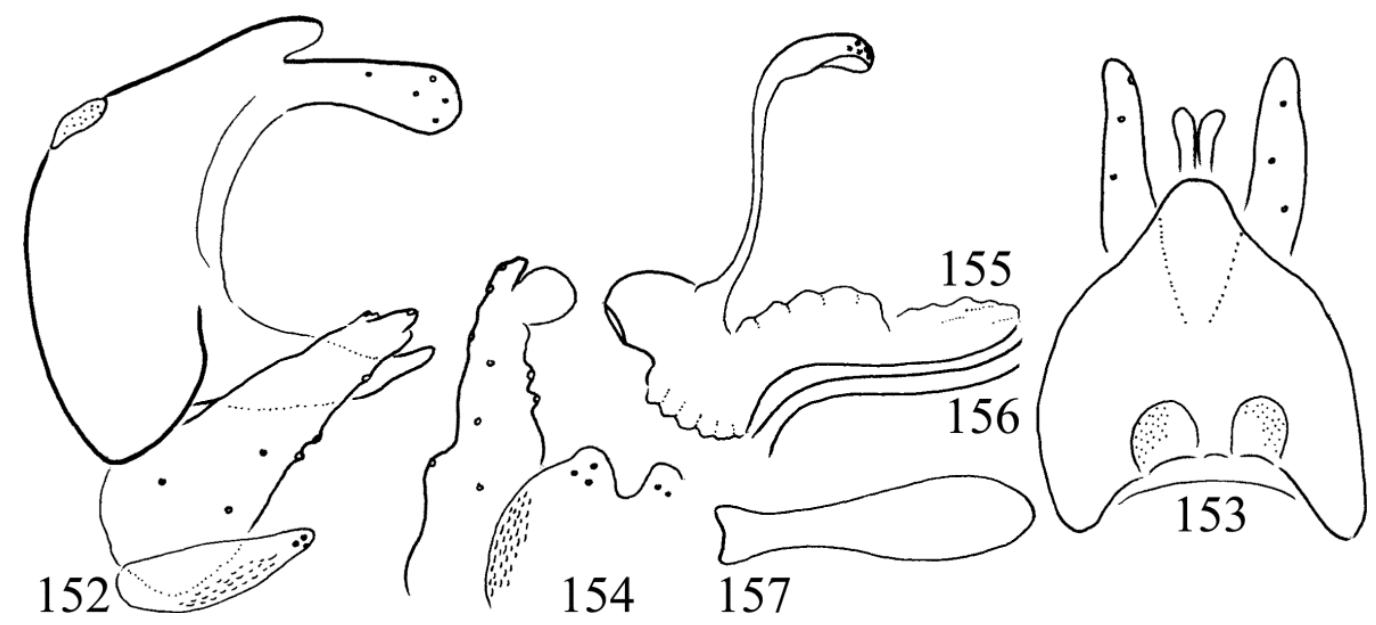

Figures 152-157. Nectopsyche silva sp. nov. Holotype: 152 = male genitalia in left lateral view, $153=$ male genitalia in dorsal view, $154=$ left gonopod with apicomesal lobe and ventral plate in ventral perpendicular view; $155=$ phallic organ with the sigmoid profile of phallicata in lateral view; $156=$ sigmoid profile in two specimens from the same population; $157=$ phallicata in ventral view.

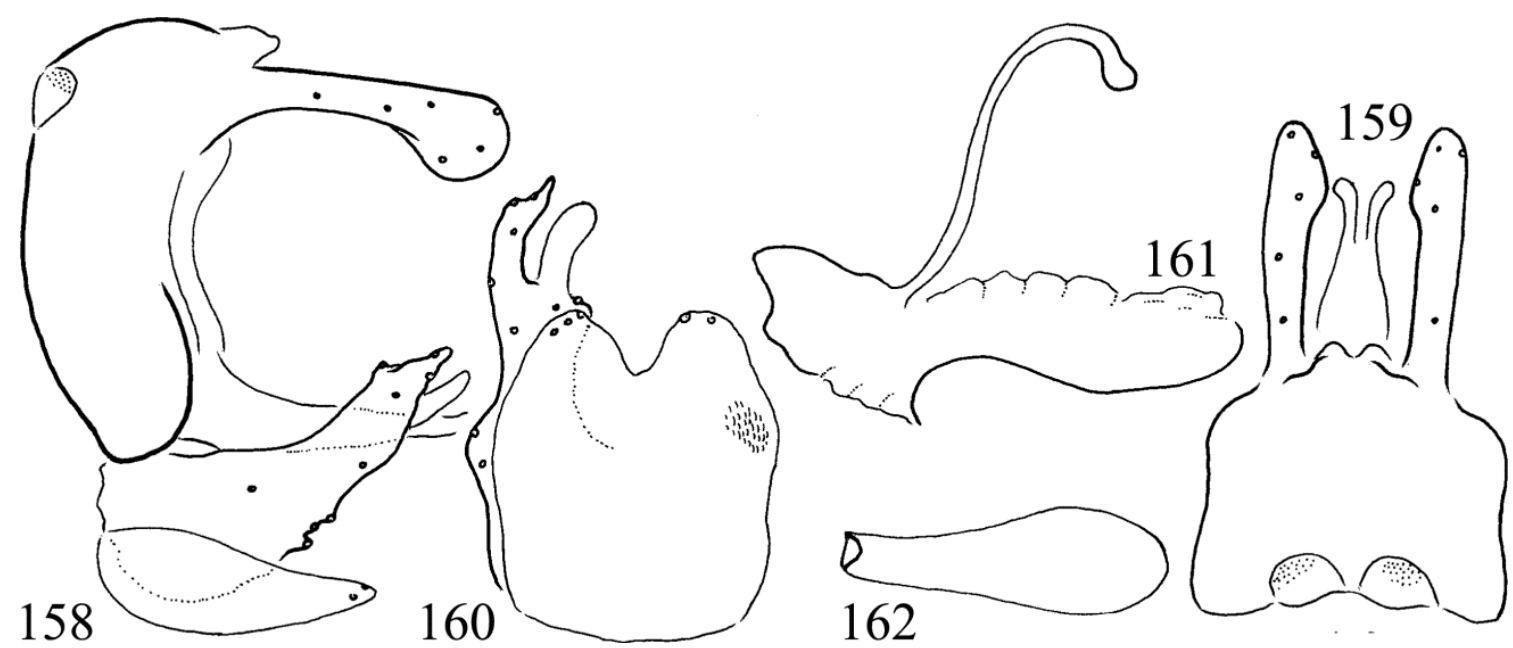

Figures 158-162. Nectopsyche sima sp. nov. Holotype: 158 = male genitalia in left lateral view, $159=$ male genitalia in dorsal view, $160=$ left gonopod with apicomesal lobe and ventral plate in ventral perpendicular view; $161=$ phallic organ with the sigmoid profile of phallicata in lateral view; $162=$ phallicata in ventral view.

dorsal view; the endotheca without any setae; lateral sigmoid profile of the phallicata with small basal curve, apical curve present and less produced, the entire profile is stretched, less sigmoid.

Etymology. silva, from "szilva" plumb in Hungarian, refers to the circular, but smaller apicomesal lobe on the gonopods.

\section{Nectopsyche sima Oláh \& Oláh, sp. nov.}

(Figures 158-162)

Material examined. Holotype, Ecuador, Amazonian Lowland, Terra Firme, Gareno Lodge, near Puerto Napo, 400 m, 13.VIII.2011, light trap, leg. J. Oláh jr. (1 male, OPC). 
Diagnosis. This new species has the scoop shaped basoventral processes of gonopods fused. Most close to $N$. maculipennis, but differs by the particular combination of both the adaptive and neutral traits. Tergite IX less produced posterad; cerci with long and slender shaft, shaft dorsum straight, head semicircular; gonopod head differently lobed, basoventral lobes fused, not free. Sigmoid profile diverged, although not exactly drawn on the holotype of $N$. maculipennis.

Description (in alcohol). This species has small eyes. Length of forewing $7 \mathrm{~mm}$, forewing uniform and unicolor without any pattern and any scales as visible on specimens stored in alcohol, sparsely covered with light and short hairs; the pterostigmal area enlarged and swollen. Maxillary palp formula IV-(I,II,III)-V. Tibial spur formula 0-2-2.

Male genitalia. Abdominal segment IX without sternum; its ventral ending located at pivoting fulcrum rounded with braced margin; tergum IX slightly produced posterad fused to remnant of segment X. The superanal complex has the less sclerotized horizontal very short pair of dorsomesal process, remnant of segment $\mathrm{X}$ visible as the continuation of tergum IX; the deeply shifted sclerotized horizontal lateral processes, the paraproct narrow with dorsad pointing apices in lateral view and slightly dilated and laterad directed in dorsal view. Cerci without fork, slender straight shaft and ventrad produced semicircular head. Gonopods slightly arching upward, broader basad in lateral view; its basoventrum less pigmented and discernible as fused to the basoventrum of the other gonopod; scoop shaped pair of basoventral processes also fused; apicomesal lobe elongated, mesad curving; part of apical surface rugose by semicircular lines. Phallic organ seems articulating to the basomesal ridge of the gonopods; the pair of swan-necked dorsal phallothecal processes very slender with downward directed short spatulate apex; the endotheca without any setae; lateral profile of the phallicata distinct sigmoid with spacious basal curve.

Etymology. sima, from "sima" smooth in Hungarian, refers to the uniform and unicolour forewing membrane without any pattern, as visible on the single male in alcohol.

\section{Nectopsyche terda sp. nov.}

(Figures 163-167)

Material examined. Holotype, French Guiana, Maripasoula, Lawa River, Gzaan Dayé, $4^{\circ} 01.130^{\prime}$ $\mathrm{N}, 54^{\circ} 19.015^{\prime} \mathrm{W}, 74 \mathrm{~m}, 8 . \mathrm{II} .2007$, FRG 14, leg. N. Jönsson (1 male, SMNH).

Diagnosis. This new species has the scoopshaped basoventral processes of gonopods fused. Most close to $N$. valla sp. n., but differs by the particular combination of both the adaptive and neutral traits. Tergite IX less produced posterad; cerci with downward produced head; gonopod head multi-lobed, paraproct shouldered rightangled; apicomesal lobe of gonopods elongated rounded, sigmoid profile more stretched.

Description. (in alcohol). This species has small eyes. Length of forewing $7 \mathrm{~mm}$, forewing membrane dark brown, uniform and unicolor without any pattern on specimen stored in alcohol. Maxillary palp formula IV-(I,II,III)-V. Tibial spur formula 0-2-2.

Male genitalia. Abdominal segment IX without sternum; its ventral ending located at pivoting fulcrum is rounded with braced margin; tergum IX less produced posterad with monolobed apex in dorsal view. The superanal complex has deeply shifted sclerotized horizontal lateral processes, the paraproct with pronounced lateral shoulder almost right angular, visible both from lateral and dorsal view. Cerci without fork, head ventrad turning. Gonopods almost straight in lateral view; apex multi-lobed; its basoventrum less pigmented; scoop-shaped pair of basoventral processes fused, with narrow and deep apicomesal cleft, lobes with two setae laterad; apicomesal lobe elongated rounded; part of apical surface rugose. Phallic organ seems articulating to the basomesal ridge of the gonopods; the pair of swan-necked dorsal phallothecal processes slender with large fanshaped apex in perpendicular dorsal view; the endotheca without any setae; lateral sigmoid profile of the phallicata stretched.

Etymology. terda, from "térd" knee in Hungarian, refers to the more right angled shoulder on the paraproct. 


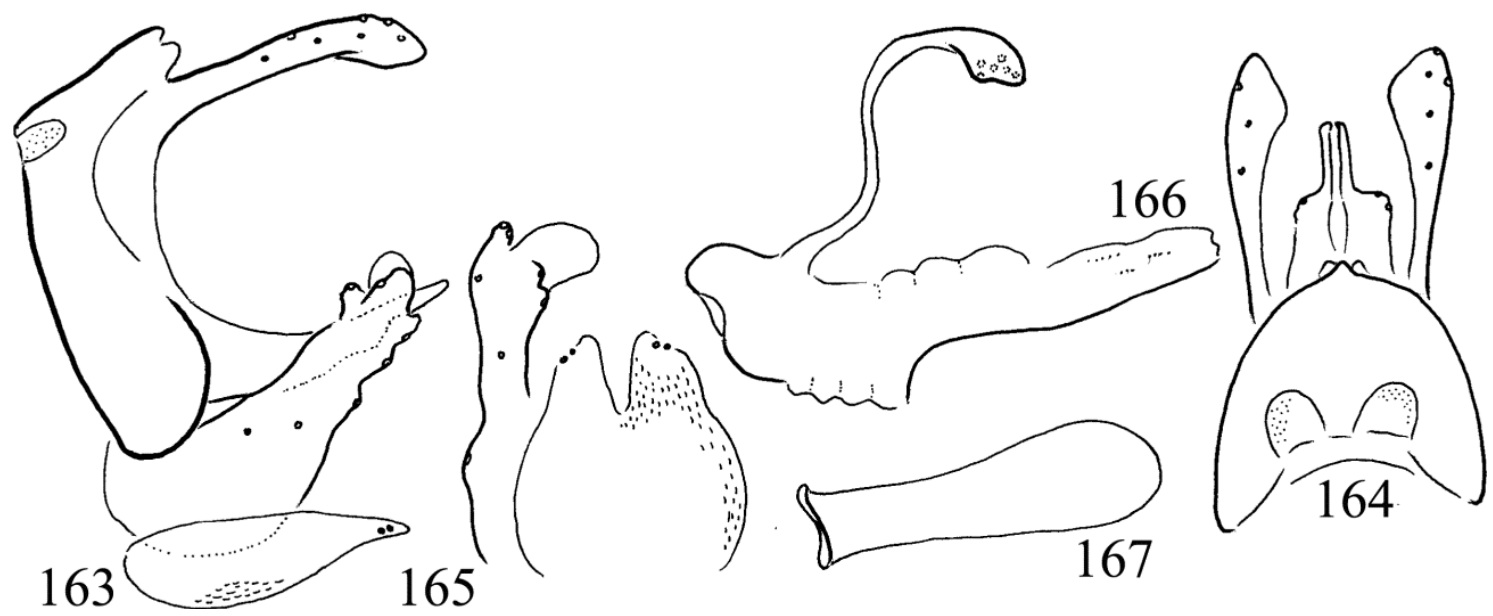

Figures 163-167. Nectopsyche terda sp. nov. Holotype: 163 = male genitalia in left lateral view, $164=$ male genitalia in dorsal view, $165=$ left gonopod with apicomesal lobe and ventral plate in ventral perpendicular view; $166=$ phallic organ with the sigmoid profile of phallicata in lateral view; $167=$ phallicata in ventral view.

\section{Nectopsyche vagota Oláh, Johanson \& Malm,} sp. nov.

(Figures 168-173)

Material examined. Holotype, French Guiana, Maripasoula, Lawa River, Gzaan Dayé, $4^{\circ} 01.130^{\prime}$ $\mathrm{N}, 54^{\circ} 19.015^{\prime} \mathrm{W}, 74 \mathrm{~m}, 8 . \mathrm{II} .2007, \mathrm{FRG} 14$, leg. N. Jönsson (1 male, SMNH). Paratype, Approuague, Kaw Mtn., $4^{\circ} 32.833^{\prime} \mathrm{N}, 52^{\circ} 11.452^{\prime} \mathrm{W}, 77$ mao, 24.I.2007, FRG5, light trap, leg. N. Jönsson (1 male, OPC).

Diagnosis. This new species has the scoopshaped basoventral processes of gonopods fused. Most close to N. kurta sp. nov., but differs by the longer sternite IX; by cerci regularly truncated apicad, not capitate; by more produced and laterad turning apex of the phallothecal dorsal process; sigmoid profile diverged, straight middle.

Description (in alcohol). This species has small eyes. Length of forewing $7 \mathrm{~mm}$, forewing membrane uniform and unicolor without any pattern on specimen stored in alcohol. Maxillary palp formula (I,IV)-(II,III)-V. Tibial spur formula 0-2-2.

Male genitalia. Abdominal segment IX without sternum; its ventral ending located at pivoting fulcrum rounded with braced margin; tergum IX produced posterad with monolobed apex in dorsal view. The superanal complex has deeply shifted sclerotized horizontal lateral processes, the paraproct narrowing apicad with laterad and upward produced knobby apex. Cerci without fork, very short and straight vertical truncated. Gonopods straight dorsad in lateral view; its basoventrum more developed; scoop-shaped pair of basoventral processes fused, with wide apicomesal cleft with a single subapical sensory seta on both lobes; apicomesal lobe broad elongated quadrangular; part of apical surface rugose. Phallic organ seems articulating to the basomesal ridge of the gonopods; the pair of swan-necked dorsal phallothecal processes slender with large laterad turning apex; the endotheca without any setae; lateral sigmoid profile of the phallicata with well-developed basal curve, apical curve less developed.

Etymology. vagota, from "vágott" truncated in Hungarian, refers to the straight-cut, truncated apical margin of the short cerci.

\section{Nectopsyche valla Oláh, Johanson \& Malm, sp. nov.}

(Figures 174-178)

Material examined. Holotype, French Guiana, Roura, Cacao, $4^{\circ} 33.639^{\prime} \mathrm{N}, 52^{\circ} 24.629^{\prime} \mathrm{W} 66 \mathrm{~m}$, 28.i.2007, FRG 8, leg. N. Jönsson (1 male, SMNH). Paratypes: same as holotype (2 males, SMNH; 1 male, OPC). 


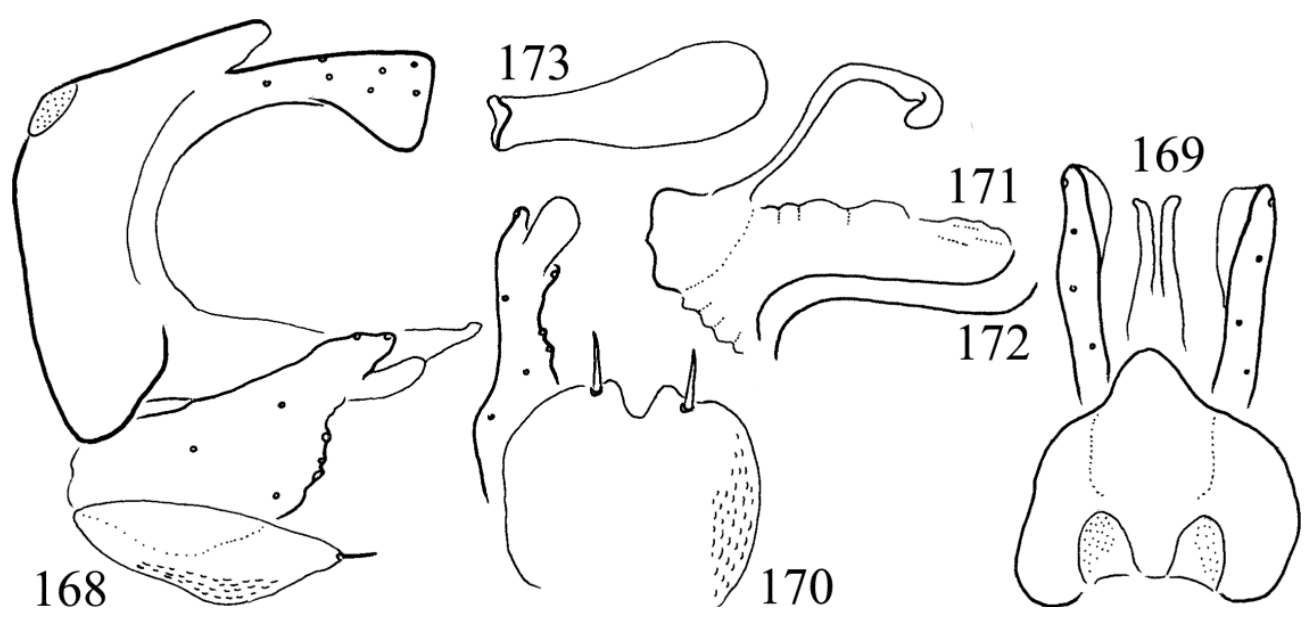

Figures 168-173. Nectopsyche vagota sp. nov. Holotype: $168=$ male genitalia in left lateral view, $169=$ male genitalia in dorsal view, $170=$ left gonopod with apicomesal lobe and ventral plate in ventral perpendicular view; 171 = phallic organ with the sigmoid profile of phallicata in lateral view; $172=$ sigmoid profile in one specimen from the same population; 173 = phallicata in ventral view.
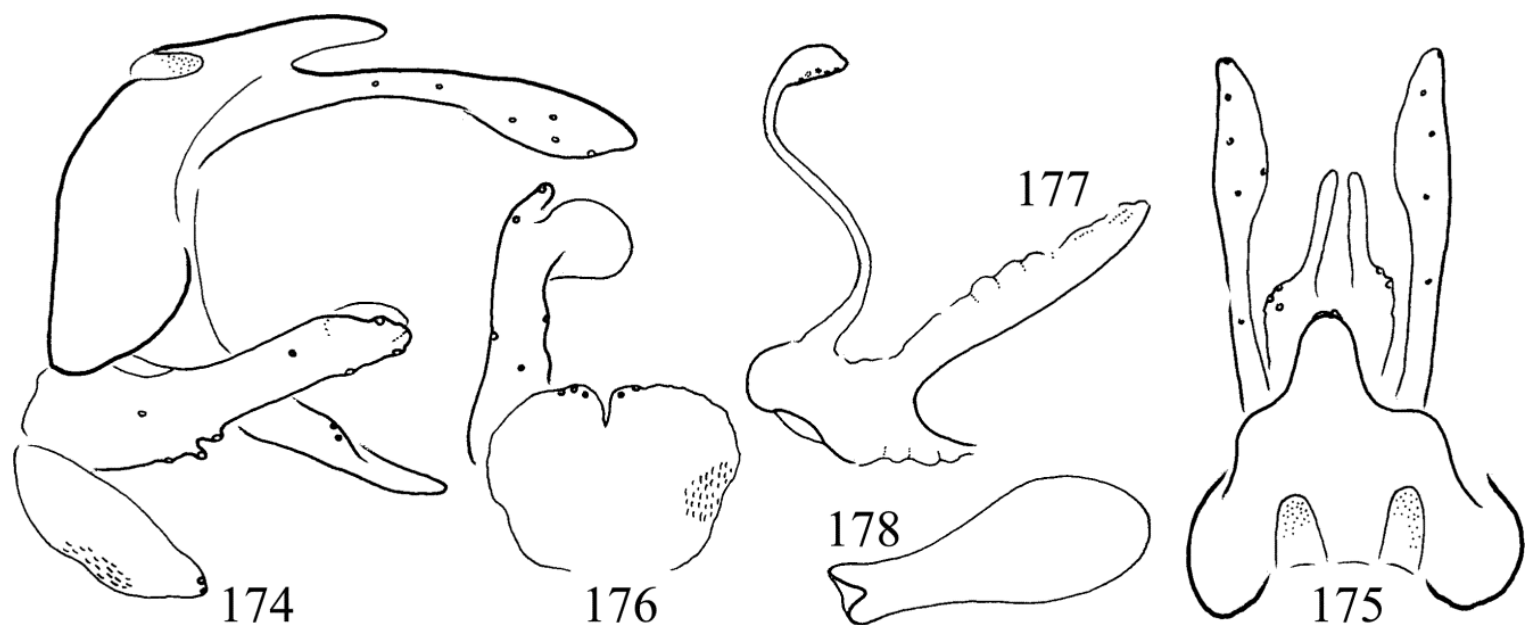

Figures 174-178. Nectopsyche valla sp. nov. Holotype: $174=$ male genitalia in left lateral view, $175=$ male genitalia in dorsal view, $176=$ left gonopod with apicomesal lobe and ventral plate in ventral perpendicular view; 177 = phallic organ with the sigmoid profile of phallicata in lateral view; $178=$ phallicata in ventral view.

Diagnosis. This new species has the scoop shaped basoventral processes of gonopods fused. Most close to $N$. multilineata, but differs by having no any pattern on forewing at least in alcohol; by the particular combination of both the adaptive and neutral traits. Tergite IX more produced posterad; cerci with ventrally produced head; gonopod head simple lobed, paraproct strongly shouldered. Sigmoid profile diverged.
Description (in alcohol). This species has small eyes. Length of forewing $6 \mathrm{~mm}$, forewing membrane uniform and unicolor without any pattern on specimen stored in alcohol. Maxillary palp formula IV-(I,II,III)-V. Tibial spur formula 0-2-2.

Male genitalia. Abdominal segment IX without sternum; its ventral ending located at pivoting fulcrum is subquadrangular with braced 
margin; tergum IX strongly produced posterad with monolobed apex in dorsal view. The superanal complex has deeply shifted sclerotized horizontal lateral processes, the paraproct with pronounced lateral shoulder visible both from lateral and dorsal view. Cerci without fork, convex shaft, and head ventrad produced. Gonopods almost straight in lateral view; its basoventrum less pigmented; scoop shaped pair of basoventral processes fused, with narrow and deep apicomesal cleft; apicomesal lobe rounded; part of apical surface rugose. Phallic organ seems articulating to the basomesal ridge of the gonopods; the pair of swan-necked dorsal phallothecal processes slender with large apex, triangular fan-shaped in perpendicular dorsal view; the endotheca without any setae; lateral profile of the phallicata with welldeveloped basal curve, apical curve less produced.

Etymology. valla, from "váll, válla" shoulder, shoulder of something in Hungarian, refers to the well-developed lateral shoulder on the paraproct.

\section{Nectopsyche albida species group}

Species in this group are characterised with enlarged gonopod basement. They are distributed mostly in the Nearctic faunal region. A single Neotropical species, N. muelleri has some resemblance to the group, but there was no specimens available for study. Its real relation needs further study to confirm.

\section{Nectopsyche dorsalis (Banks, 1901)}

Material examined. Mexico, State of Veracruz, Los Tuxtlas area, Rio la Palma, near to the Estacion the Biologia Los Tuxtlas, $18^{\circ} 33.680^{\prime} \mathrm{N}$, 9502.943'W, 30 mao, 26.VI.2006, light Trap, leg. M. Espeland \& T. Malm (1 male, SMNH)

\section{Nectopsyche gracilis (Banks, 1901)}

Material examined. Mexico, State of Veracruz, Los Tuxtlas area, Rio Maquinas, near to the Estacion the Biologia Los Tuxtlas, 18 $37.392^{\prime} \mathrm{N}$, 95'05.418'W, 9 mao, 27.VI.2006, light trap, leg.
M. Espeland \& T. Malm (2 males SMNH; 1 male $\mathrm{OPC})$

\section{Nectopsyche acutiloba species group}

A species group with highly modified gonopod, and the harpago especially elongated. This is synapomorphic character of the group. Cerci and parameres are simple plesiomorphic. Two known species belong to this species group: N. acutiloba Flint, N. taleola Flint.

\section{Nectopsyche acutiloba Flint, 1974}

Material examined. French Guiana, Iracouba, Iracoubo: Circue Morpio $5^{\circ} 29.266^{\prime} \mathrm{N}, 53^{\circ} 17.910^{\prime}$ W 24 mao 01.II.2007 FRG 11 leg. N. Jönsson (2 males, SMNH; 1 male, OPC).

\section{Nectopsyche punctata species group}

A species group of the genus having step-like pattern on the ventrum of the cercal shaft, this means that in lateral view the basoventrum of cerci widens abruptly basad with a step, not gradually as it does at every other species in the entire genus. According to the principles of diversity, generality, locality and parsimony this cercal shape divergence delimiting this species group is a result of ancestral integration, not a species level product of the contemporary, recent past divergence.

Besides the five new species described here two known species belong to this group: $N$. punctata (Ulmer, 1905) and $N$. jenseni (Ulmer, 1905) with five uncertain synonymies and obscured species status (see below!). Synonymies were established only by forewing pattern, frequently incomplete, or by gross genital morphology. Applying the speciation trait procedures of fine phenomics and examining the available samples we have found two speciation traits, the apicomesal lobe of the gonopods and the sigmoid profile of the phallicata highly diverged and rather stable to delineate incipient species of recent divergences. We have examined specimens stored 
in alcohol and found all the species without any wing pattern. Divergences are abundant and patterns are somewhat variable also in the details of the forewing marking (Flint 1991) as well as both in colour and in gross genital structure species differences are often subtle, but stable even in sympatry (Holzethal 1995). These empirical experiences explain why we have found so many new incipient species by speciation traits with fine structure analysis in such a small material. Considering our very limited sampling effort we believe that many new siblings are still waiting to be collected and described also in the $N$. punctata species group. Nectopsyche punctata sensu lato have been recorded from Argentina to Panama (Flint 1981), or even to Mexico, but we believe that these records from different regions may represent independent incipient sibling species. A comprehensive revision of the available type materials is required by fine phenomics of speciation traits in order to re-establish synonymies and species status as well as to study further the speciation trait divergences on larger population samples. Here we describe five new species, survey unjustified synonymies without type materials and present their uncertain specific status.

\section{Nectopsyche eka Oláh, Johanson \& Malm, sp. nov.}

(Figures 179-185)

Material examined. Holotype: Peru, Dept Lima, Pacaran, Prov Canete, River Chillon Obrajillo, $12^{\circ} 52^{\prime} 05^{\prime \prime} \mathrm{S}, 76^{\circ} 02^{\prime} 60^{\prime} \mathrm{W}, 877 \mathrm{~m}, 16-17 . \mathrm{III}$. 2006, light trap, leg. J.C. Lopez \& F.M. Carlos (1 male, SMNH). Paratypes: same as holotype (1 male, SMNH; 1 male, OPC). San Martin Prov., Rio Negro, 37 km (rd.) W Moyobamba, near Olmos-Tarapoto rd., $6^{\circ} 00.278^{\prime} \mathrm{S}, \quad 77^{\circ} 15.437^{\prime} \mathrm{W}$, light, loc. 05, 6.I.2009, leg. T. Malm \& K.A. Johanson (1 male, SMNH).

Diagnosis. This new species differs from all the other species in the group in the details of all the gross genital structures, although their range of variation is not known. There are well defined stable divergences in the shape of the speciation traits. The sigmoid profile characterized by acute angled basal curve and the ventral form of phal- licata is wedge shaped. The apicomesal lobe of the gonopods broad, rounded fan-shaped.

Description (in alcohol). This species has small eyes. Length of forewing is $11 \mathrm{~mm}$; forewing uniform and unicolor without any pattern on specimen stored in alcohol. The pterostigmal area enlarged and swollen. Maxillary palp formula (I,II,III,IV)-V. Tibial spur formula 0-2-2.

Male genitalia. Abdominal segment IX very short, without sternum; its ventral ending, located at pivoting fulcrum of gonopods and phallic organ, rounded quadrangular with braced margin; tergum IX much produced posterad, elongated narrowing in lateral view; with shallow cleft in dorsal view; pair of punctate acrotergite well separated. The superanal complex has no discernible dorsomesal process, the upper remnant of segment X; the deeply shifted pair of sclerotized horizontal lateral processes, the paraproct with blunt apex in dorsal view and rounded obliquely truncate in lateral view. Cerci un-forked, parallelsided with a ventral step or berm on middle position, that results in a broader basal half. Gonopods slightly arching; basoventral process short, triangular in ventral view; apicomesal lobe broad, rounded fan-shaped mesad turning in ventral view, partially pegged on apical surface. Phallic organ is indistinct it seems articulating to the basomesal ridge of the gonopods; well discernible the pair of swan-necked dorsal phallothecal processes with enlarged and elongated downward directed head with a ventral concavity partially rugose; endothecal setal spines lacking; sigmoid lateral profile of the phallicata with acute angled basal curve; in ventral view the phallicata wedgeshaped anterad.

Etymology. eka, from ,ék” wedge in Hungarian, refers to the phallicata tapering to a thin edge, anterad in ventral view.

\section{Nectopsyche jenseni (Ulmer, 1905)}

(Figures 186-188)

Leptocella jenseni Ulmer, 1905: 75.“16 Exemplare (ふ, ㅇ) von Jensen-Haarup im December 1904 gesammelt: Santa Rosa, Provinz Mendoza, Argentinien; in meiner Sammlung." 
Leptocella mixta Navas, 1920: 67. „Patria. República Argentina: Alta Gracia, provincia de Córdoba, 1-8 abril de 1920, Carlos Bruch (Col. Bruch)." Schmid 1949: 386, male redescribed and redrawn, based on two males from the Navas collection; collected later in 1922 and 1927, not included in the type series, this is not the holotype. Flint 1966b: 9, to synonymy with $N$. punctata. Flint et al. 1999: 77, to synonymy with $N$. jenseni.

Leptocella lucipeta Navas, 1923: 200-201. „Patria. República Argentina: Alta Gracia, 24 de desembre de 1921. Atreta per la Ilum. (Col. Bruch i meva).” In the species description mistakenly female genital drawing was presented as male genitalia. Schmid 1949: 386, no male in Navas collection. Flint et al. 1999: 77, to synonymy.

Leptocella Banks, 1899: 214: Flint 1974: 127, to synonymy with Nectopsyche.

Remarks. Comparing the published original drawings of $N$. jenseni Ulmer (1905), and $N$. mixta Navas (1920) with the redrawn drawings of N. mixta by Schmid (1949) we feel uncomfortable. In these drawings we have presented only the periphallic structures of gross morphology: cerci, paraprocts and gonopods. Speciation traits of the apicomesal lobe on gonopod and of the sigmoid profile on the phallicata were drawn only by Schmid. Most probably Ulmer and Navas have prepared their drawings from intact and not from cleared and cleaned genitalia.

Based on the neutral, non-adaptive traits of gross morphology it is probable that the three drawings have been drawn from different animals or species. Ulmer has drawn his drawing from the type series of 16 specimens (Santa Rosa, Mendoza Province, Argentina) Navas from his male type (Alta Gracia, Córdoba Province, Argentina) and Schmid not from Navas'type, but from two males collected later (4.I.1922, 3.II. 1927; "provenant de Alta Gracia, Chili"). Re-examination of the gross structures and the examination of the speciation traits of the original type specimens on cleared genitalia are required to evaluate reliably the synonymies and the species status of $N$. jenseni. However, either this careful revision of type materials or the collection and description of unknown representatives of this species group are unlikely in the present devastated state of the western taxonomy.

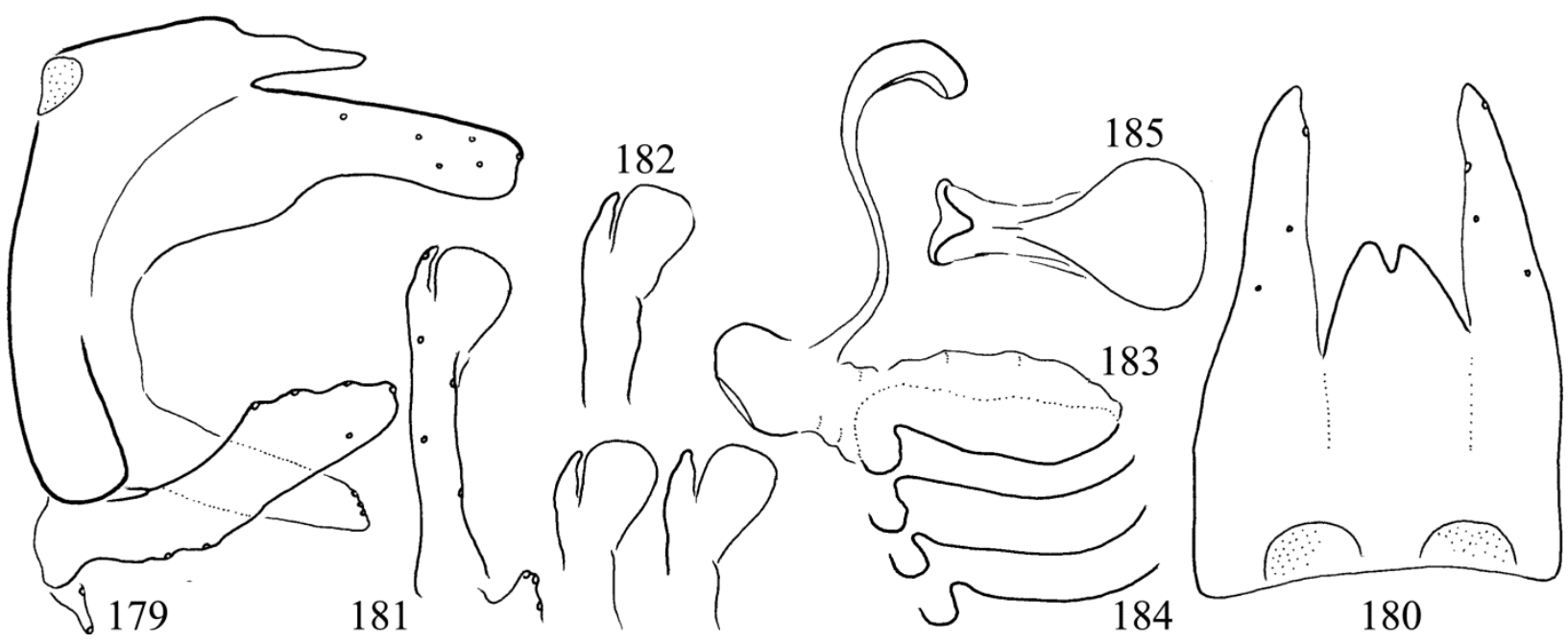

Figures 179-185. Nectopsyche eka sp. nov. $179=$ male genitalia in left lateral view; $180=$ genitalia in dorsal view; $181=$ left gonopod with apicomesal lobe in ventral perpendicular view; $182=$ apicomesal lobe on gonopod of three specimens from the same population; 183 = phallic organ with the sigmoid profile of phallicata in lateral view; $184=$ sigmoid profile of phallicata of three specimens from the same population; $185=$ phallicata in ventral view. 


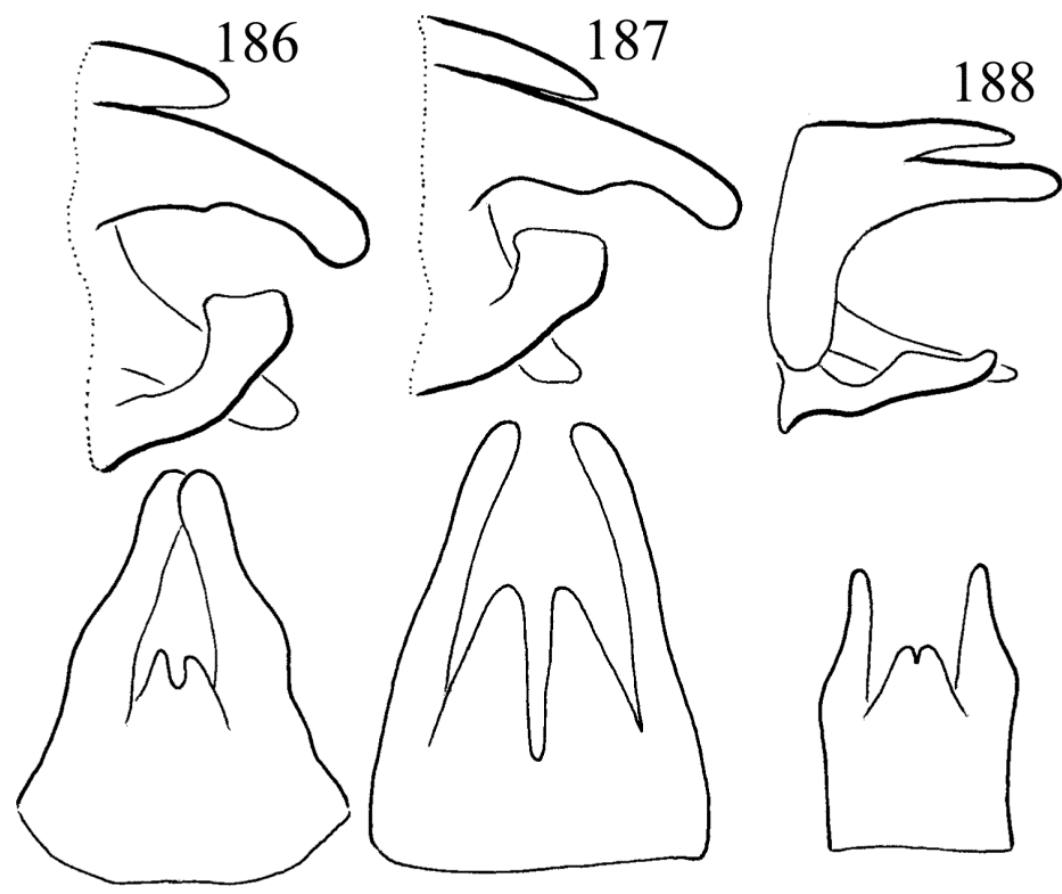

Figures 186-188. Nectopsyche jenseni (Ulmer, 1905). Reconstruction of original drawings in lateral and dorsal view: $186=N$. jenseni $($ Ulmer, 1905); $187=N$. mixta $($ Navas, 1920); $188=$ N. mixta (Navas, 1920), drawn by Schmid $(1949)$.

\section{Nectopsyche kurtula Oláh, Johanson \& Malm, sp. nov.}

(Figures 189-193)

Material examined. Holotype, Argentina: Chaco, PN Chaco, campground, $77 \mathrm{~m}, 26^{\circ} 48.608^{\prime} \mathrm{S}$, $59^{\circ} 36.893^{\prime}$ W, 12.I.2008, leg. K. Hill, D. Marshall $\&$ M. Moulds (1 male, SMNH).

Diagnosis. This new species is most close to N. padka sp. nov. but differs by having tergite IX less produced posterad; gonopod fan-shaped. The speciation traits are distinctly diverged; apicomesal lobe of gonopods broader with short neck basad; sigmoid profile irregular and more stretched; phallicata broad fan-shaped in ventral view, not simply circular.

Description (in alcohol). This species has small eyes. Length of forewing is $10 \mathrm{~mm}$; forewing uniform and unicolor without any pattern and any scales as visible on specimens stored in alcohol. Forewing pterostigmal area enlarged and swollen. Maxillary palp formula (I, II, IV)-III-V. Tibial spur formula 0-2-2.
Male genitalia. Abdominal segment IX without sternum; its ventral ending, located at pivoting fulcrum of gonopods and phallic organ, rounded with braced margin; tergum IX less produced posterad; slight mesal excision present posterad, pair of punctate circular acrotergite well separated. The superanal complex has no discernible dorsomesal process, the upper remnant of segment X; the deeply shifted pair of sclerotized horizontal lateral processes, the paraproct with blunt apex in dorsal view and truncate in lateral view. Cerci unforked, slightly falcate with a ventral step or berm on middle position, that results in a broader basal half. Gonopods slightly arching and fan-shaped upward while almost equal broad in lateral view; basoventral process long filiform; apicomesal lobe broad circular with short neck in ventral view, partially pegged on apical surface. Phallic organ indistinct, it seems articulating to the basomesal ridge of the gonopods; well discernible the pair of swan-necked dorsal phallothecal processes with enlarged and elongated downward directed head with a ventral concavity partially rugose, packed with short pegs; endothecal setal spines lacking; sigmoid lateral profile of the phallicata 
irregular, stretched in lateral view; in ventral view the phallicata broad fan-shaped posteriorly.

Etymology. kurtula, from „kurtul” shortens in Hungarian, refers to the presence of an abbreviated neck on the basis of the apicomesal lobe of gonopods.

\section{Nectopsyche letra Oláh, Johanson \& Malm, sp. nov.}

(Figures 194-198)

Material examined. Holotype: French Guiana, Roura, Cacao, $4^{\circ} 33.639^{\prime} \mathrm{N}, 52^{\circ} 24.629^{\prime} \mathrm{W} 66 \mathrm{~m}$, 28.i.2007, FRG 8, leg. N. Jönsson (1 male, SMNH).

Diagnosis. This new species has relations to the $N$. padka sp. nov. by having a step or berm on the lateral profile of the cercal ventrum, unique in the genus, but differs by having posterad produced tergite IX bifid, not quadrifid; cerci capitate, not parallel-sided; gonopods angled ventrad, not simple; apicomesal lobe on gonopods fanshaped, not circular; sigmoid profile of the phallicata with less produced basal curve.

Description (in alcohol). This species has small eyes. Length of forewing is $11 \mathrm{~mm}$; forewing uniform and unicolor without any pattern some black scales visible on specimen stored in alcohol. The pterostigmal area enlarged and swollen. This single holotype could be a teneral male specimen. Maxillary palp formula IV(I,II,III)-V. Tibial spur formula 0-2-2 .

Male genitalia. Abdominal segment IX without sternum; its ventral ending, located at pivoting fulcrum of gonopods and phallic organ, rounded with braced margin; tergum IX much produced posterad, elongated narrowing in lateral view; deeply cleft in dorsal view; pair of punctate acrotergite well separated. The superanal complex has no discernible dorsomesal process, the upper remnant of segment X; the deeply shifted pair of sclerotized horizontal lateral processes, the paraproct with blunt apex in dorsal view and rounded obliquely truncate in lateral view. Cerci un-forked, capitate with a ventral step or berm on middle position, that results in a broader basal half. Gonopods with a horizontal basal and a nearly vertical apical region; basoventral process short; apicomesal lobe fan-shaped mesad turning in ventral view, partially pegged on apical surface. Phallic organ is indistinct it seems articulating to the basomesal ridge of the gonopods; well discernible is the pair of swan-necked dorsal phallothecal processes with enlarged and elongated downward directed head with a ventral concavity partially rugose; endothecal setal spines lacking; sigmoid lateral profile of the phallicata with less developed; in ventral view the phallicata with broad quadrangular apical half.

Etymology. letra, from „létra” ladder or stair in Hungarian, refers to the step or berm like ventral pattern on middle of the cerci.

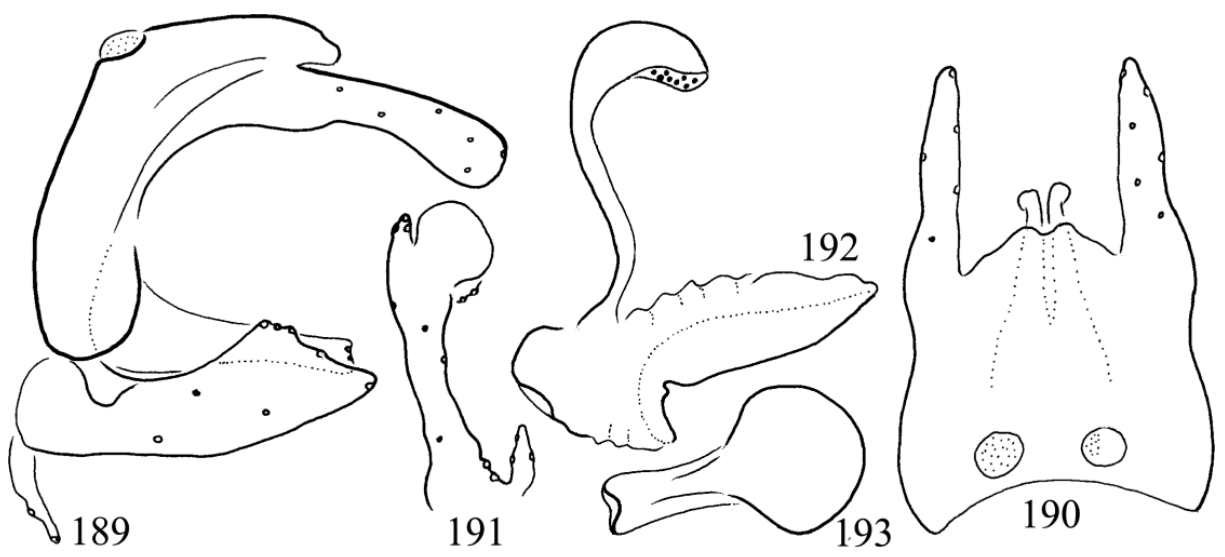

Figures 189-193. Nectopsyche kurtula sp. nov. Holotype: 189=male genitalia in left lateral view, 190=male genitalia in dorsal view, 191=left gonopod with apicomesal lobe in ventral perpendicular view; 192=phallic organ with the sigmoid profile of phallicata in lateral view; $193=$ phallicata in ventral view. 


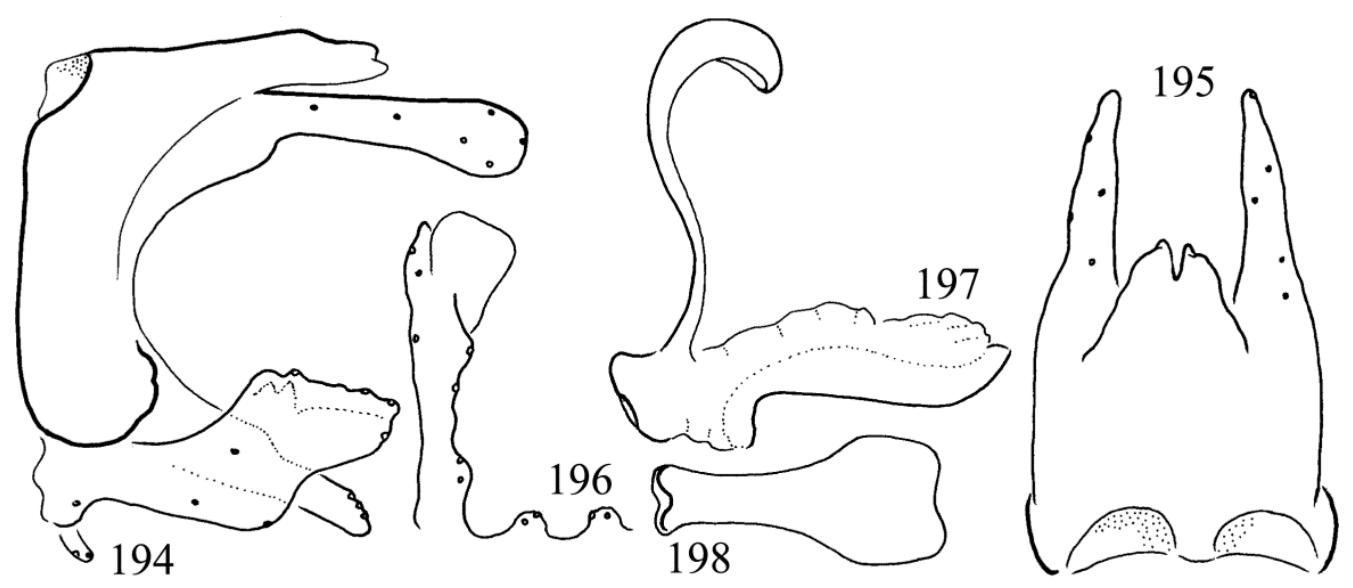

Figures 194-198. Nectopsyche letra sp. nov. Holotype: 194 = male genitalia in left lateral view, 195 = male genitalia in dorsal view, 196 = left gonopod with apicomesal lobe in ventral perpendicular view; $197=$ phallic organ with the sigmoid profile of phallicata in lateral view; $198=$ phallicata in ventral view.

\section{Nectopsyche padka Oláh \& Oláh, sp. nov.}

(Figures 199-203)

Material examined. Holotype, Ecuador, West Andean foothills, Tinalandia Nature Reserve, Rio Toachi, $85 \mathrm{~km}$ from Quito, $600 \mathrm{~m}$, 19.III.2011, light trap, leg J. Oláh jr. (1 male, OPC).

Diagnosis. This new species has relations to the $N$. jenseni and $N$. punctata species by having a step or berm on the lateral profile of cercal ventrum, unique in the genus. Unfortunately the specific status of both $N$. jenseni and $N$. punctata is rather confused. The lectotype drawings of the single male $N$. punctata (Flint 1966) has no similarity to the original, detailed drawings (Ulmer 1905) both drawn from the same single male deposited in the Vienna Museum. The cercal berm is lacking, paraproct tip pointed and the posterad produced tergite IX is monolobed at the lectotype drawings; the cercal berm is highly produced, the paraproct tip is rounded bulky and the posterad produced tergite IX is with clearly deep bilobed apical apices. Moreover the other published drawings prepared from a specimen collected in Venezuela and identified as $N$. punctata differ from both the original and from the lectotype drawings. The three drawings may represent three distinct species. Similar ambiguous drawings are published and synonymies established for $N$. jenseni.
Nectopsyche padka sp. nov. differs from all the published drawings mixed and synonymised under $N$. punctata and $N$. jenseni by having quadrilobed apex of the posterad produced tergite IX, not bilobed or monolobed; circular apicomesal lobe on the gonopods, not truncate or rounded truncate; paraproct tip obliquely truncate ventrad; sigmoid profile of the phallicata is different. Moreover, the holotype of $N$. padka sp. nov. has forewing without any pattern and any scales.

Description (in alcohol). This species has small eyes. Length of forewing is $10 \mathrm{~mm}$; forewing uniform and unicolor without any pattern and any scales as visible on specimens stored in alcohol. The forewings are sparsely covered with light and short hairs; the pterostigmal area enlarged and swollen. This single holotype could be a teneral male specimen. Maxillary palp formula (I,IV)-(II,III)-V. Tibial spur formula 0-2-2.

Male genitalia. Abdominal segment IX without sternum; its ventral ending, located at pivoting fulcrum of gonopods and phallic organ, rounded with braced margin; tergum IX much produced posterad, elongated narrowing in lateral view, almost reaching the head of the cerci; deeply cleft in dorsal view and the lateral lobes are bifid, pair of punctate acrotergite well separated. The superanal complex has no discernible dorsomesal process, the upper remnant of segment X; the deeply shifted pair of sclerotized horizontal lateral pro 


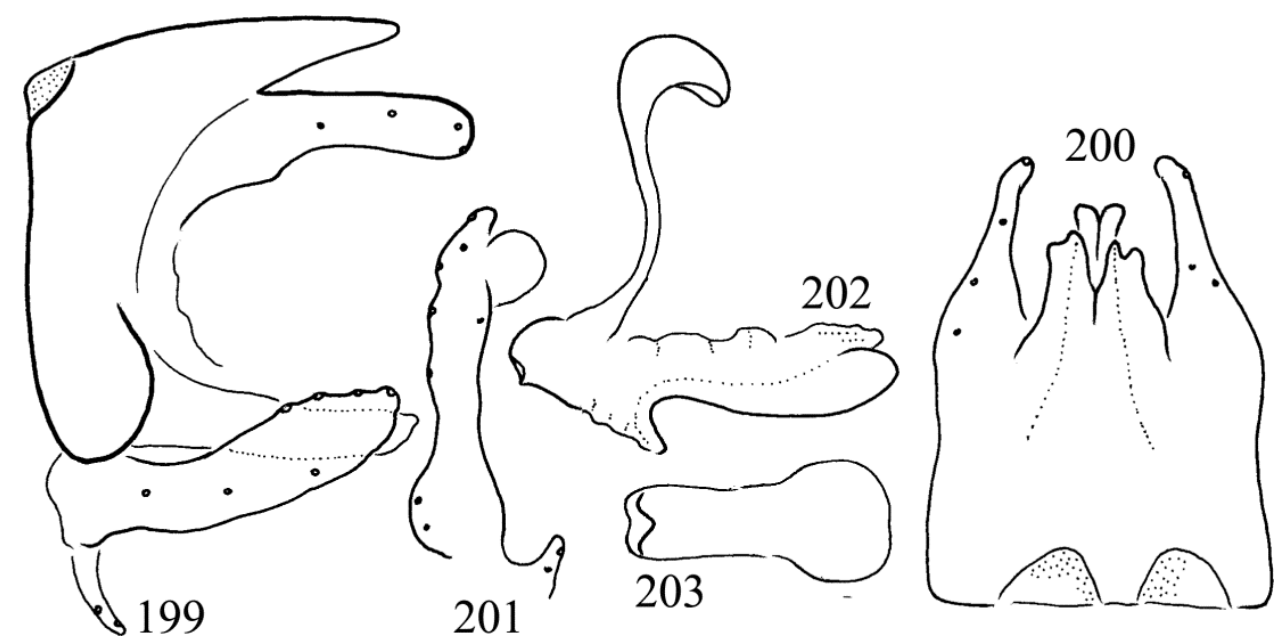

Figures 199-203. Nectopsyche padka sp. nov. Holotype: $199=$ male genitalia in left lateral view, $200=$ male genitalia in dorsal view, $201=$ left gonopod with apicomesal lobe in ventral perpendicular view; $202=$ phallic organ with the sigmoid profile of phallicata in lateral view; 203 = phallicata in ventral view.

cesses, the paraproct with blunt apex in dorsal view and rounded truncate in lateral view. Cerci un-forked, nearly parallel-sided with a ventral step or berm on middle position, that results in a broader basal half. Gonopods slightly arching upward while almost equal broad in lateral view; basoventral process long filiform; apicomesal lobe produced circular and mesad turning in ventral view, partially pegged on apical surface. Phallic organ indistinct, it seems articulating to the basomesal ridge of the gonopods; well discernible the pair of swan-necked dorsal phallothecal processes with enlarged and elongated downward directed head with a ventral concavity partially rugose; endothecal setal spines lacking; sigmoid lateral profile of the phallicata with short and low basal curve and gradually upward turning apical curve in lateral view; in ventral view the phallicata capitate posteriorly.

Etymology. padka, from ,padka” berm in Hungarian, refers to the step or berm like ventral pattern on middle of the cerci.

\section{Nectopsyche punctata (Ulmer, 1905)}

(Figures 204-206)

Leptocella punctata Ulmer, 1905: 75. "3 Exemplare (2ㅇ, $\left.1 \delta^{\Uparrow}\right)$ im Wiener Museum, bez. Rio Preto zwischen Boquerao und Sta Rita, Braz., Exped. Penther 1903.”
Leptocella fenestrata Banks, 1913: 237. „Type.-ô. From Lino, Panama, $800 \mathrm{~m}$. (Fassl). Flint 1966b: 9, to synonymy.

Leptocella spegazzinia Navas, 1920: 69. „Patria. Paraguay, por el rio Paraguay, febrero de 1920, Carlos Spegazzini (Col. Mia)." Flint 1981: 34, to synonymy.

Leptocella ambitiosa Navas, 1933: 118. „Patria. Santa Fe, 5. XII.1929, 6.III.1930. Bridarolli." Schmid, 1949: 386, to synonymy with N. mixta. Flint 1966: 9, to synonymy.

Leptocella Banks, 1899: 214: Flint 1974: 127, to synonymy with Nectopsyche.

Remarks. Compared to $N$. jenseni, the synonymies and the species status of $N$. punctata are even more uncertain. The published original drawings of $N$. punctata Ulmer (1905) is based on the single male type ("bez. Rio Preto zwischen Boquerao und Sta Rita, Braz."), but the drawings prepared by Flint (1966) from the same lectotype male are completely different. In these drawings we have presented only the periphallic structures of gross morphology: cerci, paraprocts and gonopods. Based only on the comparison of published drawings of the neutral, non-adaptive traits of gross morphology it is probable that the two drawings have been drawn from different animals or species. The dorsal view of the posterad produced tergite IX as well as the lateral view of the cerci, the gonopods and especially the paraprocts are completely different. The differences are not explainable by the different drawings styles. Re- 


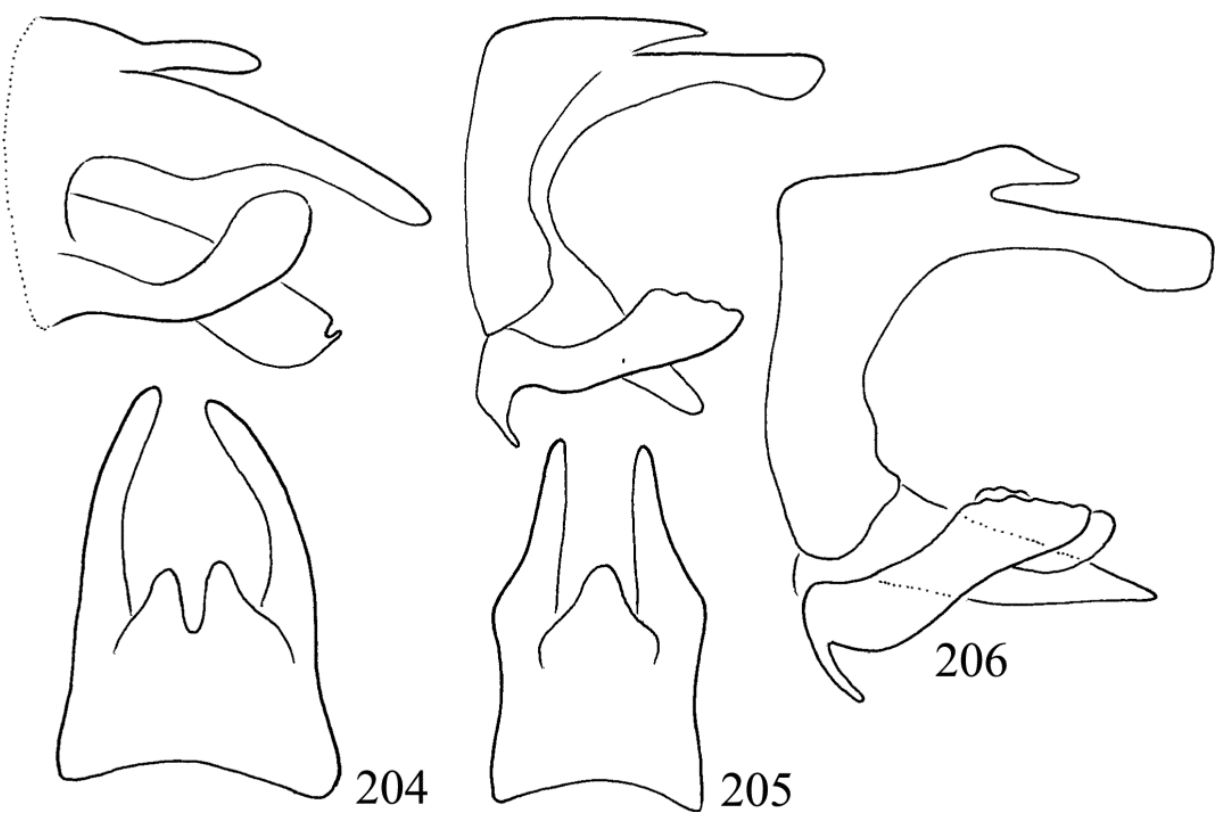

Figures 204-206. Nectopsyche punctata (Ulmer, 1905). Reconstruction of original drawings in lateral and dorsal view: $204=N$. punctata $($ Ulmer), 1905; $205=N$. punctata (Ulmer, 1905), drawn by Flint (1966); $206=N$. punctata $($ Ulmer, 1905), drawn by Flint (1981).

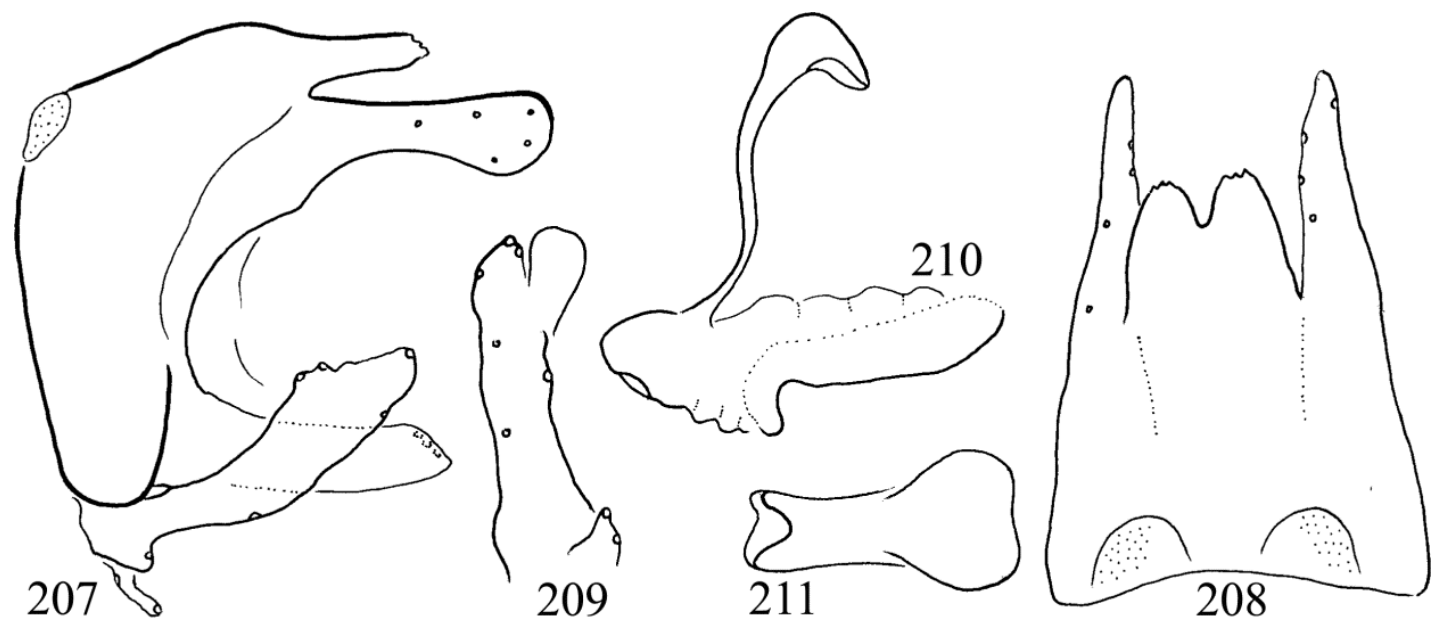

Figures 207-211. Nectopsyche vezna sp. nov. Holotype: $207=$ male genitalia in left lateral view, $208=$ male genitalia in dorsal view, $209=$ left gonopod with apicomesal lobe in ventral perpendicular view; $210=$ phallic organ with the sigmoid profile of phallicata in lateral view; 211 = phallicata in ventral view.

examination of the gross structures and examination of the speciation traits of the original type specimens on cleared genitalia are required to evaluate reliably the synonymies and the species status of $N$. punctata. Until this revision is realised we have to work with the original drawings of Ulmer, and it is clear that a number of species have been mixed under this name. 


\section{Nectopsyche vezna Oláh, Johanson \& Malm, sp. nov.}

(Figures 207-211)

Material examined. Holotype: Peru, San Martin Prov., Rio Mayo, 11 km (rd.) E Mayobamba, $6^{\circ} 04.989^{\prime} \mathrm{S}, 7^{\circ} 53.065^{\prime} \mathrm{W}$, light, loc. 06, 6.I.2009 leg. T. Malm \& K.A. Johanson (1 male, SMNH).

Diagnosis. This new species differs from all the other species in the group in the details of all the gross genital structures, although their range of variation is not known. There are well defined stable divergences in the shape of the speciation traits. The sigmoid profile characterized by right angled basal curve and the ventral form of phallicata is heart shaped. The apicomesal lobe of the gonopods are narrow, with rounded apical margin.

Description (in alcohol). This species has small eyes. Length of forewing is $11 \mathrm{~mm}$; forewing uniform and unicolor without any pattern on specimen stored in alcohol. The pterostigmal area enlarged and swollen. Maxillary palp formula (I,II,III,IV)-V. Tibial spur formula 0-2-2.

Male genitalia. Abdominal segment IX, medium-long, without sternum; its ventral ending, located at pivoting fulcrum of gonopods and phallic organ, rounded with braced margin; tergum IX much produced posterad, elongated slightly narrowing in lateral view; with shallow cleft in dorsal view; lateral lobes fringed truncate; pair of punctate acrotergite well separated. The superanal complex has no discernible dorsomesal process, the upper remnant of segment $X$; the deeply shifted pair of sclerotized horizontal lateral processes, the paraproct with blunt apex in dorsal view and rounded obliquely truncate in lateral view. Cerci un-forked, short and capitate with a ventral step or berm on middle position that result in a broader basal half. Gonopods slightly arching; basoventral process short; apicomesal lobe narrow with rounded apical margin, mesad turning in ventral view, partially pegged on apical surface. Phallic organ indistinct it seems articu- lating to the basomesal ridge of the gonopods; well discernible the pair of swan-necked dorsal phallothecal processes with enlarged and elongated downward directed head with a ventral concavity partially rugose; endothecal setal spines lacking; sigmoid lateral profile of the phallicata with right angled basal curve; in ventral view the phallicata heart-shaped.

Etymology. vezna, from „vézna” slim, thin in Hungarian, refers narrow apicomesal lobes of gonopods.

\section{Nectopsyche gemma species group}

The gemma section of the genus was originally established by Flint (1981) as species having metallic silvery scales and black eye-spots on forewing as well as forked cerci. This character combination for the Nectopsyche gemma species group was listed with detailed description of the forewing pattern and with giving two additional genitalic characters to the species group: basally broad gonopods and the phallic organ with several endothecal spines (Holzenthal 1995).

However, N. ortizi Holzenthal has gemma type forewing pattern, but no forked cerci and no spines in the endotheca. Without monophyly the group was treated only informally. Here we describe a new species $N$. eltera sp. nov. with typical gemma type genitalia of forked cerci, but with uniform and unicolor dark brown forewing densely packed with recumbent brown setae. This indicates the primacy of the ancestral divergence of the fork development on the cercal head accompanied by the ancestral development of the endothecal spines and to less stably the ancestral development of gonopod base enlargement. $\mathrm{Nec}$ topsyche ortizi Holzenthal is a member of the ancestral plesiomorphic Nectopsyche candida species group having no fork on cercal head, no endothecal spines and no base enlargement on the gonopods. Gemma type forewing pattern is present also in other members of the ancestral $N$. candida species group: exquisita, flavofasciata, flinti sp. nov. nigricapilla. 


\section{Nectopsyche argentata Flint, 1991}

(Figures 212-217)

Nectopsyche argentata Flint, 1991: 94-95. "Material-Holotype, male: Colombia, Dpto. Antioquia, Quebrada Honda, Marsella (12 km SW Fredonia) $1450 \mathrm{~m}, 3-4$ Mar. 1984, C. M. \& O. S. Flint, Jr. USNM Type.” Paratypes: from Costa Rica, Mexico and Venezuela.

Nectopsyche argentata Flint, 1991: 94: Holzenthal 1995: 6668 , diagnosis and redescription; figures 6, 14: not indicated, but drawn probably from material collected in Costa Rica. Examined and listed N. argentata specimens from Costa Rica, Mexico and Peru. Some paratypes from Costa Rica are re-described as a new species: N. utleyorum Holzenthal, 1995.

Remarks. This is again a species that probably represents a species complex of closely related incipient sibling species. In studies working on closely related incipient species it is strictly required to indicate the exact origin of the published drawings. It is not known exactly whether figures of $N$. argentata by Holzenthal (1995) was drawn from specimen collected in Costa Rica or from other material examined. The holotype of the true genuine $N$. argentata Flint, 1991 was collected in Antioquia, Colombia. The surrounding mountain ranges have their own closely related sibling species of the gemma group. It is unlikely that the drawn specimen, probably from Costa Rica, are identical with the holotype of $N$. argentata Flint collected near Fredonia of Antioquia, Colombia.

Based on the comparison of the published figures we suppose that the specimen drawn under the name $N$. argentata by Holzethal is not identical with the true $N$. argentata Flint species. The neutral periphallic organs have been diverged: dorsum IX, the cerci, the gonopods, the tip of superanal complex, that is the paraproct and especially the phallic organ are distinctly different. The speciation trait of the apicomesal lobe on the gonopods is diverged, rounded at the holotype of $N$. argentata Flint and truncate at Holzenthal's drawing. The sigmoid profile of the phallicata also clearly differs between the two species.

We suppose that the examined and listed specimens under Nectopsyche argentata by Holzethal (1995) collected from Costa Rica, Mexico and Peru may represent more undescribed incipient species.
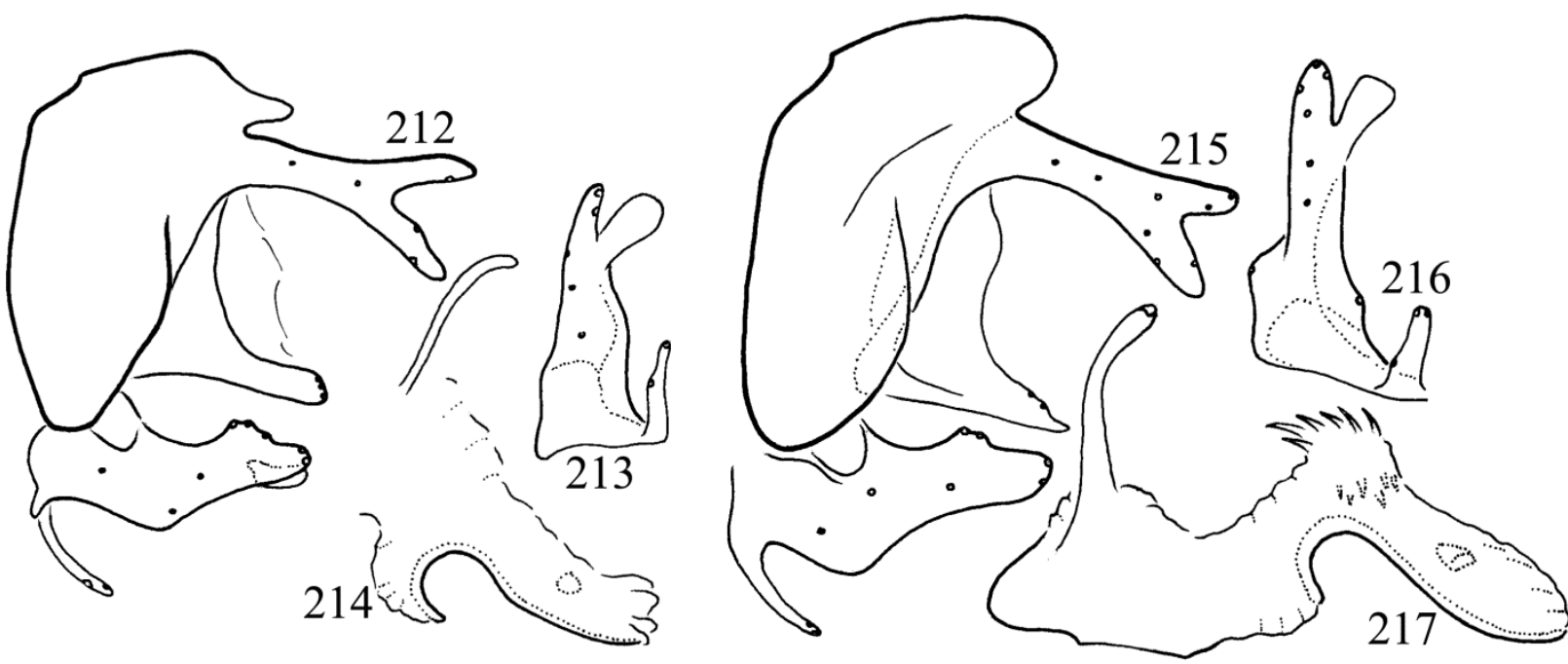

Figures 212-217. Nectopsyche argentata Flint, 1991. Reconstruction of original drawings. $212=$ male genitalia in left lateral view; 213 = left gonopod with apicomesal lobe in ventral perpendicular view; $214=$ phallic organ with the sigmoid profile of phallicata in lateral view. Holzenthal (1995): 215 = male genitalia in left lateral view; 216 = left gonopod with apicomesal lobe in ventral perpendicular view; $217=$ phallic organ with the sigmoid profile of phallicata in erected state in lateral view. 


\section{Nectopsyche bunka Oláh \& Oláh, sp. nov.}

(Figures 218-223)

Material examined. Holotype, Colombia, West Andes, West Slope, Tatama National Park, El Cairo, 11.III.2011, light trap, leg. J. Oláh jr. (1 male, OPC). Paratypes: same as holotype (2 males, OPC). Peru: Huanuco, stream at Carpish, $2500 \mathrm{~m}$, 76 $09^{\circ} \mathrm{W}, 9^{\circ} 40^{\prime} \mathrm{S}, 28$.VI.-3.VII.2005, Malaise trap, leg. F.M. Carlos. (2 males, 3 females NRM; 1 male, 2 females, OPC). Huanuco, stream at Chinchao, $2200 \mathrm{~m}, 76^{\circ} 00^{\prime} \mathrm{W}, 9^{\circ} 66^{\prime} \mathrm{S}, 18-26 . \mathrm{VI}$. 2005, Malaise trap, leg. F.M. Carlos. (3 males, SMNH; 2 males, OPC).

Diagnosis. This species belongs to the Nectopsyche gemma group with distinct eye-spots on the forewings visible also in alcohol. Nectopsyche bunka sp. nov. is closest to N. argentata Flint, described from Colombia (holotype) but differs by having ventral ending of segment IX quadratic, not tapering, ventral arm of the forked head of the cerci more developed, especially its venrobasal region. However, these periphallic neutral nonadaptive structures are more liable to variation, although these divergences are similar at the twelve males available for variability examina- tion. The apicomesal lobe on the gonopods that is the fused harpago is definitely clavate, not spatulate, but the basal constriction may vary, there are specimens with weak basal constriction. Most important divergences are fixed in the phallic organ. The sigmoid lateral profile of the phallicata is highly diverged from the holotype of $N$. argentata and is very stable even in remote populations sampled in Ecuador and Peru. All the males both from Ecuador and Peru have elongated sigmoid profile with small basal curve. The setal structure of the endotheca integrated in completely different pattern and seems also stable. It is represented by a simple band of small spines at $N$. argentata Flint, but at $N$. bunka sp. nov. the endothecal setal pattern is more complex composed of 4 very specific cup-based stout spines, and a group of spines of argentata type. This spine pattern in the aedeagus is surprisingly stable at all the examined 3 specimens from Colombia and 5 specimens from Peru.

Description (in alcohol). This species has small eyes. Length of forewing $9 \mathrm{~mm}$, with gemma-type forewing pattern as visible on specimens stored in alcohol. Maxillary palp formula IV-(I,II,III)-V. Tibial spur formula 0-2-2.

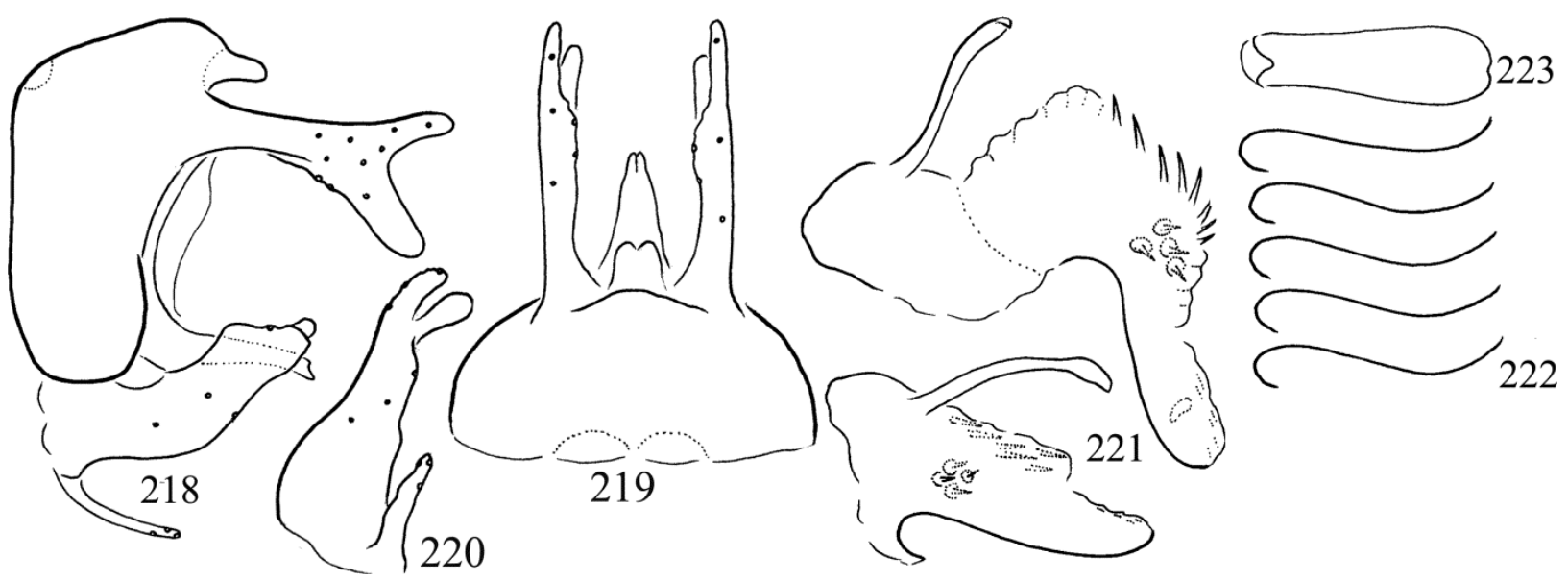

Figures 218-223. Nectopsyche bunka sp. nov. Holotype: $218=$ male genitalia in left lateral view, $219=$ male genitalia in dorsal view, 220 = left gonopod with apicomesal lobe in ventral perpendicular view; 221 = phallic organ with the sigmoid profile of phallicata in lateral view, in everted and inverted states; 222 = sigmoid profile of five specimens: first two from Ecuador population, last three from Peru population; 223 = phallicata in ventral view. 
Male genitalia. Abdominal segment IX without sternum; its ventral ending located at pivoting fulcrum quadrangular with braced margin; tergum IX rounded both in lateral and dorsal view. The superanal complex has the less sclerotized horizontal short dorsomesal process, remnant of segment $\mathrm{X}$ bifid, slightly asymmetric and visible as the continuation of tergum IX; the deeply shifted sclerotized horizontal lateral processes, the paraproct is narrow pointing in dorsal view and obliquely truncate in lateral view. Cerci forked, ventral arm with more developed basoventral region and with glabrous shining apical part without any cuticular outgrowths. Gonopods arching upward while almost equal broad in lateral view; basoventral process long filiform; apicomesal lobe clavate with constricted basal shaft; apicomesal lobe pegged on apical surface and supplied with 2 setae ventrolaterad. Phallic organ is indistinct, it seems articulating to the basomesal ridge of the gonopods. Well discernible the pair of swannecked dorsal phallothecal processes with laterad pointing, slightly clavate and rugose head, and the endothecal setal pattern composed of 4 very specific cup-based short but stout spines, and a bunch of several straight or slightly curved spines; ventral profile of the phallicata slight sigmoid.

Etymology. bunka, from „bunkó, bunkós” clavate in Hungarian, refers to the apicomesal lobe on the gonopods with constricted basal stem and clavate apicad rounding apex in ventral perpendicular view.

\section{Nectopsyche eltera Oláh \& Oláh, sp. nov.}

(Figures 224-228)

Material examined. Holotype, Colombia, Dusky Starfrontlet Bird Reserve, Cordillera Occidental, Urrao, Antioquia, 6 $6^{\circ} 6^{\prime} 10.8^{\prime \prime} \mathrm{N}, 76^{\circ} 5^{\prime} 25.15^{\prime} \mathrm{W}$, 8.II.2014, caught by hand, leg. A.G. Duff (1 male, OPC).

Diagnosis. This is a unique species, with unusual combination of forewing pattern and genitalic structures. The relationship of this species is obscure. The forked cerci and endotheca with several spines relate this species to the Nectopsyche gemma group but without eye-spots and even without any pattern visible in alcohol. According to the collector the homogenous, unicolor dark forewing was distinct on the freshly collected intact forewing and this is confirmed by the evenly dense setal cover of dark uniform and unicolor recumbent hairs.

Description (in alcohol). This species has small eyes. Length of forewing $10 \mathrm{~mm}$; forewing uniform and unicolor without gemma-type pattern as visible on specimens stored in alcohol. Maxillary palp formula (I,IV)-(II,III)-V. Tibial spur formula 0-2-2.

Male genitalia. Abdominal segment IX without sternum; its ventral ending, located at pivoting fulcrum of gonopods and phallic organ, slightly narrowing with braced margin; tergum IX produced posterad narrowing in dorsal view. The superanal complex has the less sclerotized horizontal medium-long dorsomesal process, the upper remnant of segment $\mathrm{X}$ slightly bifid in dorsal view, and visible as the continuation of tergum IX; the deeply shifted sclerotized horizontal lateral processes, the paraproct narrow pointing in dorsal view and obliquely truncate in lateral view. Cerci forked, dorsal and ventral arms highly different; ventral arm with more developed basoventral region and with pointing apical part. Gonopods slightly arching upward while almost equal broad in lateral view; basoventral process long stout filiform; apicomesal lobe produced truncate and mesad turning in ventral view pegged on apical surface. Phallic organ indistinct, it seems articulating to the basomesal ridge of the gonopods. Well discernible the pair of swannecked dorsal phallothecal processes with laterad pointing, slightly clavate and rugose head, and the endothecal setal pattern composed of 6 very specific cup-based short but stout spines, and a bunch of several straight or slightly curved spines; lateral profile of the phallicata is straight with strongly posterad turning basal curve.

Etymology. eltera, from „eltérö" different in Hungarian, refers to the forked apex of cerci, the ventral arm is pointed, not with rounded tip like the dorsal arm; pointed ventral arm is unique in the gemma group characterized by forked apex of cerci. 


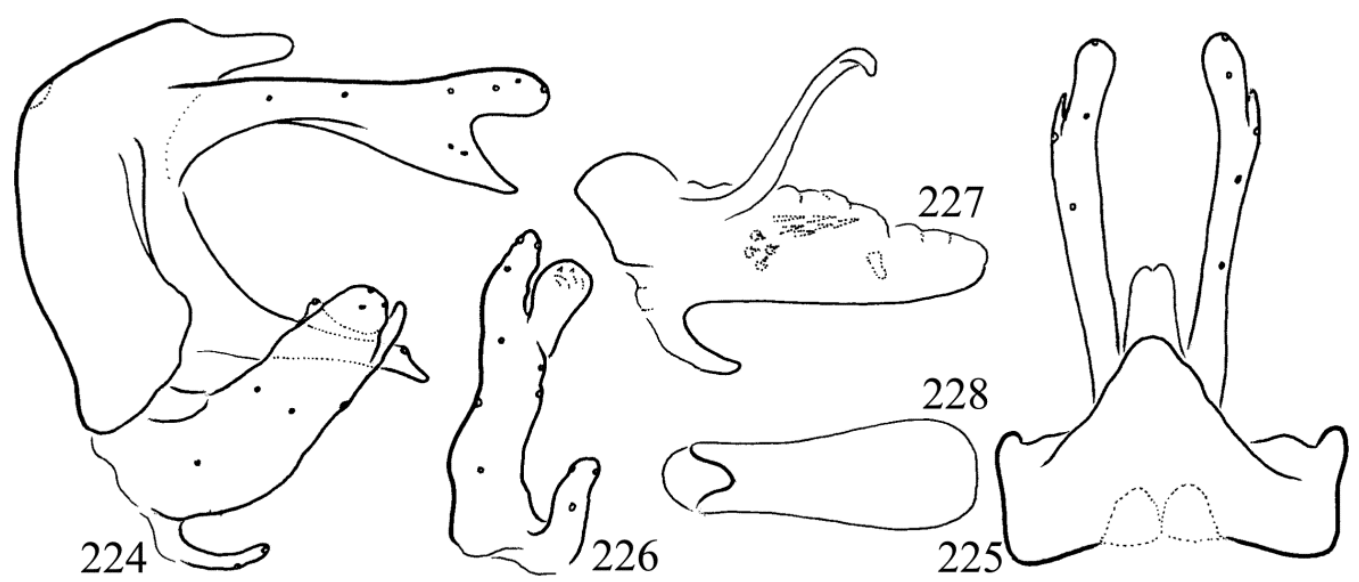

Figures 224-228. Nectopsyche eltera sp. nov. Holotype: $224=$ male genitalia in left lateral view, $225=$ male genitalia in dorsal view, 226 = left gonopod with apicomesal lobe in ventral perpendicular view; 227 = phallic organ with the sigmoid profile of phallicata in lateral view; $228=$ phallicata in ventral view.
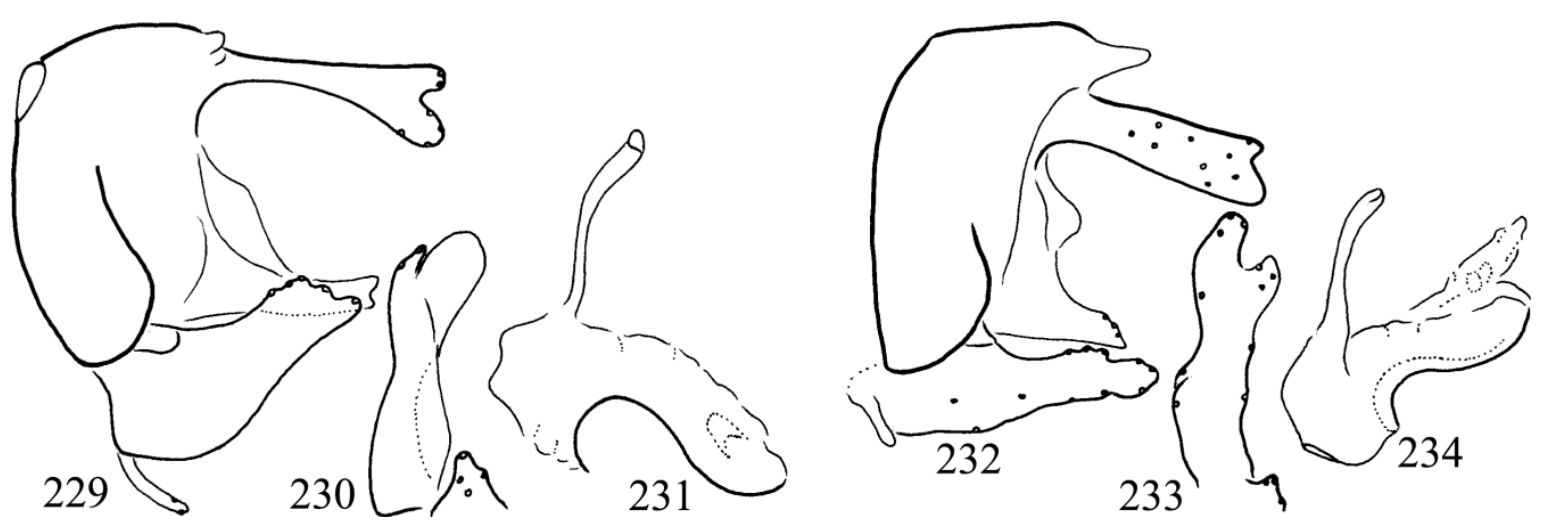

Figures 229-234. Nectopsyche flintorum sp. nov. Reconstruction of original drawingsby Flint (1991): Holotype $229=$ male genitalia in left lateral view; $230=$ left gonopod with apicomesal lobe in ventral perpendicular vie; $231=$ phallic organ with the sigmoid profile of phallicata in lateral view. Compared with Holzenthal (1995): $232=$ male genitalia in left lateral view; 233 = left gonopod with apicomesal lobe in ventral perpendicular view; $234=$ phallic organ with the sigmoid profile of phallicata in lateral view.

Nectopsyche flintorum Oláh \& Oláh, sp. nov.

(Figures 229-234)

Nectopsyche sp. Flint 1991: 95. "Material. - Colombia, Dpto. Antioquia: Quebrada La Cebolla, El Retiro (trap A), 21 May-1 Dec 1983, U. Matthias, 1§, 4우. Quebrada La Ayurá, Envigado (trap B), 6 Aug 1983, U. Matthias, 1 đ’".

Nectopsyche exophthalma Holzenthal, 1995:68-69. "This is probably the species mentioned by Flint (1991) from Antioquia, Colombia." Nectosyche sp. of Flint drawn from Colombia is not identical with $N$. exophthalma Holzenthal described and drawn probably from Costa Rica. Misidentification!
Diagnosis and description. Flint (1991) has characterised this species as the third one of the gemma group from Antioquia, Colombia easily recognised by males having very large eyes and male genitalia also differ from that of the other two species: $N$. argentata and $N$. gemma. Lacking pinned male in good condition that is without the knowledge of intact forewing pattern he preferred to leave the species unnamed. Holzenthal (1995) has described $N$. exophthalma from Costa Rica also with large eyes and stated its probable identity with Flint's Nectopsyche species with large 
eyes from Colombia. However, according to the genitalia the $N$. exophthalma Holzenthal, 1995 described from Costa Rica and the Nectopsyche sp. Flint (1991) reported from Colombia represent two independent species. Based on the single male specimen deposited in USNM here we describe Nectopsyche sp. from Colombia as a new species Nectopsyche flintorum sp. nov.

Relying on the original descriptions and on the excellent drawings both of Flint's species from Colombia and of Holzenthal's species from Costa Rica we recorded sufficient species level divergences to distinguish these two species based both on neutral periphallic organs and on adaptive speciation traits. Nectopsyche flintorum sp. nov. has cerci deeply forked, not shallowly forked; paraproct long, not short; paraproct tip truncate pointing dorsad, not pointing ventrad; apicomesal lobe on gonopod large rounded, not small triangular. The most stable speciation trait, the sigmoid lateral profile of the ventral margin of the phallicata is completely different.

Etymology. We named this species in honour of Oliver Flint and his family who has first reported it with excellent drawings.

\section{Nectopsyche gemmoides Flint, 1981}

Material examined. Mexico, State of Veracruz, Los Tuxtlas area, Rio la Palma, near to the Estacion the Biologia Los Tuxtlas, $18^{\circ} 33.680^{\prime} \mathrm{N}$, 9502.943'W, 30 mao, 26.VI.2006, light Trap, leg. M. Espeland \& T. Malm (3 males, 5 females; SMNH; 3 males, 2 females; OPC).

Remarks. This is again a species that probably represents a species complex of closely related incipient sibling species. The speciation traits of apicomesal lobe of gonopods and the sigmoid profile of the phallicata on the six males of our Mexican population exhibit significant divergences compared to the type drawings from Venezuela (Flint 1981), to Holzenthal's (1995) drawings probably from Costa Rica and to the Botosaneanu (1993) drawings of $N$. cupreosqamosa from Trinidad synonymised with $N$. gemmoides by
Flint (1996). In the examined Mexican population the apicomesal lobe of gonopods exhibited a rather large range of shape variations. At the same time the sigmoid profile of the phallicata was very stable. We think that specimens identified and listed under the name of Nectopsyche gemmoides from Brazil, Colombia, Costa Rica, Ecuador, Guatemala, Guyana, Mexico, Nicaragua, Panama, Paraguay, Peru, Trinidad and Venezuela definitely represent several independent sibling species. It requires a detailed population study of samples from the listed countries on speciation traits to delineate these incipient phylogenetic species.

\section{Nectopsyche huzva Oláh, Johanson \& Malm, sp. nov.}

(Figures 235-240)

Material examined. Holotype, Holotype, Bolivia, Tarija Dept. Alarache la Mamorra, El Baden, 22.20661 ${ }^{\circ} \mathrm{S}, 64.61536^{\circ} \mathrm{W}, 1106$ mas, 12.XI.2013, light trap, ID \#NHRS-BOL13-14, leg. N. Apelqvist, J. Jonsson \& V. Sossa, Export permit: SENASAG No 019471 (1 male, SMNH). Paratypes: same as holotype (104 males, 42 females, SMNH; 39 males, 12 females; OPC).

Diagnosis. This species belongs to the Nectopsyche gemma group with distinct eye-spots visible also in alcohol and is closest to $N$. gemma neotype, redescribed from Brazil, but differs both by neutral and adaptive traits. Neutral traits: tergum IX elongated; formation of the cercal fork diverged. Adaptive traits: paraproct more tapering, its vertical less sclerotized connecting structure with a pronounced angle midway; apicomesal lobe of gonopod broad, not elongated; sigmoid profile of the phallicata elongated with less produced apical curve. This specific pattern of the sigmoid profile is very stable in the examined population.

Description (in alcohol). This species has small eyes. Length of forewing $10 \mathrm{~mm}$, with gem$m a$-type forewing pattern as visible on specimens stored in alcohol. Maxillary palp formula (I,II,IV)-III-V. Tibial spur formula 0-2-2. 


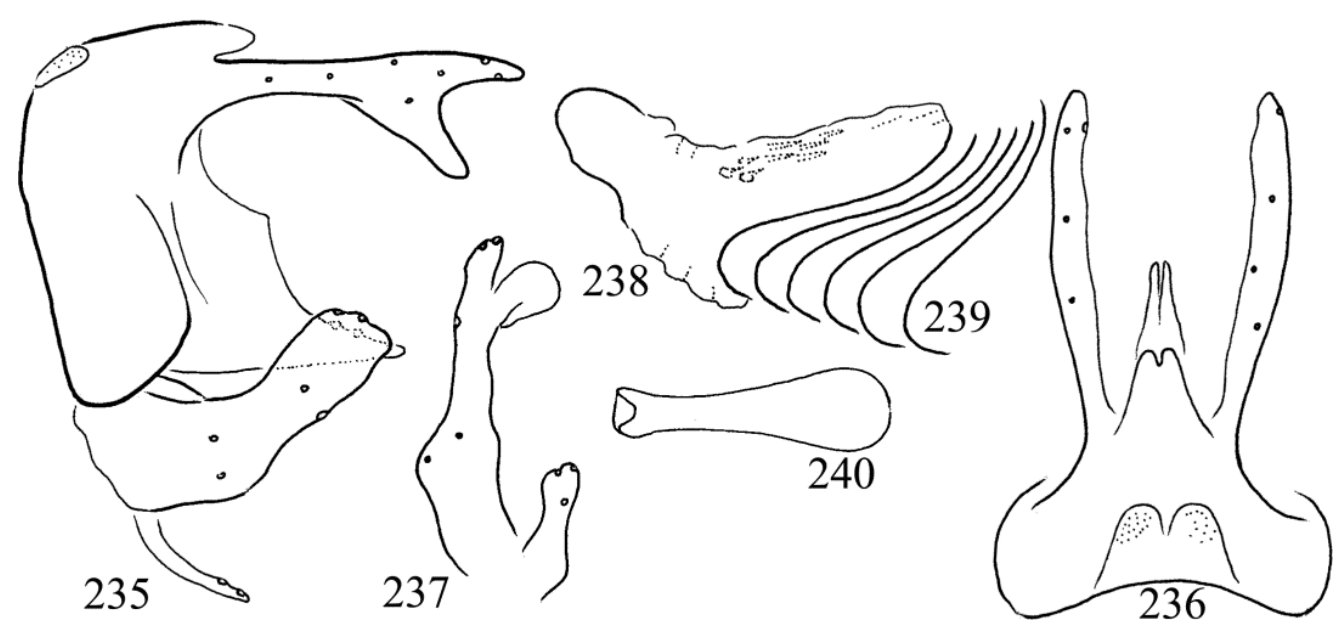

Figures 235-240. Nectopsyche huzva sp. nov. Holotype: $235=$ male genitalia in left lateral view, $236=$ male genitalia in dorsal view, 237 = left gonopod with apicomesal lobe in ventral perpendicular view; $238=$ phallic organ with the sigmoid profile of phallicata in lateral view; $239=$ sigmoid profile of five specimens from the same population; $240=$ phallicata in ventral view.

Male genitalia. Abdominal segment IX without sternum; its ventral ending, located at pivoting fulcrum, rounded with braced margin; tergum IX elongated, bifid posterad. The superanal complex has no well-discernible horizontal dorsomesal process, remnant of segment $\mathrm{X}$ as the continuation of tergum IX; the vertical less sclerotized connecting structure with a pronounced angle midway; the deeply shifted sclerotized horizontal lateral processes, the paraproct is narrow pointing in lateral view. Cerci forked, ventral arm with more developed basoventral region and with glabrous shining apical part without any cuticular outgrowths. Gonopods slightly arching upward, while almost equal broad in lateral view; basoventral process long filiform; apicomesal lobe large, broad with rounded apical margin. Phallic organ indistinct, it seems articulating to the basomesal ridge of the gonopods, without any swannecked dorsal phallothecal processes; the endothecal setal pattern composed of short but stout spines as well as with very specific cup-based short but stout spines; ventral profile of the phallicata with elongated apical curve.

Etymology. huzva, from „húzva” drawn, pulling in Hungarian, refers to the elongated apical curve of the sigmoid profile of the phallicata.

\section{Nectopsyche iva Oláh, Johanson \& Malm sp. nov.}

(Figures 241-246)

Material examined. Holotype, Peru: Yauyos Province, Dep Lima, River Yauyos, $410 \mathrm{~m}, 11^{\circ}$ 46'19''S, 75'29'58' 'W, 19.III.2006, light trap, leg. J.C. Lopez \& F.M. Carlos, (1 male, SMNH). Paratypes: same as holotype (6 males, 10 associated females, SMNH; 5 males, 5 females, OPC). Yauyos Province, Dep Lima, River Yauyos, 3410

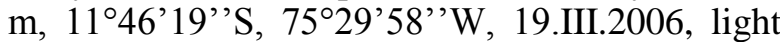
trap, leg. J.C. Lopez \& F.M. Carlos, (1 male, SMNH). Canta Province, Dep Lima, River Chillon Obrajillo, $2800 \mathrm{~m}, 11^{\circ} 28^{\prime} 25^{\prime}$ 'S, $76^{\circ} 37^{\prime} 27^{\prime}$ ' $\mathrm{W}$, III.2006, light trap, leg. J.C. Lopez \& F.M. Carlos (12 males, 2 females, SMNH; 6 males, 1 female; OPC)

Diagnosis. This beautiful new large-sized species belongs to the $N$. gemma species complex of the $N$. gemma species group without swan-neck shaped phallothecal dorsal process. Most close to $N$. kajla sp. nov. but differs from it first by its double size, the arc-shaped apicomesal lobe not turning mesad; the sigmoid profile of the phallicata less curved basad and more curved apicad. The basoventral lobes are highly variable by the 


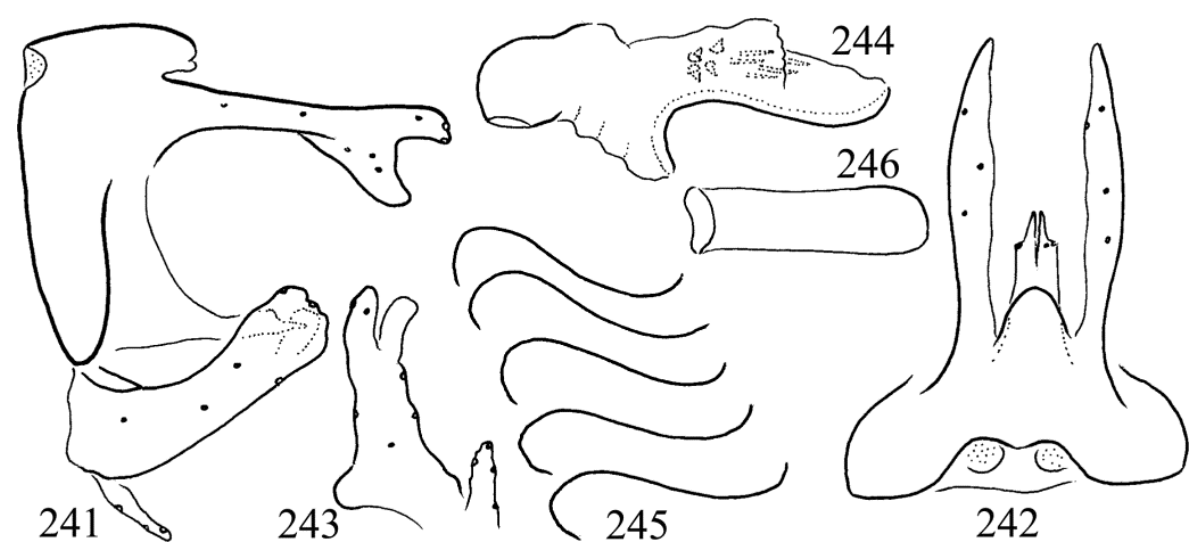

Figures 241-246. Nectopsyche iva sp. nov. Holotype: 241 = male genitalia in left lateral view, $242=$ male genitalia in dorsal view, 243 = left gonopod with apicomesal lobe in ventral perpendicular view; $244=$ phallic organ with the sigmoid profile of phallicata in lateral view; $245=$ sigmoid profile of five specimens from the same population; 246 = phallicata in ventral view.

produced alveoli; the apicomesal lobe has detectable range of variation, but the sigmoid profile is stable at all of the examined paratypes.

Description (in alcohol). This species has small eyes and large body. Length of forewing 10 $\mathrm{mm}$; forewing with gemma-type membrane pattern well visible on all specimens stored in alcohol. Maxillary palp formula IV-(I,II,III)-V. Tibial spur formula 0-2-2.

Male genitalia. Abdominal segment IX very short, without sternum; its ventral ending, located at pivoting fulcrum of gonopods and phallic organ, tapering with braced margin; tergum IX less produced and monolobed in dorsal view. The superanal complex present with the deeply shifted sclerotized horizontal lateral processes, the paraproct with subapical humps of small shoulder. Cerci with almost straight dorsum and forked apex; dorsal and ventral arms are different; dorsal arm straight continuation of the shaft, truncate; ventral arm ventrad directed, more developed and glabrous without cuticular outgrowths but with a sensory setae present. Gonopods with rounded apex; basoventral process elongated digitiform; apicomesal lobe slightly arching mesad in ventral view pegged on apical surface. Phallic organ is indistinct; it seems articulating to the basomesal ridge of the gonopods. Well discernible is the endothecal setal pattern composed of several long spines and 4-5 cup-based short and stout spines; lateral sigmoid profile of the phallicata is with a regular basal curve and more produced apical curve.

Etymology. iva, from „ív” arc in Hungarian, refers to the shape of apicomesal lobe on the gonopods having an arching pattern.

\section{Nectopsyche kajla Oláh, Johanson \& Malm, sp. nov.}

(Figures 247-250)

Material examined. Holotype, French Guiana: Approuaguekaw: Kaw Mtn., $104 \mathrm{~m}, 4^{\circ} 33.035^{\prime} \mathrm{N}$, $52^{\circ} 11.661^{\prime} \mathrm{W}$, Malaise trap, 23.I.-7.II.2007, FRG MF3 leg. N. Jönsson (1 male, SMNH).

Diagnosis. This new species belongs to the $N$. gemma species complex of the $N$. gemma species group without swan-neck shaped phallothecal dorsal process and with broad elongated basoventral process of the gonopods. Most close to $N$. tomora sp. nov. but differs by the mesad turned apicomesal lobe, not fan-shaped; by the broad digitiform basoventral process on the gonopods.

Description (in alcohol). This species has small eyes and small body. Length of forewing 5 $\mathrm{mm}$; forewing with scattered black scales; the gemma-type pattern is not discernible on the single specimen stored in alcohol; forewing mem 


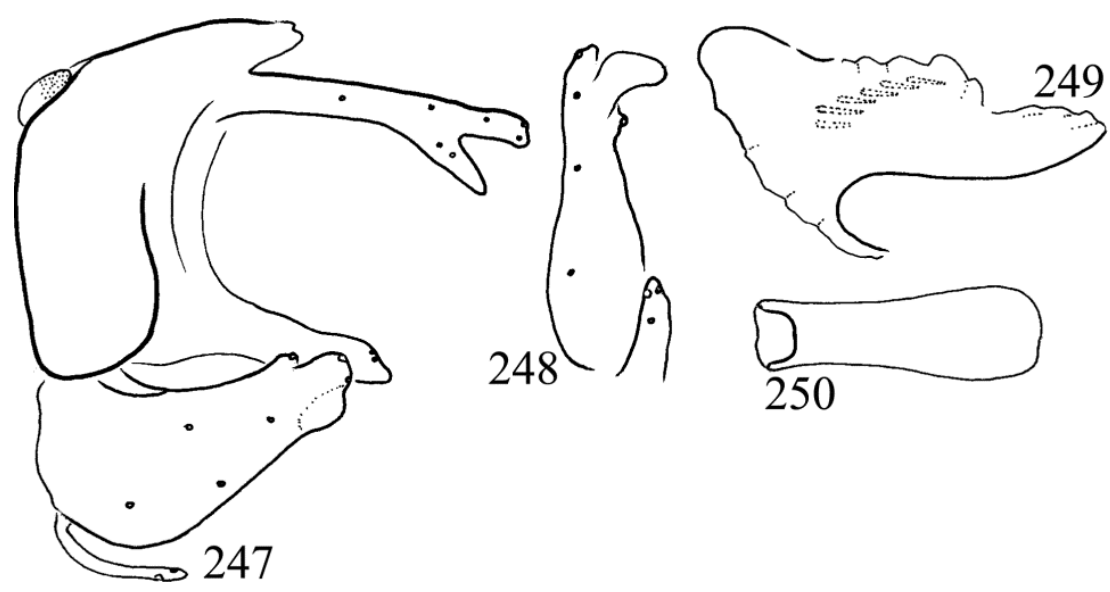

Figures 247-250. Nectopsyche kajla sp. nov. Holotype: $247=$ male genitalia in left lateral view, 248 = left gonopod with apicomesal lobe in ventral perpendicular view; $249=$ phallic organ with the sigmoid profile of phallicata in lateral view; $250=$ phallicata in ventral view.

brane unicoloured, without any pattern. Maxillary palp formula (I,II,III,IV)-V. Tibial spur formula $0-2-2$.

Male genitalia. Abdominal segment IX without sternum; its ventral ending, located at pivoting fulcrum of gonopods and phallic organ, rounded with braced margin; tergum IX produced and gradually narrowing posterad in dorsal view, with bifid apex in dorsal view. The superanal complex present with the deeply shifted sclerotized horizontal lateral processes, the paraproct with obliquely truncate apex in lateral view. Cerci with almost straight dorsum and forked apex; dorsal and ventral arms different; dorsal arm straight continuation of the shaft, truncate; ventral arm ventrad directed, glabrous without cuticular outgrowths but with a few sensory setae. Gonopods with patterned apex and broad basoventrally in lateral view; basoventral process elongated broad digitiform; apicomesal lobe turning mesad in ventral view pegged on apical surface. Phallic organ indistinct; it seems articulating to the basomesal ridge of the gonopods. Well discernible the endothecal setal pattern composed of several long spines; lateral sigmoid profile of the phallicata is with a regular half-circular basal curve and less produced apical curve.

Etymology. kajla, from „kajla” bending downward in Hungarian, refers to the shape of apicomesal lobe on the gonopods having mesad and downward produced pattern.

\section{Nectopsyche nilta Oláh, Johanson \& Malm, sp. nov.}

(Figures 251-255)

Material examined. Holotype, Holotype, Bolivia, Tarija Dept. Alarache la Mamorra, El Baden, 22.20661 ${ }^{\circ} \mathrm{S}, 64.61536^{\circ} \mathrm{W}, 1106$ mas, 12.XI.2013, light trap, ID \#NHRS-BOL13-14, leg. N. Apelqvist, J. Jonsson \& V. Sossa, Export permit: SENASAG No 019471 (1 male, SMNH).

Diagnosis. This species belongs to the Nectopsyche gemma group with distinct eye-spots visible also in alcohol and is closest to $N$. argentata Flint, described from Colombia (holotype), but differs both by neutral and adaptive traits. Neutral traits: ventral arm of the cercal fork is more robust, gonopods with less produced ventral angle. Adaptive traits: paraproct more tapering, dorsal process of the phallotheca stout, not slim, apicomesal lobe of gonopod bigger, sigmoid profile of the phallicata differs by open basal curve.

Description (in alcohol). This species has small eyes. Length of forewing $11 \mathrm{~mm}$, with gem$m a$-type forewing pattern as visible on specimens stored in alcohol. Maxillary palp formula (I,II,IV)-III-V. Tibial spur formula 0-2-2.

Male genitalia. Abdominal segment IX without sternum; its ventral ending located at pivoting fulcrum is rounded with braced margin; tergum 


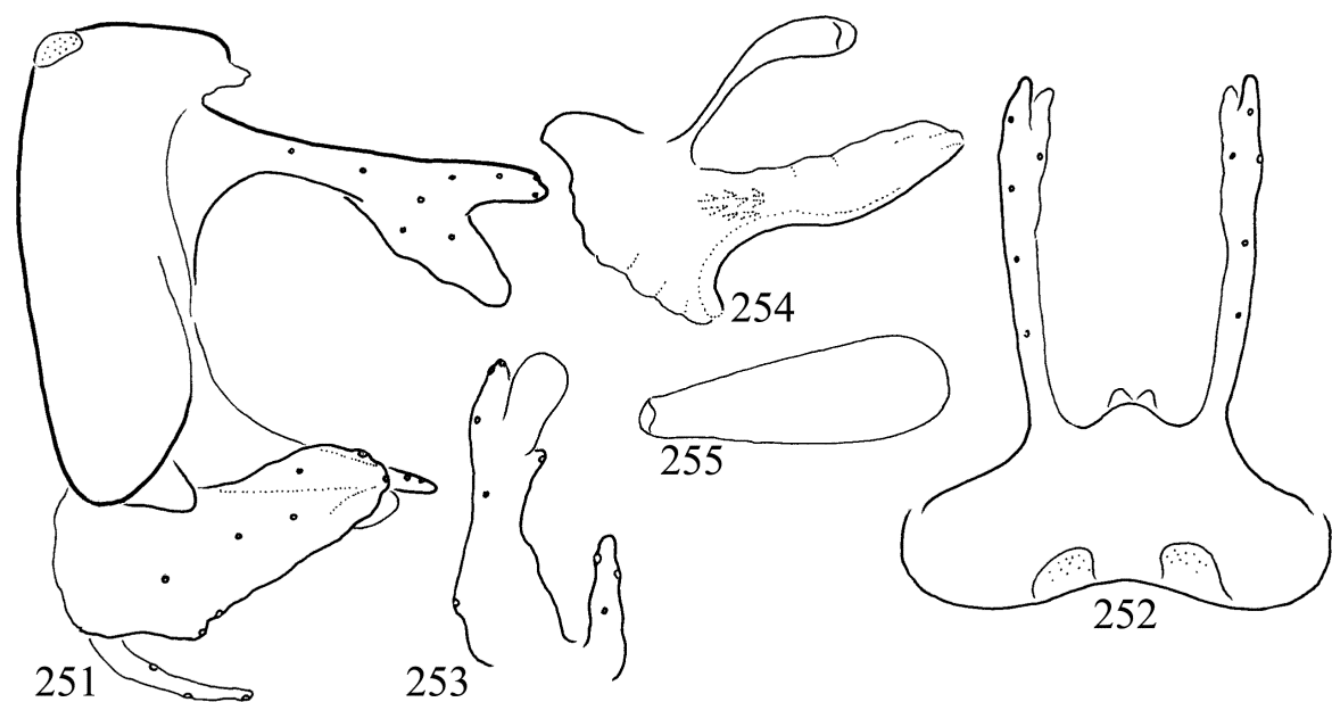

Figures 251-255. Nectopsyche nilta sp. nov. Holotype: 251 = male genitalia in left lateral view, $252=$ male genitalia in dorsal view, 253 = left gonopod with apicomesal lobe in ventral perpendicular view; 254 = phallic organ with the sigmoid profile of phallicata in lateral view; $255=$ phallicata in ventral view.

IX rounded both in lateral and dorsal view. The superanal complex has the less sclerotized horizontal short dorsomesal process, remnant of segment $\mathrm{X}$ bifid, slightly asymmetric and visible as the continuation of tergum IX; the deeply shifted sclerotized horizontal lateral processes the paraproct narrow pointing in lateral view. Cerci forked, ventral arm with more developed basoventral region and with glabrous shining apical part without any cuticular outgrowths. Gonopods slightly arching upward while almost equal broad in lateral view; basoventral process long filiform; apicomesal lobe large, almost parallel-sided with rounded apical margin; apicomesal lobe pegged on apical surface and supplied with 2 setae ventrolaterad. Phallic organ indistinct, it seems articulating to the basomesal ridge of the gonopods. Well discernible the pair of swan-necked dorsal phallothecal processes with laterad turning clavate and rugose head, and the endothecal setal pattern composed of short but stout spines; ventral profile of the phallicata slight sigmoid.

Etymology. nilta, from „nyilt” open in Hungarian, refers to the open basal curve of the sigmoid profile of the phallicata.

\section{Nectopsyche pohoka Oláh, Johanson \& Malm, sp. nov.}

(Figures 256-260)

Material examined. Holotype, Peru, San Martin Prov., La Catarata de Ahuashiyascu, 6 $6^{\circ} 27.544$ ' S, $76^{\circ} 18.192^{\prime} \mathrm{W}$, light, loc. 07, 7.I.2009 leg. T. Malm \& K.A. Johanson (1 male, SMNH).

Diagnosis. The forked cerci and endotheca with spines as well as its forewing pattern relate this species to the Nectopsyche gemma group. Most close to $N$. flintorum sp. nov. but differs both by neutral and adaptive genitalic traits. Neutral traits: cerci downward bending, not with straight dorsum; gonopods straight truncate, not with obliquely truncated apical margin, ventrobasal process of gonopods digitate, not triangular in ventral view. Adaptive traits: paraproct apical tip with ventral corner, not more developed dorsal corner in lateral view; apicomesal lobe of gonopods broad bellied, not elongated; sigmoid profile of the phallicata longer, less developed apical curve.

Description. (in alcohol). This species has large eyes. Length of forewing $7 \mathrm{~mm}$; forewing 


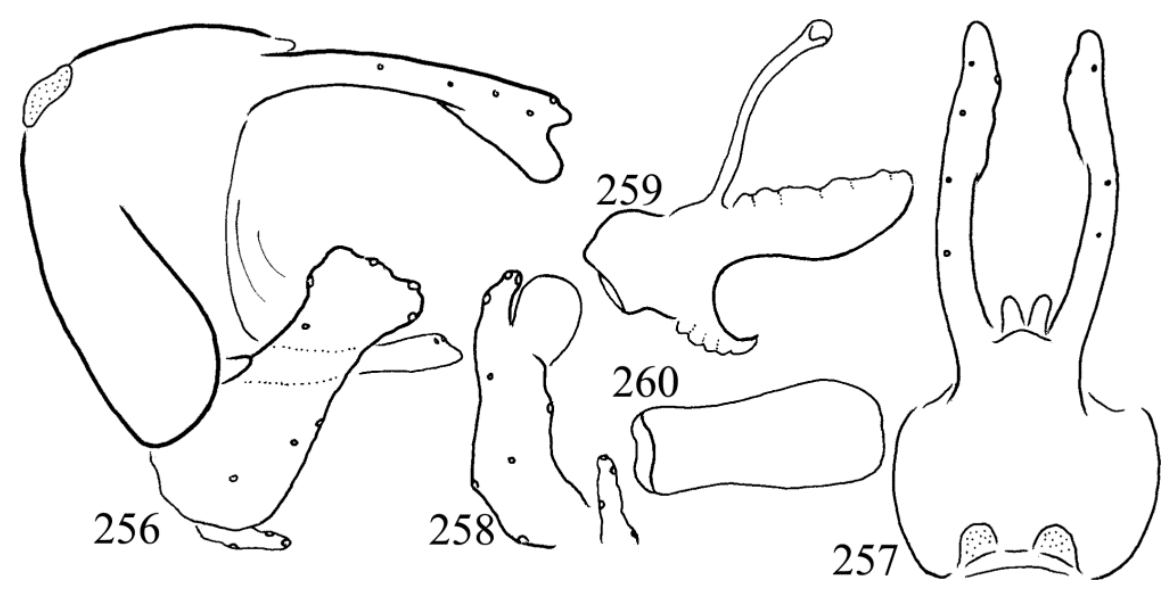

Figures 256-260. Nectopsyche pohoka sp. nov. Holotype: $256=$ male genitalia in left lateral view, $257=$ male genitalia in dorsal view, 258 = left gonopod with apicomesal lobe in ventral perpendicular view; $259=$ phallic organ with the sigmoid profile of phallicata in lateral view; $260=$ phallicata in ventral view.

with gemma-type pattern with eye-spot as visible on specimens stored in alcohol. Maxillary palp formula IV-(I,II,III)-V. Tibial spur formula 0-2-2.

Male genitalia. Abdominal segment IX without sternum; its ventral ending, located at pivoting fulcrum of gonopods and phallic organ, slightly narrowing with braced margin; tergum IX less produced posterad. The superanal complex has the less sclerotized horizontal short dorsomesal process, the upper remnant of segment $\mathrm{X}$ bifid in dorsal view, visible as the continuation of tergum IX; the deeply shifted sclerotized horizontal lateral processes, the paraproct narrow pointing in dorsal view and obliquely truncate in lateral view. Cerci forked, dorsal and ventral arms different; dorsal arm vestigial; ventral arm with more developed basoventral region. Gonopods straight with straight truncate slightly dilated apical margin; basoventral process long filiform; apicomesal lobe rounded broad. Phallic organ indistinct it seems articulating to the basomesal ridge of the gonopods. Well discernible the pair of swannecked dorsal phallothecal processes with laterad pointing, slightly clavate and rugose head, sign of endothecal spines discernible only even with large magnification; lateral profile of the phallicata is with large, strongly posterad turning basal curve.

Etymology. pohoka, from ,pohók” bellied, paunchy in Hungarian, refers to the short and broad apicomesal lobe on the gonopods.

\section{Nectopsyche setfela Oláh, Johanson \& Malm, sp. nov.}

(Figures 261-266)

Material examined. Holotype, Peru: San Martin Prov., creek crossing rd. Juan Guerra-Chazuta, $14 \mathrm{~km}$ (rd.) E Colombia Bridge, 6 ${ }^{\circ} 35.594$ 'S, $76^{\circ} 13.172^{\prime} \mathrm{W}$, light, loc. 09, 9.I.2009, leg. T. Malm \& K.A. Johanson (1 male, SMNH). Paratype: same as holotype (1 male, OPC).

Diagnosis. This species belongs to the Nectopsyche gemma group with distinct eye-spots visible also in alcohol and is closest to $N$. bunka sp. nov., but differs by having ventral arm of cerci less developed, paraproct with more pointed apicoventral process as well as speciation traits of apicomesal lobe of gonopods fan-shaped, not capitate and the sigmoid profile of the phallicata differently shaped.

Description (in alcohol). This species has small eyes. Length of forewing $7 \mathrm{~mm}$, with gem$m a$-type forewing pattern as visible on specimens stored in alcohol. Maxillary palp formula IV(I,II,III)-V. Tibial spur formula 0-2-2.

Male genitalia. Abdominal segment IX without sternum; its ventral ending located at pivoting fulcrum rounded with braced margin; tergum IX rounded both in lateral and dorsal view. The superanal complex has the less sclerotized hori 


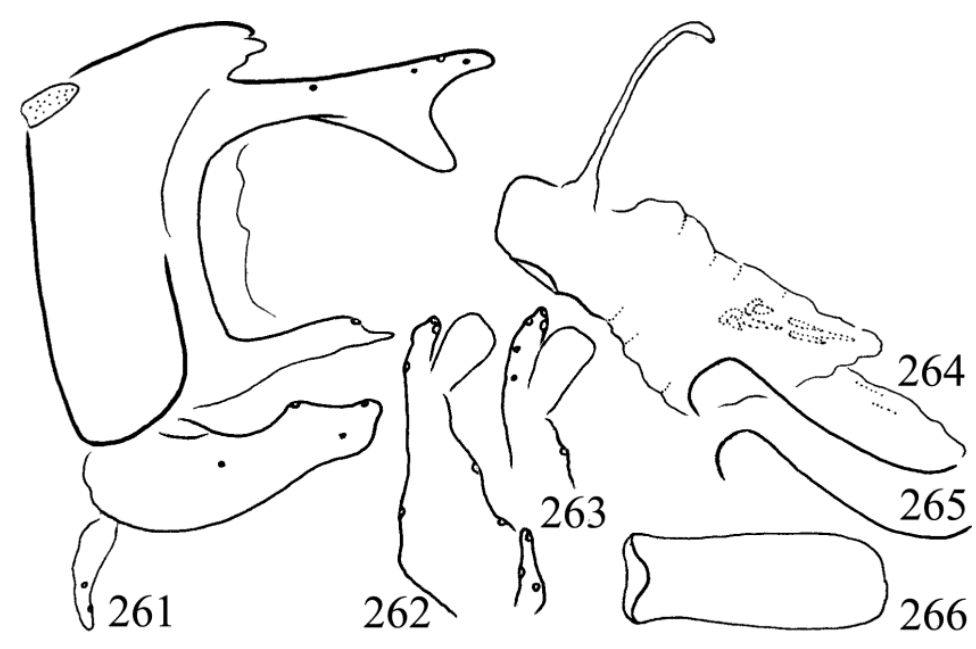

Figures 261-266. Nectopsyche setfela sp. nov. Holotype: $261=$ male genitalia in left lateral view, $262=$ left gonopod with apicomesal lobe in ventral perpendicular view; $263=$ apicomesal lobe of gonopod in one specimen from the same population; $264=$ phallic organ with the sigmoid profile of phallicata in lateral view; $265=$ sigmoid profile of one specimen from the same population; 266 = phallicata in ventral view.

zontal short dorsomesal process, remnant of segment $\mathrm{X}$ bifid, visible as the continuation of tergum IX; the deeply shifted sclerotized horizontal lateral processes, the paraproct with pointing ventral tips in lateral view. Cerci forked, ventral arm glabrous shining without any cuticular outgrowths. Gonopods arching upward while broadening basad in lateral view; basoventral process long filiform; apicomesal lobe fan-shaped. Phallic organ indistinct, it seems articulating to the basomesal ridge of the gonopods; well discernible the pair of swan-necked dorsal phallothecal processes rather slender; the endothecal setal pattern composed of a few very specific cup-based short but stout spines, and a bunch of several straight or slightly curved spines; sigmoid profile of the phallicata with produced basal curve, slightly quadrangular.

Etymology. setfela, from „szétfelé” diverging in Hungarian, refers to fan-shaped, slightly diverging margin of the apicomesal lobes of gonopods in ventral perpendicular view.

\section{Nectopsyche suta Oláh, Johanson \& Malm, sp. nov.}

(Figures 267-271)

Material examined. Holotype, Peru: San Martin Prov., creek crossing rd. Juan Guerra-Chazuta,
$14 \mathrm{~km}$ (rd.) E Colombia Bridge, 6³5.594'S, $76^{\circ}$ 13.172'W, light, loc. 09, 9.I.2009, leg. T. Malm \& K.A. Johanson (1 male, SMNH). Paratype: same as holotype (1 male, SMNH; 1 male, OPC).

Diagnosis. This species belongs to the Nectopsyche gemma group with distinct eye-spots visible also in alcohol and is closest to N. setfela sp. nov., but differs by having ventral arm of cerci less developed, paraproct with reduced lateral processes as well as speciation traits of apicomesal lobe of gonopods digitate, not fan-shaped and the sigmoid profile of the phallicata short with large basal curve.

Description (in alcohol). This species has small eyes. Length of forewing $7 \mathrm{~mm}$, with gem$m a$-type forewing pattern as visible on specimens stored in alcohol. Maxillary palp formula IV(I,II,III)-V. Tibial spur formula 0-2-2.

Male genitalia. Abdominal segment IX without sternum; its ventral ending located at pivoting fulcrum rounded with braced margin; tergum IX rounded both in lateral and dorsal view. The superanal complex has the deeply shifted sclerotized horizontal lateral processes, the paraproct abbreviated, and not-process-like, rather plate-like with triangular shape in lateral view. Cerci forked, ventral arm glabrous shining without any cuticular 


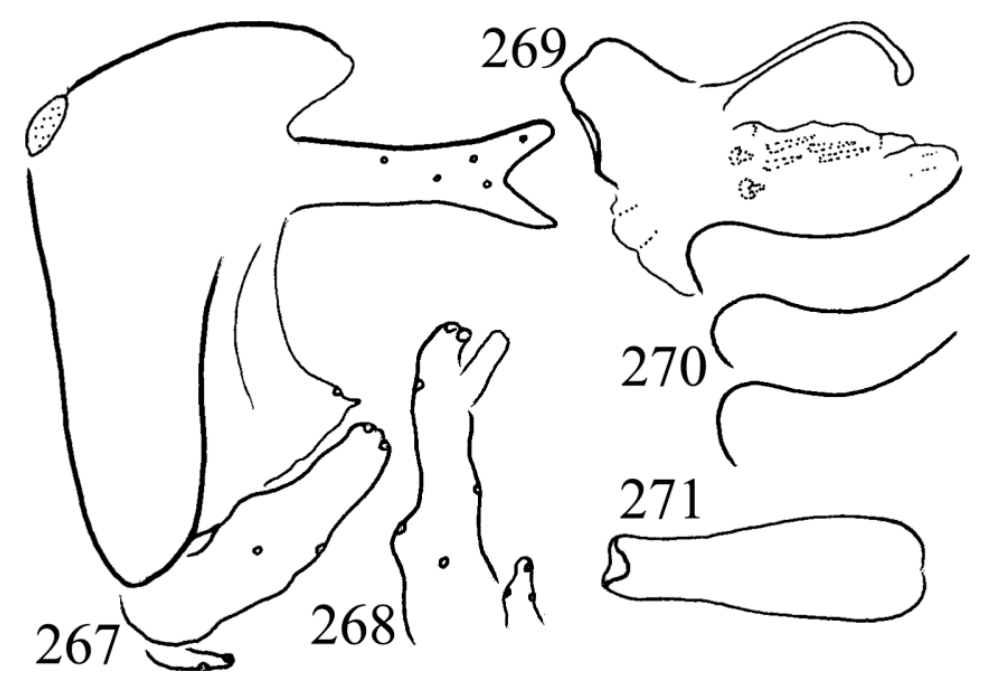

Figures 267-271. Nectopsyche suta sp. nov. Holotype: 267 = male genitalia in left lateral view, 268 = left gonopod with apicomesal lobe in ventral perpendicular view; 269 = phallic organ with the sigmoid profile of phallicata in lateral view; $270=$ sigmoid profile of two specimens from the same population; $271=$ phallicata in ventral view .

outgrowths. Gonopods straight, less broadening basad in lateral view; the basoventral process short broad-based filiform; apicomesal lobe digitate. Phallic organ indistinct, it seems articulating to the basomesal ridge of the gonopods; well discernible the pair of swan-necked dorsal phallothecal processes rather slender; the endothecal setal pattern composed of a few very specific cupbased short but stout spines, and a bunch of several straight or slightly curved spines; sigmoid profile of the phallicata is short with produced basal curve.

Etymology. suta, from ,suta" not complete, abbreviated in Hungarian, refers to the unusually integrated paraproct with reduced length.

\section{Nectopsyche taga Oláh \& Oláh, sp. nov.}

(Figures 272-276)

Material examined. Holotype, Ecuador, Amazonian Lowland, Terra Firme, Gareno lodge, near Puerto Napo, 400 m, 13-14.VIII.2011, light trap, leg. J. Oláh jr. (1male, OPC). Paratypes: same as holotype ( 1 male, 6 females; OPC).

Diagnosis. The reduced dorsal arm on the cercal head relates this species to $N$. tuanis Holzen- thal, but differs by having more posterad produced tergite IX, more robust paraproct in lateral view, the apicomesal lobe on gonopods with constricted basal part and the swan-necked dorsal process on the phallotheca vestigial as well as the sigmoid lateral profile of the phallicata with spacious basal hook formation.

Description. (in alcohol). This species has small eyes. Length of forewing $7 \mathrm{~mm}$, with gem$m a$-type forewing pattern as visible on specimens stored in alcohol. Maxillary palp formula IV(I,II,III)-V. Tibial spur formula 0-2-2.

Male genitalia. Abdominal segment IX without sternum; its ventral ending located at pivoting fulcrum quadrangular with braced margin; tergum IX highly produced posterad fused to remnant of segment $X$. The superanal complex has the less sclerotized horizontal short dorsomesal process, remnant of segment $\mathrm{X}$ visible as the continuation of tergum IX; the deeply shifted sclerotized horizontal lateral processes, the paraproct narrow pointing in dorsal view and rounded in lateral view with 2 setae dorsoapicad. Cerci forked, dorsal arm reduced, ventral arm more developed glabrous shining, without any cuticular outgrowths. Gonopods is arching upward, broader basad in lateral view; basoventral process fili 


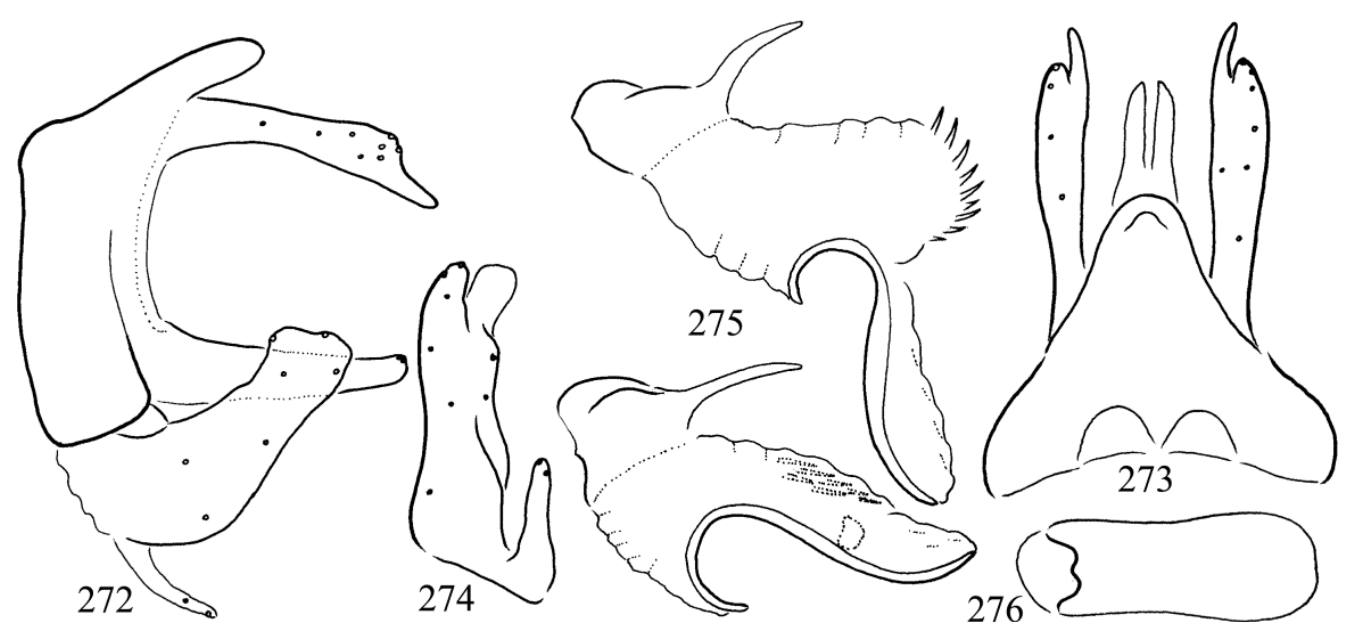

Figures 272-276. Nectopsyche taga sp. nov. Holotype: $272=$ male genitalia in left lateral view, $273=$ male genitalia in dorsal view, 274 = left gonopod with apicomesal lobe in ventral perpendicular view; $275=$ phallic organ with the sigmoid profile of phallicata in lateral view; $276=$ phallicata in ventral view.

form; apicomesal lobe capitate, constricted basally; part of apical surface pegged, rugose. Phallic organ seems articulating to the basomesal ridge of the gonopods; the pair of swan-necked dorsal phallothecal processes reduced to short filiform process; the endothecal setal pattern composed of a bunch of several straight or slightly curved spines; lateral profile of the phallicata slight sigmoid with spacious basal curve.

Etymology. taga, from "tágas" spacious" in Hungarian, refers to the lateral sigmoid profile of the sclerotized ventrum of the phallicata with very large extended basal hook.

\section{Nectopsyche tarka Oláh, Johanson \& Malm, sp. nov.}

(Figures 277-282)

Material examined. Holotype, French Guiana: Approuaguekaw, Kaw Mtn., 104 m, 433.035'N, $52^{\circ} 11.661^{\prime} \mathrm{W}$, Malaise trap, 23.I.-7.II.2007, FRG MF3 leg. N. Jönsson (1 male, SMNH). Paratypes: Approuaguekaw, Kaw Mtn., $104 \mathrm{~m}, 4^{\circ} 33.035^{\prime} \mathrm{N}$, $52^{\circ} 11.661^{\prime} \mathrm{W}$, Malaise trap, 4-12.II.2007, FRG MF3 leg. N. Jönsson (1 male, SMNH; 1 male, OPC).

Diagnosis. This new species belongs to the $N$. gemma species complex of the N. gemma species group without swan-neck shaped phallothecal dorsal process and with broad elongated basoventral process of the gonopods. Most close to $N$. tomora sp. nov. but differs by its larger size; by the dark brown forewing membrane pattern; by the lateral profile of the gonopods having backward directed angle on the head in lateral view; by the apicomesal lobe less fan-shaped; by the sigmoid profile of the phallicata having more pronounced apical curve. Genital structures are similar, most diverged, although subtle is the sigmoid profile of the phallicata.

Description (in alcohol). This species has small eyes. Length of forewing $7 \mathrm{~mm}$; forewing with black scales scattered; the gemma-type pattern is not discernible on the single specimen stored in alcohol; forewing membrane patterned: darker transversal band on the $\mathrm{M}$, patch on $\mathrm{Cu} 1 \mathrm{a}$ subapicad and longitudinal band between $\mathrm{Cu} 1 \mathrm{~b}$ and costa. One paratype, probable a pharate specimen is without any membrane pattern, but scales present. Maxillary palps are lacking. Tibial spur formula 0-2-2.

Male genitalia. Abdominal segment IX without sternum; its ventral ending, located at pivoting fulcrum of gonopods and phallic organ, slightly narrowing with braced margin; tergum IX produced and gradually narrowing posterad in dorsal view, with bifid apex in dorsal view. The super 


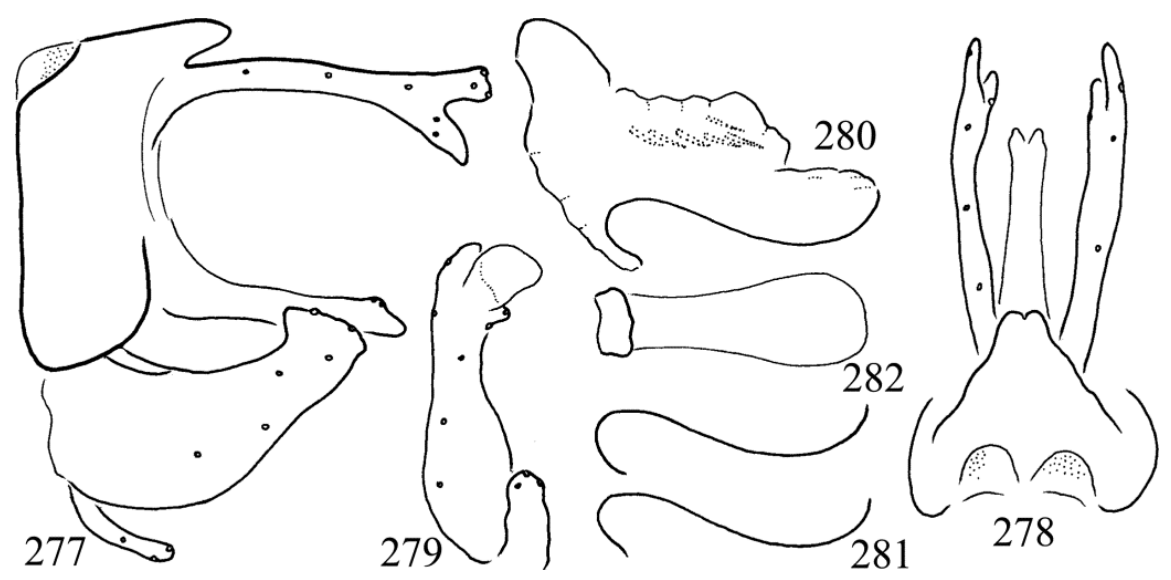

Figures 277-282. Nectopsyche tarka sp. nov. Holotype: 277 = male genitalia in left lateral view, $278=$ genitalia in dorsal view; $279=$ left gonopod with apicomesal lobe in ventral perpendicular view; $280=$ phallic organ with the sigmoid profile of phallicata in lateral view; 281 = sigmoid profile of two specimens from the same population; 282 = phallicata in ventral view.

anal complex present with the deeply shifted sclerotized horizontal lateral processes, the paraproct with subapical dorsal hump. Cerci with slightly convex dorsum and forked apex; dorsal and ventral arms are different; dorsal arm straight continuation of the shaft, truncate; ventral arm ventrad directed, glabrous without cuticular outgrowths but with a few sensory setae. Gonopods with backward directed dorsal angle on the apex and broad basoventrally in lateral view; basoventral process elongated broad digitiform; apicomesal lobe broadly produced rounded quadrangular and mesad turning in ventral view pegged on apical surface. Phallic organ indistinct; it seems articulating to the basomesal ridge of the gonopods. Well discernible the endothecal setal pattern composed of several long spines; lateral sigmoid profile of the phallicata is with a regular half-circular basal curve and well produced apical curve.

Etymology. tarka, from ,tarka” multi-coloured, patterned in Hungarian, refers to the dark membrane pattern on the forewing.

\section{Nectopsyche tomora Oláh, Johanson \& Malm sp. nov.}

(Figures 283-290 )

Material examined. Holotype, French Guiana: Approuaguekaw: Kaw Mtn., 104 m, 4³3.035'N, $52^{\circ} 11.661^{\prime} \mathrm{W}$, Malaise trap, 4-12.II.2007, FRG MF3 leg. N. Jönsson (1 male, SMNH)
Diagnosis. This new species belongs to the $N$. gemma species complex of the $N$. gemma species group without or with only vestigial swan-necked shaped phallothecal dorsal process and with broad elongated basoventral process of the gonopods. The lateral profile of the gonopods has more rounded apex and enlarged on basoventral region compared to known species. All the known members of the complex has variously elongated apicomesal lobes, the new species has short and very broad fan-shaped apicomesal lobes. The sigmoid profile of the phallicata is most close to the gemma profile, but the basal curve is not so deep.

Description (in alcohol). This species has small eyes and small body. Length of forewing $5.5 \mathrm{~mm}$; forewing with black scales on the eyespot region and light scales scattered, the gemmatype pattern is not discernible on the single specimen stored in alcohol. Maxillary palp formula (I,IV)-(II,III)-V. Tibial spur formula 0-2-2.

Male genitalia. Abdominal segment IX without sternum; its ventral ending, located at pivoting fulcrum of gonopods and phallic organ, is slightly narrowing with braced margin; tergum IX produced posterad narrowing in dorsal view, with bifid apex in dorsal view. The superanal complex without discernible less sclerotized horizontal medium-long dorsomesal process, the upper remnant of segment $\mathrm{X}$; the deeply shifted sclerotized horizontal lateral processes, the paraproct with 


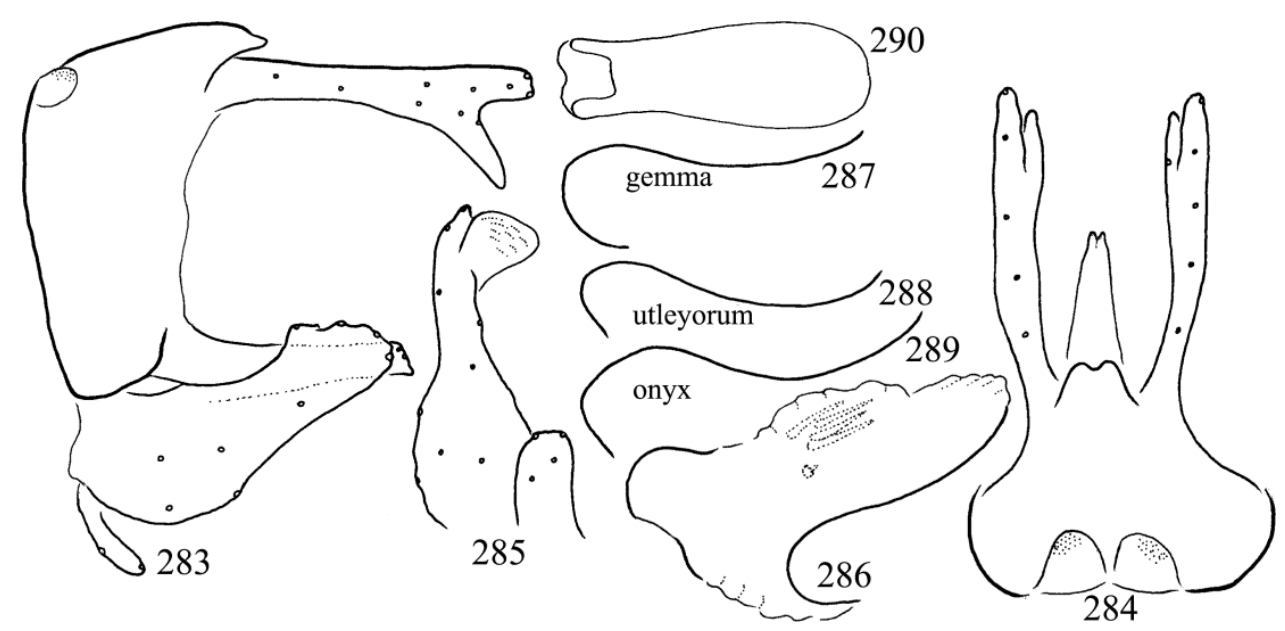

Figures 283-290. Nectopsyche tomora sp. nov. Holotype: 283 = male genitalia in left lateral view, $284=$ genitalia in dorsal view; 285 = left gonopod with apicomesal lobe in ventral perpendicular view; $286=$ phallic organ with the sigmoid profile of phallicata in lateral view; $287=$ sigmoid profile of $N$. gemma; $288=$ sigmoid profile of $N$. utleyorum; $289=$ sigmoid profile of $N$. onyx $; 290=$ phallicata in ventral view.

obliquely truncate apex in lateral and double pointed in dorsal view. Cerci with straight dorsum and forked apex; dorsal and ventral arms are different; dorsal arm straight continuation of the shaft, truncate; ventral arm ventrad directed, glabrous without cuticular outgrowths but with a few sensory setae. Gonopods with rounded irregular apex and broad basoventrally in lateral view; basoventral process elongated quadrangular; apicomesal lobe broadly produced fan-shaped and mesad turning in ventral view pegged on apical surface. Phallic organ indistinct, it seems articulating to the basomesal ridge of the gonopods. Well discernible the endothecal setal pattern composed of several long spines and a few cup-based short but stout spines; lateral sigmoid profile of the phallicata with a regular half-circular basal curve.

Etymology. tomora, from „tömör” solid in Hungarian, refers to the short and broad shape of the apicomesal lobe of the gonopods.

Acknowledgements - We highly appreciate and acknowledge the valuable materials of population samples provided to our studies by Kjell Arne Johanson and Tobias Malm at the Swedish Museum of Natural History, Department of Zoology, by John Morse at Clemson University, Arthropod Collection, by Steven C. Harris at Clarion University of Pennsylvania, and by Albane Vilarino at the University of Sao Paulo. Constructive criticism by Kjell Arne Johanson on an earlier version of the manuscript is also much appreciated.

\section{REFERENCES}

BANKS, N. (1899): Descriptions of new North American neuropteroid insects. Transactions of the American Entomological Society, 25: 199-218.

BANKS, N. (1901): A list of neuropteroid insects from Mexico. Transactions of the American Entomological Society, 27: 361-371.

BANKS, N. (1913): Synopses and descriptions of exotic Neuroptera. Transactions of the American Entomological Society, 39: 201-242, plates 23-26.

BANKS, N. (1920): New neuropteroid insects. Bulletin of the Museum of Comparative Zoology, 64: 299-362. doi: 10.5962/bhl.title.28705

BANKS, N. (1938): New West Indian neuropteroid insects. Revista de Entomologia, 99: 285-304.

BlaHNiK, R.J. \& Holzenthal, R.W. (2014): Review and redescription of species in the Oecetis avara group, with the description of 15 new species (Trichoptera, Leptoceridae). ZooKeys, 376: 1-83. doi: 10.3897/zookeys.376.6047

Botosaneanu, L. (1979): The caddis-flies (Trichoptera) of Cuba and of Isla de Pinos: a synthesis. Studies on the fauna of Curacao and other Caribbean Islands, 59: 33-62.

BotosaneAnu, L. (1980): Trichoptères adultes de Cuba collectés par les zoologists cubains. Mitteilungen der Münchner Entomologischen Gesellschaft, 69: 91-116. 
Botosaneanu, L. \& Alkins-Koo, M. (1993): The caddis flies (Insecta: Trichoptera) of Trinidad and Tobago, West Indies. Bulletin de l'Institut Royal des Sciences Naturelles de Belgique, Entomologie, 63: 5-45.

CRISP, M.D. \& CoOK, L.G. (2005): Do early branching lineages signify ancestral traits? Trends in Ecology and Evolurtion, 20(3): 122-128. doi:10.1016/j.tree.2004.11.010

FLINT, O.S. JR. (1966a): Notes on certain Nearctic Trichoptera in the Museum of Comparative Zoology. Proceedings of the United States National Museum, 118(3530): 373-390.

FLINT, O.S. JR. (1966b): Studies of Neotropical caddisflies, III: types of some species described by Ulmer and Brauer. Proceedings of the United States National Museum, 120(3559): 1-20, plates 1-2.

FLINT, O.S. JR. (1968): The caddisflies of Jamaica (Trichoptera). Bulletion of the Institute of Jamaica Science Series, 19: 1-68.

FLINT, O.S. JR. (1972): Studies of Neotropical caddisflies, XIV: on a collection from northern Argentina. Proceedings of the Biological Society of Washington, 85: 223-248.

FLINT, O.S. Jr. (1974a): Studies of Neotropical caddisflies, XV: the Trichoptera of Suriname. Studies on the Fauna of Suriname and other Guyanas, 14(55): 1-151.

FLINT, O.S. Jr.(1974b): Checklist of the Trichoptera, or caddisflies, of Chile. Revista Chilena de Entomologia, 8: 83-93.

FLINT, O.S. JR. (1981): Studies of Neotropical caddisflies, XXVIII: the Trichoptera of the Río Limón Basin, Venezuela. Smithsonian Contributions to Zoology, 330: 1-61.

FLINT, O.S. JR. (1982): Trichoptera of the Area Platense. Biologia Acuatica, 2: 1-70.

FLINT, O.S. JR. (1983): Studies of Neotropical caddisflies, XXXIII: new species from austral South America (Trichoptera). Smithsonian Contributions to Zoology, 377: 1-100. doi: 10.5479/si.00810282.377

FLINT, O.S. JR. (1991): Studies of Neotropical caddisflies, XLV: The taxonomy, phenology, and faunistic of the Trichoptera of Antioquia, Colombia. Smithsonian Contributions to Zoology, 520: 1-113. doi: 10.5479/si.00810282.520
Flint, O.S. JR., Holzenthal, R.W. \& HaRRIS, S.C. (1999): Nomenclatural and systematic changes in the Neotropical caddisflies (Insecta: Trichoptera). Insecta Mundi, 13(1-2): 73-84.

GAVRILETS, S. (2004): Fitness landscapes and the origin of species. Princeton University Press, Princeton, NJ. 480 pp.

GOULD, S.J. \& VRBA, E.S. (1982): Exaptation - a missing term in the science of form. Paleobiology, 8(1):4-15. doi: 10.1017/S0094837300004310

HADDOCK, J.D. (1977): The biosystematics of the caddis fly genus Nectopsyche in North America with emphasis on the aquatic stages. The American Midland Naturalist, 98(2): 382-421. doi: $10.2307 / 2424989$

HAGEN, H. (1861) Synopsis of the Neuroptera of North America. Smithsonian Miscellaneous Collections, 4(1): 1-347.

HARRIS, S.C. (1986): New species of caddisflies (Trichoptera) from Alabama. Proceedings of the Entomological Society of Washington, 88(1): 30-41.

HenNIG, W. (1950): Grundzüge einer Theorie der phylogenetischen Systematik. Deutscher Zentralverlag, Berlin, $370 \mathrm{pp}$.

HenNig, W. (1966): Phylogenetic Systematics. University of Illinois Press, Urbana, 263 pp.

Holzenthal, R.W. (1995): The caddisfly genus Nectopsyche: new gemma group species from Costa Rica and the Neotropics (Trichoptera: Leptoceridae). Journal of the North American Benthological Society 14(1):61-83. doi: 10.2307/1467725

KolenATI, F.A. (1859): Fauna des Altvaters (hohen Gesenkes der Sudeten). Jahreshefte der naturwissenschaftlichen Sektion der Kaiser und Königlichen Rahr. Schl. Gesellschaft zur Beförderung des Ackerbaues, der Natur- und Landeskunde, 1858: 1-85.

MÜLLER, F. (1879): Über Phryganiden (letters to his brother). Zoologischer Anzeiger 2: 38-40, 180-182, 283-284, 405-407.

MÜlleR, F. (1880): Sobre as casas construidas pelas larvas de Insectos Trichopteros de provincia de Santa Catherina. Archivos do Museu nacional do Rio do Janeiro, 3: 99-134, 210-215, 134 plates.

NAVAS, L. (1916). Neuroptera Nova Americana. Series I, II. Memoire della Pontificia Accademia Romana dei Nuovi Lincei, Serie II, 2: 59-80. 
NAVAS, L. (1920): Insectos Sudamericanos (1a, 2a y 3a serie). Anales de la Sociedad Cientifica Argentina, 90: 33-72.

NAVAS, L. (1922): Insectos exoticos. Brotéria, Série Zoológica, 20: 49-63.

NAVAS, L. (1923): Estudis sobre Neuroters (Insectes). Arxius de I'Institut de Ciencies, 7: 179-203.

NAVAS, L. (1933): Insectos de la Argentina. Revista de la Academia de Ciencias Exactas, Fisico-Quimicas y Naturales de Zaragoza, 16: 87-120.

OLÁH, J. (2010): Ökoszisztéma szolgáltatások a vidékgazdaságban. Valóság, 53(5): 87-93.

OLÁH J. (2014): On the Trichoptera of Batanta Island (Indonesia, Papua, Raja Ampat Archipelago), III. Folia Entomologica Hungarica, 75: 91-131.

OLÁH, J. (2016): New species and records of Trichoptera collected by Mr. A. G. Duff. More phenomics and less genomics! Opuscula Zoologica, Budapest 47(2): 155-171. doi: 10.18348/opzool.2016.2.155

OlÁH, J. (2017): Is the genus Potamophylax highly polymorphic? Acta Entomologica Musei Nationalis Pragae 57(1): 253-257.

OlÁH, J., ChVoJKa, T.P., CoPPA, G., GODUNKO, R.J., Lodovici, O., MaJeckA, K., MAJeCKI, J., SZCZESNY, B., URBANIC, G. \& VAlle, M. (2015) Limnephilid taxa revised by speciation traits: Rhadicoleptus, Isogamus, Melampophylax genera, Chaetopteryx rugulosa, Psilopteryx psorosa species groups, Drusus bolivari, Annitella kosciuszkii species complexes (Trichoptera, Limnephilidae). $O$ puscula Zoologica, Budapest, 46(1): 3-117. doi: 10.18348/opzool.2015.1.3

Oláh, J., Beshiov, S., Chvojka, T.P., Ciubuc, C., COPPA, G., IBRAHIMI, H., KovÁCs, T., MEY, W. \& OLÁH, J. JR. (2017): Revision of Drusinae subfamily (Trichoptera, Limnephilidae): divergence by paraproct and paramere, speciation in isolation by integration. Opuscula Zoologica, Budapest, 48(1): 3-228. doi: 10.18348/opzool.2017.S1.3
Ross, H.H. (1944): The caddis flies, or Trichoptera, of Illinois. Bulletin of the Illinois Natural History Survey 23(1): 1-326.

SCHMID, F. (1949): Les Trichopteres de la collection Navas. EOS, Espanola Entomologica, 25(3-4): 305-426.

SCHMID, F. (1998): The insects and arachnids of Canada Part 7. Genera of the Trichoptera of Canada and adjoining or adjacent United States. NRC Research Press, Ottawa, 289 pp.

SCHMITT, M. (2016): Hennig, Ax, and present-day mainstream cladistics, on polarising characters. Peckiana, 11: 35-42.

SERVEDIO, M.R., VANDOORN, G.S., KoPP, M., FrAME, A.M. \& Nosil, P. (2011): Magic traits in speciation: 'magic' but not rare. Trends in Ecology and Evolution 26(8):389-397. doi:10.1016/j.tree.2011.04.005

SHAW, K.L. \& MulleN, S.P. (2011): Genes versus phenotypes in the study of speciation. Genetica, 139: 649-661. doi: 10.1007/s10709-011-9562-4

ULMER, G. (1905): Neue und wenig bekannte außeuropäische Trichopteren, hauptsächlich aus dem Wiener Museum. Annalen des Kaiserlich-königlich Naturhistorischen Hofmuseums, 20: 59-98.

WÄGELE，J.W. (1994): Review of methodological problems in 'computer cladistics' exemplified with a case study on Isopod phylogeny (Crustacea: Isopoda). Zeitschrift für zoologische Systematik und Evolutionsforschung, 32: 81-107. doi: 10.1111/j.1439-0469.1994.tb00474.x

WALKER, F. (1852): Catalogue of the specimens of Neuropterous insects in the collections of the British Museum, 1: Phryganides-Perlides. British Museum (Natural History), London, 192 pp.

WINTHER,R.G. (2009): Character analysis in cladistics: abstraction, reification, and the search for objectivity. Acta Biotheoretica 57: 129-162. doi 10.1007/s10441-008-9064-7 